\title{
Optimisation of Synthesis,
}

\section{Purification and Reformulation of (R)- $\left[N\right.$-methyl- $\left.{ }^{11} \mathrm{C}\right] \mathrm{PK} 11195$ for In Vivo PET Imaging Studies}

Vítor Hugo Pereira Alves

Integrated Master in Biomedical Engineering

Physics Department

Faculty of Sciences and Technology of University of Coimbra 

To my Parents, 



\title{
Optimisation of Synthesis, Purification and Reformulation of (R)-[N-methyl- $\left.{ }^{11} \mathrm{C}\right] \mathrm{PK} 11195$ for In Vivo PET Imaging Studies
}

\author{
Vítor Hugo Pereira Alves
}

Supervisor: Miguel de Sá e Sousa Castelo Branco

Co-supervisor: Antero José Pena Afonso de Abrunhosa

Dissertation presented to the Faculty of Sciences and Technology of the University of Coimbra to obtain a Master's degree in Biomedical Engineering

Physics Department

Faculty of Sciences and Technology of University of Coimbra 
This copy of the thesis has been supplied on condition that anyone who consults it is understood to recognize that its copyright rests with its author and that no quotation from the thesis and no information derived from it may be published without proper acknowledgement. 


\section{Acknowledgments}

First of all, I would like to express my gratitude to Professor Antero Abrunhosa, for the opportunity given to carry out this work, for all the knowledge and for the full confidence. More than a project supervisor, he was a friend and excellent professor for his support and encouragement to reach the defined goals.

To Professor Miguel Castelo-Branco, director of the Institute for Nuclear Sciences Applied to Health and also supervisor of this work for all support and interest in this project.

To Professor Francisco Alves, I am grateful for his full availability to help, and for all the times that I asked for carbon-11.

To all the team at ICNAS-Produção, they have been a big help to me in many ways during the last year. First, I would like to thank Gonçalo Clemente, my 'master', for all the shared knowledge, the useful discussions and for all the support. I would also like to thank Sérgio Carmo, João Oterelo, Pedro Lopes and Ricardo Faustino for the help with my integration in the team, for the constant support and interest in this work. All of them were important for the development of the work and have become my friends.

To Professor Miguel Morgado, for all the work on coordinating the Biomedical Engineering course, and great advice for future Biomedical Engineers.

To my friends and colleagues, for all the support, patience and suggestions.

To my parents: my mother Teresa and my father Joaquim, to whom this dissertation is dedicated. I would like to thank them for all the support in the last years. They made it all possible. I also would like to thank to my sister Melissa for her support.

Finally, I would like thank to my girlfriend, Neide, for all the support and everything that she means for me. I could not survive without her encouragement and guidance. 

Inflammation, in general, is a physiological response of the body to different types of tissue injury, causing a cascade of coordinated cellular and biochemical reactions. Neurodegenerative, inflammatory and neoplastic disorders involve neuroinflammatory reactions that isolate the damaged tissue and promote immune responses. Likewise, neuroinflammation (NI) implicates a complex orchestrated response to various stimuli in the central nervous system (CNS) aiming towards tissue preservation and restoration. Neuroinflammatory reactions involve a cellular response by activating cells of the monocyte lineage, whether resident or circulating. Microglia are the resident cells of the monocyte lineage in the CNS and their activation constitutes a main feature of neuroinflammation. The process involves an overexpression of the $18 \mathrm{kDa}$ translocator protein (TSPO) receptor by cells of monocyte/macrophage lineage and, in the central nervous system (CNS), by activated microglia. PK11195 is a specific ligand for the TSPO receptor and therefore a marker for activated microglia. The $(\mathrm{R})$-enantiomer radiolabelled with Carbon-11, (R)-[N-Methyl- $\left.{ }^{11} \mathrm{C}\right] \mathrm{PK} 11195$, is the most widely used radiotracer for in vivo TSPO imaging with PET.

In this work we report on the optimisation of the synthesis, purification and reformulation of (R)-[N-methyl $\left.-{ }^{11} \mathrm{C}\right] \mathrm{PK} 11195$ by the captive solvent method with the aim of being used for in vivo PET imaging studies.

Carbon-11 is obtained as $\left[{ }^{11} \mathrm{C}\right] \mathrm{CO}_{2}$ by irradiation of a gas target $\left(\mathrm{N}_{2}+0.5 \% \mathrm{O}_{2}\right)$ using the ${ }^{14} \mathrm{~N}(\mathrm{p}, \alpha){ }^{11} \mathrm{C}$ nuclear reaction in a IBA Cyclone $18 / 9$ cyclotron. $\left[{ }^{11} \mathrm{C}\right] \mathrm{CH}_{3} \mathrm{I}$ is produced by the 'liquid-phase' reduction of $\left[{ }^{11} \mathrm{C}\right] \mathrm{CO}_{2}$ with $\mathrm{LiAlH}_{4} / \mathrm{THF}(0.1 \mathrm{M})$ to $\left[{ }^{11} \mathrm{C}\right] \mathrm{CH}_{3} \mathrm{OLi}$ and further addition of $\mathrm{HI}$ on a methyl iodide production system. $\left[{ }^{11} \mathrm{C}\right] \mathrm{CH}_{3} \mathrm{I}$ is then distilled at $120{ }^{\circ} \mathrm{C}$, trapped in captive solvent loop pre-loaded with (R)-[N-desmethyl]PK11195 precursor solution (dissolved on $100 \mu \mathrm{l}$ of DMSO and saturated with $30 \mathrm{mg}$ of $\mathrm{KOH}$ ), and reaction takes place. Reaction products $\left(\left[{ }^{11} \mathrm{C}\right]-\mathrm{X}\right)$ go through a semi-preparative reverse-phase C18 HPLC column for purification. Finally, (R)-[N-methyl- $\left.{ }^{11} \mathrm{C}\right] \mathrm{PK} 11195$ is formulated in $9 \mathrm{ml}$ of physiological saline $(0.9$ $\%$ and $1 \mathrm{ml}$ of $\mathrm{EtOH}$, and filtered through a sterilizing $0.22 \mu \mathrm{m}$ membrane filter.

Synthesis process is carried out in about 35 minutes, and quality control tests were performed to ensure the good quality of product. $149.71 \pm 50.25 \mathrm{mCi}$ of $(\mathrm{R})-\left[{ }^{11} \mathrm{C}\right] \mathrm{PK} 11195$ were obtained at EOS with specific activities between $15-25 \mathrm{GBq} / \mu \mathrm{mol}$ on a short overall synthesis time. 
The captive solvent method offers an easy and reproducible way to automate the routine production of $\left[{ }^{11} \mathrm{C}\right]$-labelled radiopharmaceuticals for human use. The production method is fast, considering the short half-life of carbon-11 (20.4 min.) and can produce the final products in high radiochemical purities and good specific activities.

Keywords: $\left[{ }^{11} \mathrm{C}\right] \mathrm{PK} 11195$, carbon-11, captive solvent loop, 'wet' method, $\left[{ }^{11} \mathrm{C}\right] \mathrm{CO}_{2}$, $\left[{ }^{11} \mathrm{C}\right] \mathrm{CH}_{3} \mathrm{I}$, neuroinflammation, microglia, TSPO, PET. 
Resumo

A inflamação, em geral, é uma resposta fisiológica do corpo para com diferentes tipos de lesão do tecido, provocando uma cascata coordenada de reacções celulares e bioquímicas. Distúrbios neurodegenerativos, inflamatórios e neoplásicos envolvem reacções neuroinflamatórias que isolam o tecido danificado e promovem respostas imunitárias. Da mesma forma, a neuroinflamação (NI) implica uma complexa e orquestrada resposta a vários estímulos no sistema nervoso central (SNC), com vista para a preservação do tecido e sua restauração. Reacções neuroinflamatórias envolvem uma resposta celular através da activação de células da linhagem do monócito, residentes ou circulantes. Microglia são as células residentes da linhagem dos monócitos no SNC e a sua activação, constitui uma característica principal da neuroinflamação. O processo envolve uma sobre expressão dos receptores da proteína translocadora de $18 \mathrm{kDa}$ (TSPO) em células da linhagem dos monócitos/macrófagos e, no sistema nervoso central (SNC), pela activação da microglia. PK11195 é um ligando selectivo para o receptor da TSPO e, portanto, um identificador da microglia activada. O enantiómero (R) marcado radioactivamente com carbono-11, (R)-[N-metil- $\left.{ }^{11} \mathrm{C}\right] \mathrm{PK} 11195$, é o radiotraçador mais utilizado para imagiologia in vivo da TSPO com PET.

Neste trabalho, reportamos a optimização da síntese, purificação e reformulação de (R)-[N-metil- $\left.{ }^{11} \mathrm{C}\right]$ PK11195 pelo 'captive solvente method' com a finalidade de ser utilizado para imagem in vivo em estudos de PET.

Carbono-11 é obtido sob a forma de $\left[{ }^{11} \mathrm{C} \mathrm{CO}_{2}\right.$ por irradiação de um alvo de gás $\left(\mathrm{N}_{2}+\mathrm{O}_{2} 0,5 \%\right)$, utilizando a reacção nuclear ${ }^{14} \mathrm{~N}(\mathrm{p}, \alpha){ }^{11} \mathrm{C}$ num ciclotrão. $\left[{ }^{11} \mathrm{C}\right] \mathrm{CH}_{3} \mathrm{I}$ é produzido por redução de $\left[{ }^{11} \mathrm{C}\right] \mathrm{CO}_{2}$ com $\mathrm{LiAlH}_{4} / \mathrm{THF}(0,1 \mathrm{M})$ via 'fase liquida' a $\left[{ }^{11} \mathrm{C}\right] \mathrm{CH}_{3} \mathrm{OLi}$, e pela adição posterior de $\mathrm{HI}$ em um sistema de produção de iodeto de metilo, o $\left[{ }^{11} \mathrm{C}\right] \mathrm{CH}_{3} \mathrm{I}$ é destilado a $120^{\circ} \mathrm{C}$. Ao mesmo tempo, o $\left[{ }^{11} \mathrm{C}\right] \mathrm{CH}_{3} \mathrm{I}$ destilado é aprisionado num loop previamente carregado com

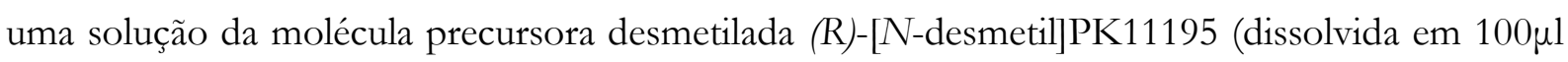
de DMSO e saturada com 30mg de $\mathrm{KOH}$ ), iniciando-se a reacção ao mesmo tempo que se aprisiona o $\left[{ }^{11} \mathrm{C}\right] \mathrm{CH}_{3} \mathrm{I}$. Produtos da reacção $([11 \mathrm{C}]-\mathrm{X})$ passam por uma coluna HPLC semipreparativa de fase reversa (C18) para purificação. Finalmente, (R)-[N-metil- $\left.{ }^{11} \mathrm{C}\right] \mathrm{PK} 11195$ foi formulado em $9 \mathrm{ml}$ de soro fisiológico $(0,9 \%)$ e $1 \mathrm{ml}$ de EtOH e filtrado através de um filtro esterilizado de membrana de $0,22 \mu \mathrm{m}$.

O processo de síntese realiza-se em cerca de 35 minutos, e testes de controlo de qualidade foram realizados para garantir a boa qualidade do produto. 149,71 $\pm 50,25 \mathrm{mCi}$ de 
(R)- $\left[{ }^{11} \mathrm{C}\right]$ PK11195 foram obtidos no final da síntese com actividades específicas entre 15-25GBq/ $\mu \mathrm{mol}$ num curto período de síntese.

O ‘captive solvente loop’ proporciona uma maneira fácil e reprodutível para automatizar a produção de rotina de radiofármacos marcados $\operatorname{com}{ }^{11} \mathrm{C}$ para uso humano. O método de produção é rápida, tendo em conta a curta meia-vida do carbono-11 (20,4 min), podendo-se produzir produtos finais com elevada pureza radioquímica e boa actividade específica.

Palavras Chave: $\left[{ }^{11} \mathrm{C}\right] \mathrm{PK} 11195$, carbono-11, captive solvent loop, 'wet' method, $\left[{ }^{11} \mathrm{C}\right] \mathrm{CO}$, $\left[{ }^{11} \mathrm{C}\right] \mathrm{CH}_{3} \mathrm{I}$, neuroinflamação, microglia, TSPO, PET. 
Index

Acknowledgments

\section{CHAPTER 1}

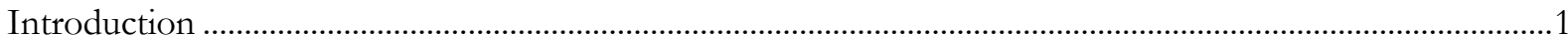

Part I: General Introduction ....................................................................................................................

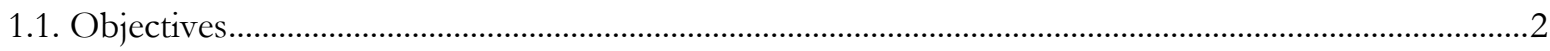

1.1.1. Timeline of the Project ................................................................................................................

1.2. The Institute for Nuclear Sciences Applied to Health...............................................................................3

Part II: Theoretical Background...............................................................................................................

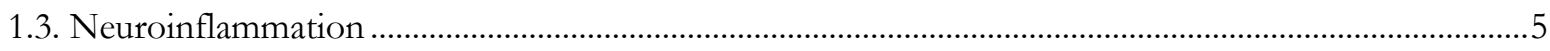

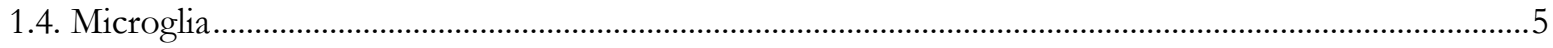

1.4.1. Activated stage of microglia..................................................................................................

1.5. $18 \mathrm{kDa}$ Translocator Protein............................................................................................................

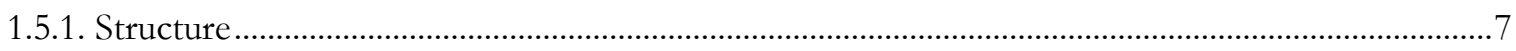

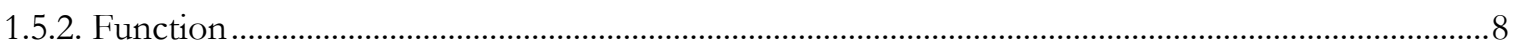

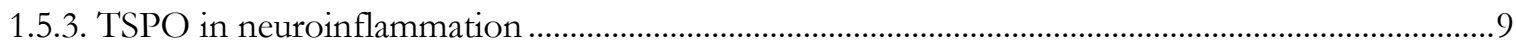

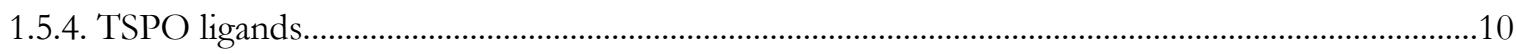

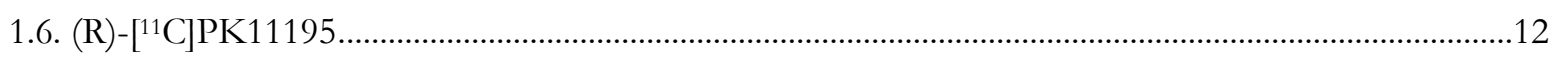

1.6.1. PET imaging studies of TSPO in human diseases.........................................................................

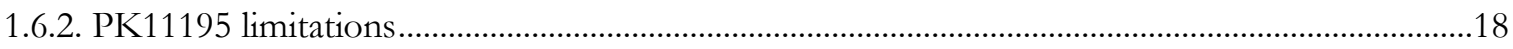

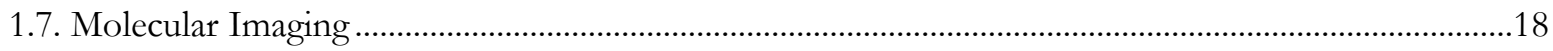

1.7.1. Molecular imaging probe concept................................................................................................19

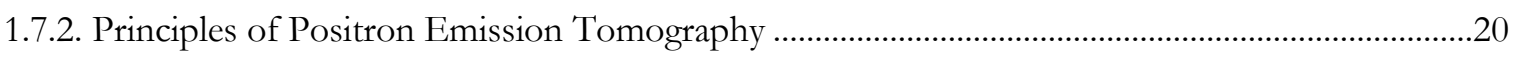

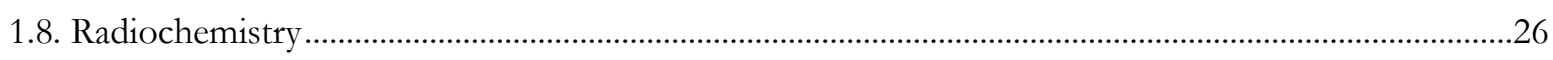

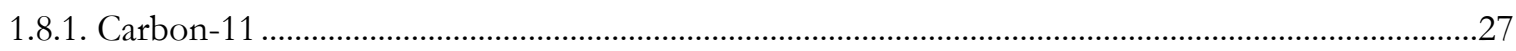

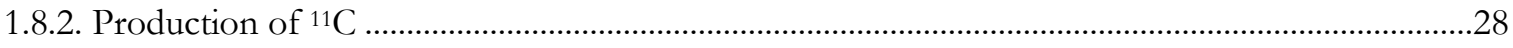

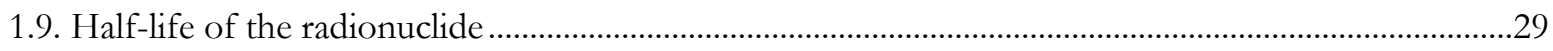




\section{CHAPTER 2}

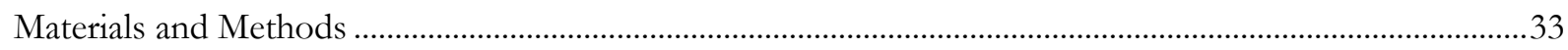

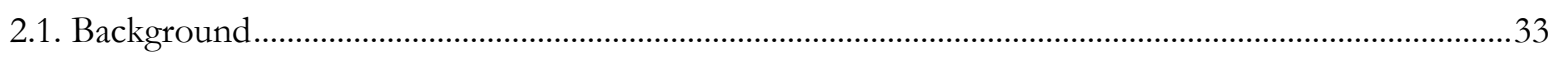

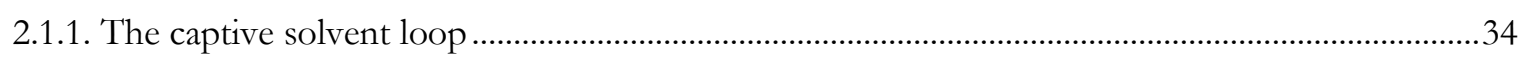

2.1.2. Quality control of PET radiolabelled compounds.............................................................................

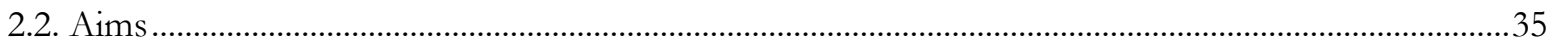

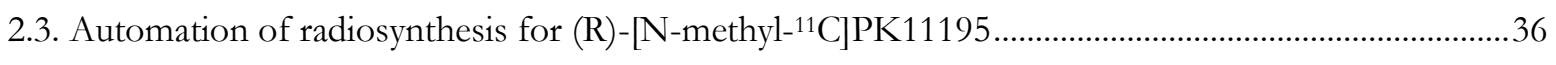

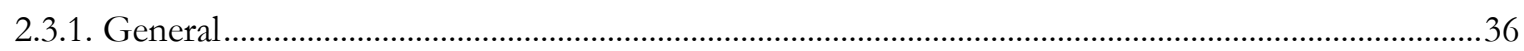

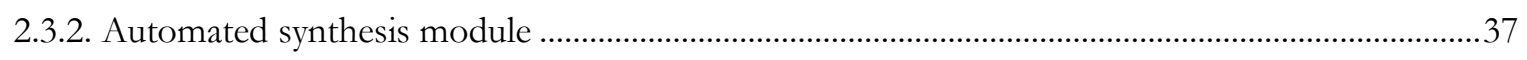

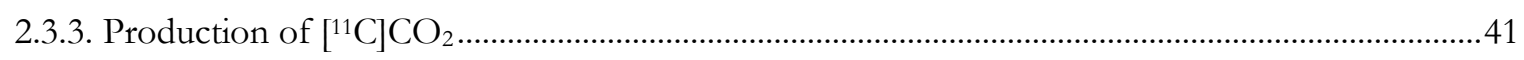

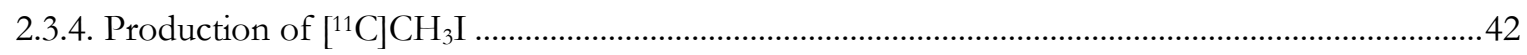

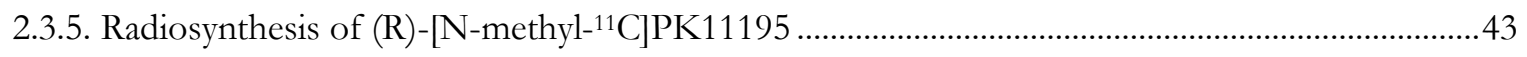

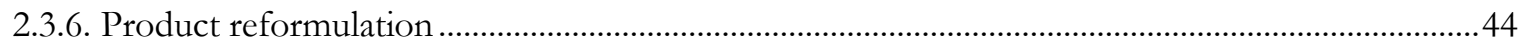

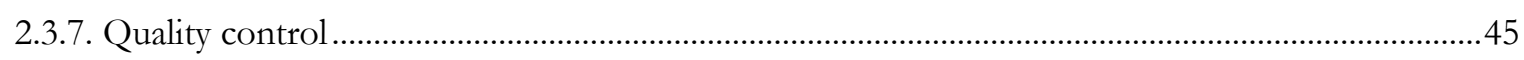

\section{CHAPTER 3}

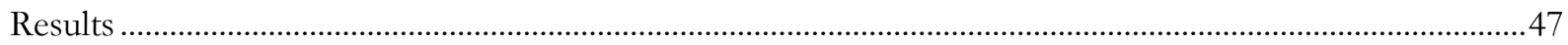

3.1. Production of $\left[{ }^{11} \mathrm{C}\right]$ methyl iodide: initial optimisations .......................................................................48

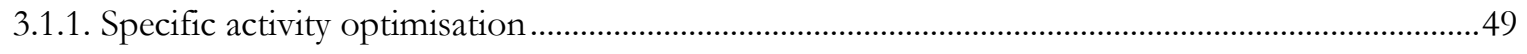

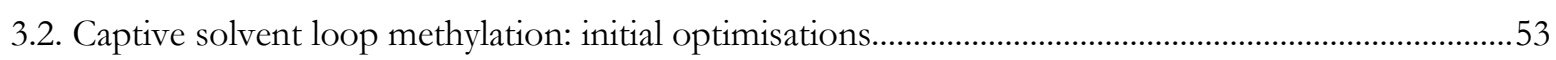

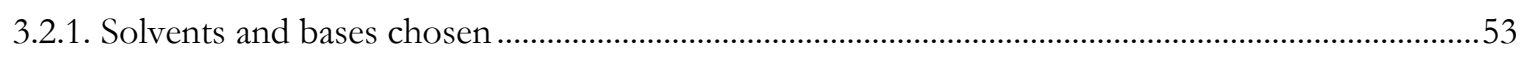

3.2.2. Precursor concentration: influence on RCY …………………………………………………........ 54

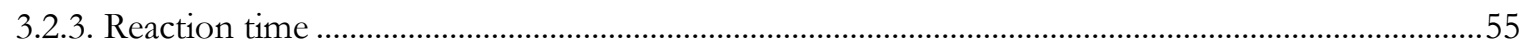

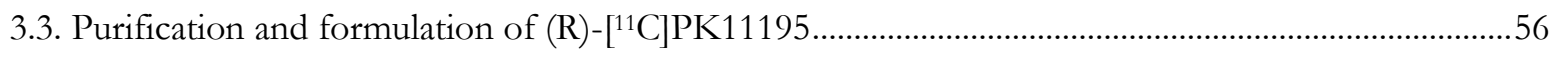

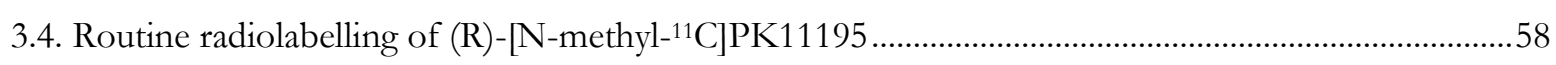

\section{CHAPTER 4}

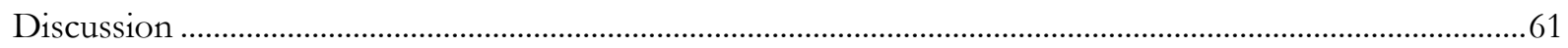

4.1. Automation of $\left[{ }^{11} \mathrm{C}\right]$ methyl iodide production....................................................................................62

4.1.1. Specific Activity ……………………………………………………………………………....62

4.1.2. Synthesis module: routine maintenance..........................................................................................64

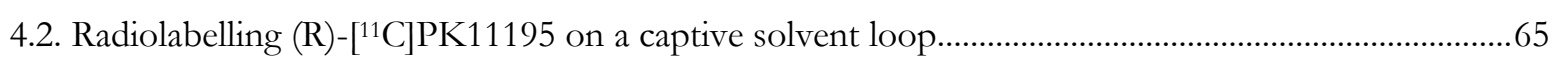

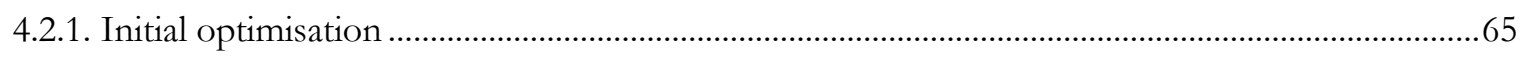

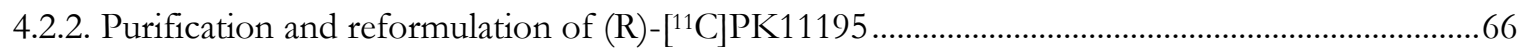

4.3. Routine synthesis, purification and reformulation of $(\mathrm{R})-\left[\mathrm{N}\right.$-methyl $\left.{ }^{11} \mathrm{C}\right] \mathrm{PK} 11195 \ldots \ldots \ldots \ldots \ldots \ldots \ldots \ldots \ldots . . . . . .66$ 


\section{CHAPTER 5}

Conclusion

\section{CHAPTER 6}

Future perspectives

.71 



\section{List of Figures}

Figure 1.1 Timeline of the work during the final year project.

Figure 1.2 Structures of TSPO as a hetero-oligomeric complex..... 8

Figure 1.3 Schematic diagram of the hetero-oligomeric complex localized on the outer mitochondrial membrane of astrocytes and microglia.

Figure 1.4 Schematic diagram of function and mechanism of $18 \mathrm{kDa}$ translocator protein (TSPO). .10

Figure 1.5 Chemical structures of some TSPO-selective compounds .11

Figure 1.6 Chemical structures of isoquinoline carboxamides .12

Figure 1.7 Chemical structures of (R)- and (S)-[11'C]PK11195. .13

Figure 1.8 PET scans with $\left[{ }^{11} \mathrm{C}\right] \mathrm{PK} 11195$ of a healthy subject and a Parkinson's disease patient. Mild microglial activation is seen in the thalamus of the healthy control but a significantly raised activation is evident in the midbrain and striata of the PD patient.

Figure 1.9 Increased $\left[{ }^{11} \mathrm{C}\right] \mathrm{PK} 11195$ binding potential $\left(\mathrm{BP}_{\mathrm{ND}}\right)$ in a Multiple Sclerosis patient when compared to a healthy normal control.

Figure 1.10 Significant increase of (R)-[11C] PK11195 uptake in Alzheimer's Disease patients when compared with control

Figure 1.11 Several key criteria for probes in molecular imaging. Adapted from [58].....

Figure 1.12 Principle of PET detection

Figure 1.13 General views of two cyclotrons from different eras First Livingston cyclotron in 1931 and an IBA Cyclone 18/9 cyclotron

Figure 1.14 Schematic structure of cyclotron showing the 'dee' structure, the ion source and the magnet.

Figure 1.15 Schematic top view of the main body of an IBA Cyclone 18/9 cyclotron

Figure 1.16 Pathways to produce ${ }^{11} \mathrm{C}$-labelling precursors. .28

Figure 2.1 Apparatus and flow diagram for trapping $\left[{ }^{11} \mathrm{C}\right]$ methyl iodide on HPLC loop, pre-charged (coated) with a non-radioactive precursor. The labelling reaction takes place instantly before injection into an HPLC semi-preparative column for purification

Figure 2.2 Schematic diagram of the $\left[{ }^{11} \mathrm{C}\right]$ methyl iodide production system

Figure 2.3 Schematic diagram of the $\left[{ }^{11} \mathrm{C}\right]$ methylation system

Figure 2.4 Schematic diagram of the disposable reformulation kit for product formulation used on reformulation system 


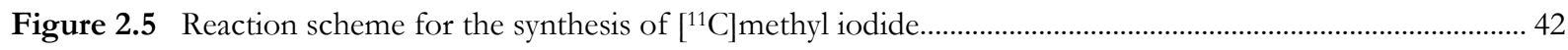

Figure 2.6 Reaction scheme for the convertion of $\left[{ }^{11} \mathrm{C}\right]$ methyl iodide into $\left[{ }^{11} \mathrm{C}\right]$ methyl triflate. ............................... 43

Figure 2.7 Reaction scheme of the of the $(\mathrm{R})-\left[{ }^{11} \mathrm{C}\right] \mathrm{PK} 11195$ synthesis in a captive solvent loop system. 44

Figure 2.8 Analytical UV HPLC trace for co-injection of (R)-[N-methyl-12C]PK11195 standard solution and (R)-[N-desmethyl]PK11195 precursor solution.

Figure 3.1 Radiosynthesis progress of (R)-[N-methyl-11C]PK11195 from EOB to EOS. 47

Figure 3.2 Diagram of in-process controls during $\left[{ }^{11} \mathrm{C}\right] \mathrm{CH}_{3} \mathrm{I}$ production.

Figure 3.3 Amount of 'cold' $\mathrm{CH}_{3} \mathrm{I}$ formed without pre-conditioning of molecular sieves before synthesis and with pre-conditioning just before the synthesis.

Figure 3.4 Amount of 'cold' $\mathrm{CH}_{3} \mathrm{I}$ formed without filtration of inert gas supplier of methyl iodide system and with filtration.

Figure 3.5 Amount of $\left[{ }^{12} \mathrm{C}\right] \mathrm{CH}_{3} \mathrm{I}$ generated under scenarios $\mathrm{Sc} 1, \mathrm{Sc} 2$ and $\mathrm{Sc} 3$ described above (A). The influence of $\left[{ }^{12} \mathrm{C}\right] \mathrm{CO}_{2}$ source by $\mathrm{LiAlH}_{4}(\mathrm{Sc} 1)$, release of $\mathrm{CO}_{2}$ from $\mathrm{MS}(\mathrm{Sc} 2)$ and the loadunload of the target $(\mathrm{Sc} 3)$ was shown on graph of the right (B)

Figure 3.6 Effect of the bombarding time on the final amount of $\left[{ }^{12} \mathrm{C}\right] \mathrm{CH}_{3} \mathrm{I}$

Figure 3.7 Influence of precursor solvent (MEK, DMSO and DMF) on the trapping efficacy of $\left[{ }^{11} \mathrm{C}\right] \mathrm{CH}_{3} \mathrm{I}$ and $\left[{ }^{11} \mathrm{C}\right] \mathrm{CH}_{3} \mathrm{OTf}$ on the captive solvent loop

Figure 3.8 Influence of precursor ((R)-[N-desmethyl]PK11195) concentration in radiochemical yield and in the ratio $\left[{ }^{11} \mathrm{C}\right] \mathrm{PK} 11195 /\left[{ }^{11} \mathrm{C}\right] \mathrm{CH}_{3} \mathrm{I}$ and total amount of radioactivity of both at EOS affected by precursor concentration.

Figure 3.9 Effect of reaction time in $\left[{ }^{11} \mathrm{C}\right] \mathrm{PK} 11195$ production. Radiochemical yields and total activity of $\left[{ }^{11} \mathrm{C}\right] \mathrm{PK} 11195$ at the end of synthesis.

Figure 3.10 Semi-preparative HPLC separation of (R)-[N-methyl- $\left.{ }^{11} \mathrm{C}\right] \mathrm{PK} 11195$. 56

Figure 3.11 Formulation of $\left[{ }^{11} \mathrm{C}\right] \mathrm{PK} 11195$ by solid phase extraction on the reformulation system. 56

Figure 3.12 Filtration testes of (R)-PK11195 with $0.22 \mu \mathrm{m}$ sterile filters using a solution of saline at $10 \%$ of ethanol.

Figure 3.13 Analytical HPLC traces for a final (R)-[N-methyl- $\left.{ }^{11} \mathrm{C}\right] \mathrm{PK} 11195$ product sample 59 


\section{List of Tables}

Table 1.1 Physical Proprieties of the most common short lived positron-emitting isotopes: Carbon-11 $\left({ }^{11} \mathrm{C}\right)$, Fluoride-18 $\left({ }^{18} \mathrm{~F}\right)$, Nitrogen-13 $\left({ }^{13} \mathrm{~N}\right)$ and Oxygen-15 $\left({ }^{15} \mathrm{O}\right) .{ }^{*} \mathrm{EC}$ : Electron capture.

Table 1.2 Characteristics of carbon-11 as a PET isotope

Table 1.3 Nuclear reactions used to produce carbon-11. Natural abundance of the irradiated stable isotope is listed in the last column.

Table 2.1 Steps for production of $\left[{ }^{11} \mathrm{C}\right] \mathrm{CH}_{3} \mathrm{I}$ from $\left[{ }^{11} \mathrm{C}\right] \mathrm{CO}_{2}$ by the 'wet method'. .42

Table 3.1 Production conditions for $\left[{ }^{11} \mathrm{C}\right] \mathrm{CH}_{3} \mathrm{I}$ 48

Table 3.2 Summary of the results of influence of different solvents and bases in the synthesis of (R)-[N-methyl-11 C]PK11195. . .54

Table 3.3 Influence of precursor concentration in the synthesis of $\left[{ }^{11} \mathrm{C}\right] \mathrm{PK} 11195$. .54 

Acronyms

\begin{tabular}{|c|c|}
\hline$\left[{ }^{11} \mathrm{C}\right] \mathrm{CH}_{3} \mathrm{I}$ & {$\left[{ }^{11} \mathrm{C}\right]$ Methyl Iodide } \\
\hline$\left[{ }^{11} \mathrm{C}\right] \mathrm{CH}_{3} \mathrm{OTf}$ & {$\left[{ }^{11} \mathrm{C}\right]$ Methyl Triflate } \\
\hline$\left[{ }^{11} \mathrm{C}\right] \mathrm{CH}_{4}$ & {$\left[{ }^{11} \mathrm{C}\right]$ Methane } \\
\hline$\left[{ }^{11} \mathrm{C}\right] \mathrm{CO}_{2}$ & {$\left[{ }^{11} \mathrm{C}\right]$ Carbon dioxide } \\
\hline$\left[{ }^{11} \mathrm{C}\right] \mathrm{PK} 11195$ & $\begin{array}{l}\text { 1-(2-chlorophenyl)-N-methyl-N-(1-methylpropyl)-3-isoquinolinecarboxamide labelled } \\
\text { with carbon-11 }\end{array}$ \\
\hline$\mu \mathrm{A}$ & micro-Ampere \\
\hline${ }^{11} \mathrm{~B}$ & Boron-11 \\
\hline${ }^{11} \mathrm{C}$ & Carbon-11 \\
\hline${ }^{12} \mathrm{C}$ & Carbon-12 \\
\hline${ }^{13} \mathrm{~N}$ & Nitrogen-13 \\
\hline${ }^{14} \mathrm{~N}$ & Nitrogen-14 \\
\hline${ }^{15} \mathrm{O}$ & Oxygen-15 \\
\hline${ }^{18} \mathrm{~F}$ & Fluorine-18 \\
\hline $3 \mathrm{D}$ & Three-dimensional \\
\hline $\mathrm{AD}$ & Alzheimer's disease \\
\hline $\mathrm{AgOTf}$ & Silver Trifluoromethanesulfonate (or Silver Triflate) \\
\hline $\mathrm{Ah}$ & Ampere-hour \\
\hline ANT & Adenine Nucleotide Transporter \\
\hline ATP & Adenosine-5'-triphosphate \\
\hline BBB & Blood Brain Barrier \\
\hline $\mathrm{Bq}$ & Bequerel \\
\hline $\mathrm{Ci}$ & Curie \\
\hline CNS & Central Nervous System \\
\hline СТ & Computed Tomography \\
\hline DC & Decay Corrected \\
\hline DMF & Dimethylformamide \\
\hline DMSO & Dimethyl Sulfoxide \\
\hline e.g. & exempli gratia ("for example") \\
\hline EC & Electron Capture \\
\hline $\mathrm{EOB}$ & End Of Bombardment \\
\hline EOS & End Of Synthesis \\
\hline $\mathrm{EtOH}$ & Ethanol \\
\hline $\mathrm{eV}$ & eletron Volt \\
\hline
\end{tabular}


FDG

FPV

GABA

GC

GMP

$\mathrm{H}_{2}$

$\mathrm{H} 2 \mathrm{O}$

$\mathrm{HCl}$

HD

$\mathrm{He}$

HI

HIV

HPLC

i.e.

ICNAS

IUPAC

$\mathrm{kDa}$

$\mathrm{KOH}$

$\mathrm{LiAlH}_{4}$

MEK

MI

MI

$\min$

mol

MRI

MS

$\mathrm{N}_{2}$

$\mathrm{NaCl}$

$\mathrm{NaF}$

NDC

NI

${ }^{\circ} \mathrm{C}$

$\mathrm{P}_{2} \mathrm{O}_{5}$

PBR

PD

PET

PiB
2- $\left[{ }^{18} \mathrm{~F}\right]$-fluoro-2-deoxy-D-glucose

Final Product Vial

$\gamma$-aminobutyric acid

Gas Chromatography

Good Manufacturing Practice

Hydrogen

Water

Hydrochloric Acid

Huntington's disease

Hellium

Hydriodic Acid

Human Immunodeficiency Virus

High Performance Liquid Chromatography

id est ("that is")

Institute for Nuclear Sciences Applied to Health (Instituto de Ciências Nucleares

Aplicadas à Saúde)

International Union of Pure and Applied Chemistry

kiloDalton

Potassium Hydroxide

Lithium Aluminium Hydride

Methyl Ethyl Ketone

Molecular Imaging

Molecular ImagingMSMultiple Sclerosis

Minutes

mole

Magnetic Resonance Imaging

Molecular Sieves

Nitrogen

Sodium Chloride

Sodium $\left[{ }^{18} \mathrm{~F}\right]$ fluoride

Non-Decay Corrected

Neuroinflammation

Degree Celsius

Phosphorus Pentoxide

Peripheral Benzodiazepine Receptor

Parkinson's disease

Positron Emission Tomography

Pittsburgh Compound B 
PK11195 1-(2-chlorophenyl)-N-methyl-N-(1-methylpropyl)-3-isoquinolinecarboxamide

PVDF Polyvinylidene Difluoride

QC

Quality Control

$\mathrm{R} \& \mathrm{D}$

Research and Development

RCY

Radiochemical Yield

SA

Specific Activity

SPE

Solid Phase Extraction

SPECT

Single Photon Emission Computed Tomography

$\mathrm{TBAOH}$

Tetrabutylammonium Hydroxide

THF

Tetrahydrofuran

TLC

Thin Layer Chromatography

TOI

Time Of Injection

TSPO

Translocator Protein (18kDa)

$\mathrm{UC}$

University of Coimbra

US

Ultrasound

UV

Ultraviolet

$\mathrm{v} / \mathrm{v}$

Volume to Volume

VDAC

Voltage-Dependent Anion Channel

$\beta^{+}$

Positron 



\section{CHAPTER 1}

Introduction

\section{PART I: General Introduction}

Inflammation, in general, is a physiological response of the body to different types of tissue injury, causing a cascade of coordinated cellular and chemical reactions. The inflammatory process isolates the damaged tissue and promotes an immune response [1]. Likewise, neuroinflammation (NI) implicates a complex orchestrated response to various stimuli in the central nervous system (CNS) aiming toward tissue preservation and restoration. Neuroinflammatory reactions involve a cellular response by activating cells of the monocyte lineage, whether resident or circulating. Microglia are the resident cells of the monocyte lineage in the CNS and their activation constitutes a main feature of neuroinflammation [2].

This activated stage of microglia, upregulates the expression of the $18 \mathrm{kDa}$ translocator protein (TSPO), which can be detected in vivo by positron emission tomography (PET) imaging 
using a selective TSPO radioligand [3]. One of the first PET ligands for human studies of activated microglia (TSPO overexpression) was PK11195, a lipid soluble isoquinoline carboxamide, labelled with carbon-11 $\left(\left[{ }^{11} \mathrm{C}\right] \mathrm{PK} 11195\right)$ [4], and it still today the most widely used radiotracer for in vivo TSPO imaging [5]. In this work we report on the optimisation of the synthesis, purification and reformulation of (R)-[N-methyl- $\left.{ }^{11} \mathrm{C}\right] \mathrm{PK} 11195$ with the aim of being used for in vivo PET imaging studies.

\subsection{Objectives}

The aim of this work is to optimize and automate the synthesis, purification and reformulation of (R)-[N-methyl $\left.{ }^{11} \mathrm{C}\right] \mathrm{PK} 11195$ in order to produce a stable, sterile and ready-to-inject solution of the radiopharmaceutical with sufficient activity and quality to be used in clinical PET studies of neuroinflammation. A substantial part of the work developed is applicable to other carbon-11 $\left({ }^{11} \mathrm{C}\right)$ labelled compounds and, in fact, has been of critical importance for the production of other tracers, notably $\left[{ }^{11} \mathrm{C}\right]$ Pittsburg Compound $\mathrm{B}\left(\left[{ }^{11} \mathrm{C}\right] \mathrm{PiB}\right)$.

Accordingly, the main objectives of the work are:

- Optimisation of synthesis process: reagents, reaction times, temperatures, solvents and bases;

- Reformulation of product in a ready-to-inject solution;

- Quality assurance of the product, e.g., quality control;

- Quality control of the product: radiochemical yield, specific activity, chemical and radiochemical purity, residual organic solvents, apyrogenecity and sterility;

- Programming and automation of the modules for routine production and troubleshooting;

- Cost optimisation of all components required for the production process (disposable spare parts, valves, reagents and solvents).

This was done in parallel with normal activities of a busy radiochemistry laboratory, including active participation in routine as well as clinical and pre-clinical production tasks. 


\subsubsection{Timeline of the Project}

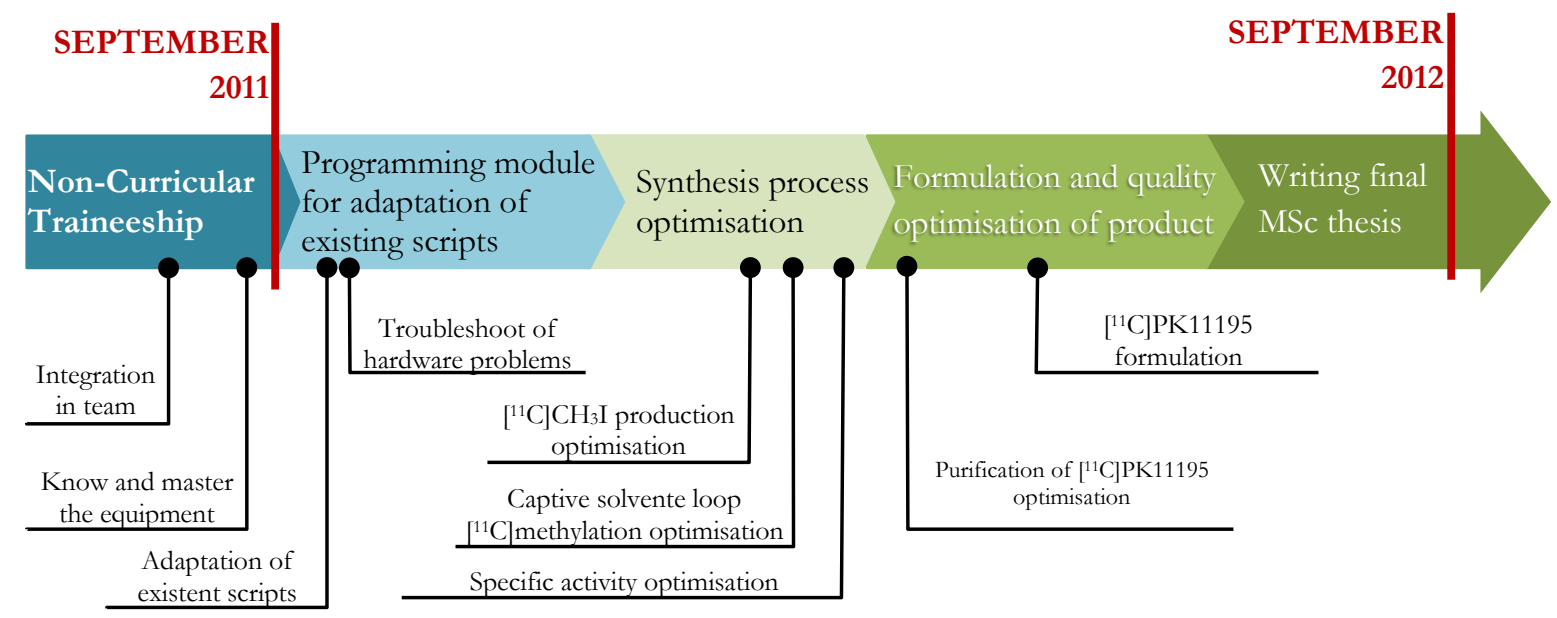

Figure 1.1 Timeline of the work during the final year project.

Involvement in all laboratory activities included a substantial contribution for an optimized production of $\left[{ }^{11} \mathrm{C}\right] \mathrm{PiB}\left(\left[{ }^{11} \mathrm{C}\right]\right.$ Pittsburg Compound $\left.\mathrm{B}\right)$. This radioligand is a benzothiazole derivative of thioflavin ' $\mathrm{T}$ that is used to image beta-amyloid deposits in Alzheimer's disease patients with positron emission tomography (PET).

This collaboration work was also presented on the 2nd Bioengineering Meeting IEEEEMBS:

G. Clemente, V. Alves, A.J. Abrunhosa, "Synthesis Optimisation of Pittsburgh Compound B by the Captive Solvent Method" - Acceptance for oral presentation at the $2^{\text {nd }}$ Bioengineering Meeting IEEEEMBS (February, 2012 in Coimbra, Portugal).

\subsection{The Institute for Nuclear Sciences Applied to Health}

The work was developed at Instituto de Ciências Nucleares Aplicadas à Saúde (ICNAS), more exactly at the Radiochemistry and Cyclotron laboratory managed by ICNAS-Produção, Unipessoal, Lda.

ICNAS is an organic unit of University of Coimbra (UC) sited on the Health Campus, and is devoted to basic as well as clinical research on the biomedical use of radiation. It was opened in 2009 and since then the radiochemistry laboratory has made available several radiopharmaceuticals labelled with short-live positron emitters (fluorine-18 and carbon-11) for research as well as routine clinical studies. Besides $\left[{ }^{18} \mathrm{~F}\right] \mathrm{FDG}$, ICNAS is currently producing other 
${ }^{18} \mathrm{~F}$-based molecules such as $\left[{ }^{18} \mathrm{~F}\right] \mathrm{NaF}$ and $\left[{ }^{18} \mathrm{~F}\right]$ Fluorocholine. As for carbon-11, the list of molecules available include $\left[{ }^{11} \mathrm{C}\right] \mathrm{PiB},\left[{ }^{11} \mathrm{C}\right] \mathrm{PK} 11195,\left[{ }^{11} \mathrm{C}\right]$ Raclopride and $\left[{ }^{11} \mathrm{C}\right]$ Flumazenil.

ICNAS is equipped with a full GMP licensed laboratory for the production of radiopharmaceuticals and since December 2011 holds a Marketing Authorization for its own $\left[{ }^{18} \mathrm{~F}\right] \mathrm{FDG}$. 


\section{Part II: Theoretical Background}

\subsection{Neuroinflammation}

The inflammatory process [2], as a physiological response to tissue insults, is basically a complex orchestrated chemical and cellular response to various stimuli aiming toward tissue preservation and restoration. The inflammatory reaction isolates the damaged tissue and promotes immune responses, leading to a local production of cytokines: protein molecules that are responsible for the mechanisms of cellular differentiation. This culminates in the formation of a scar which isolates physically the lesion form healthy tissue, which is generally beneficial in neutralizing potential threats by minimizing cellular damage and contributing to support repair and regeneration (acute inflammation). On the other hand, when excessive or persistent inflammation degenerates the tissue injury, the inflammatory response can be detrimental, initiating cellular damage (chronic inflammation). The central nervous system (CNS) is characterised by a limited ability to regenerate its own tissues, thus chronic neuroinflammation is closely related with several neurodegenerative disorders such as Parkinson's disease (PD), Huntington's disease (HD), Dementias and Multiple sclerosis [3]. Acute neuroinflammation is generally caused by some neuronal injury after which microglia migrates to the injured site to minimize injury and promotes tissue repair. Otherwise, in chronic neuroinflammation, microglia remains activated for an extended period of time and the production of mediators is continuous. This response of microglial cells contributes to an increase of the neurodestructive effects, and the worsening of the disease [6]. In fact, there is no longer a clear distinction between acute and chronic states of inflammation, and in the CNS, the distinction has not been applied consistently prevailing the notion that when inflammation is present, chronic neuroinflammation is presumed $[6]$.

\subsection{Microglia}

Microglia cells are critical in the protection of the brain parenchyma against brain injuries such as infection, trauma, ischemia, brain tumours and neurodegenerative diseases. These cells are the resident macrophages of the central nervous system and they are the main component of immune defence on the CNS, since they have the ability to become phagocytes, when needed [3]. They make up approximately $20 \%$ of the total glial population of the CNS, and act as a first line of defence against pathological insults at this primary site [7, 8]. Del Rio Hortega was the first to 
recognize the pathological importance of microglia in CNS, and he also coined the term [9]. In a healthy brain parenchyma, resting microglia do not engage in phagocytic or pinocytic activity. After an injury or CNS disease, microglial cells abandon their ramified resting-like morphology and become activated, acquiring phagocytic properties and respond to tissue insult with a complex array of inflammatory cytokines and actions, essentials for the annihilation of the neuronal insult $[3,10]$. Derived from the monocytic lineage, these cells display high sensitivity to different types of CNS injury [11], and they are able to respond quickly.

\subsubsection{Activated stage of microglia}

Microglia activation plays an important role in neuroinflammation. During the process, cells change from a resting phenotype to an activated phenotype in response to a wide variety of CNS insults. That does not mean that microglial cells are totally inactive during resting state. Quite the contrary, cells are actually quite active, and regulate their processes by continuously monitoring the external milieu $[12,13]$.

During neuroinflammation, the microglia cells suffer drastic changes in their morphology, migrate to the lesion site, proliferate and produce neurotoxic factors such as proinflammatory cytokines and reactive oxygen species. This morphological change is an important characteristic that can be observed after activation. Cells undergo changes from a ramified structure to a hyperramified and at last to an amoeboid morphology that is fully capable of fagocytosis. The amoeboid structure facilitates migration of the microglial cell through the parenchyma to the lesion sites to engulf the offending material. Microglia can become activated by disruption of the blood brain barrier (BBB), fluxes in extracellular glutamate, extracellular ATP from damage cells, and disrupted tonic inhibition via fractalkine receptor [14].

Most immune receptors that are essential to the initiation and propagation of immune responses are constitutively expressed at low levels on microglia. The immunologically relevant molecules are upregulated during the microglial activation, and the production of inflammatory mediators is stimulated [15]. Several phagocytic receptors are also expressed by microglia, functioning as the "professional" phagocytes of the CNS.

Microglia is actively repressed through signals coming from electrically active neurons, and when this tonic inhibition is removed, it can lead to microglial activation [15]. 


\section{5. $18 \mathrm{kDa}$ Translocator Protein}

Benzodiazepines are one of the most commonly prescribed class of drugs. In the CNS they bind to a specific benzodiazepine alosteric binding site on the $\gamma$-aminobutyric acid $(\mathrm{GABA})_{\mathrm{A}}$ receptor complex modulating the $\mathrm{GABA}_{\mathrm{A}}$-regulated opening of $\mathrm{Cl}^{-}$channels that is responsible for the inhibition of neuronal activity. In addition, another type of benzodiazepine binding site was identified in 1977 by Braestrup et al. [16] where they noticed that the benzodiazepine diazepam had a high affinity for the mitochondrial fractions of rat kidney. This 'peripheral' diazepam binding site was shown to be abundantly distributed in the peripheral tissues and was defined as peripheral-type benzodiazepine binding site or peripheral benzodiazepine receptor (PBR). Subsequent studies demonstrated the presence of PBR in glial and in ependymal cells of the brain [17]. It was also demonstrated that this "peripheral"-type benzodiazepine site for diazepam was pharmacologically, anatomically, structurally, and physiologically distinct from “central” benzodiazepine binding site [18].

A new name 'TSPO' was later proposed by a focus group in 2006 [19], being the peripheral benzodiazepine receptor renamed to $18 \mathrm{kDa}$ translocator protein (TSPO). This new nomenclature aims to better represents its subcellular role (or roles) as a cholesterol translocator, its putative tissue-specific function (or functions) and its molecular weight [19, 20]. TSPO is a large transmembrane protein complex found at high levels on the outer mitochondrial membrane of the cells in the peripheral organs, such as heart, kidney lung, adrenal cortex, salivary gland, testis or ovaries [21-23]. It is also founded, but at low levels, primarily associated with the glial cells in the normal brain [24].

\subsubsection{Structure}

TSPO is an $18 \mathrm{kDa}$ protein consisting of 169 amino-acids and is highly hydrophobic and rich in tryptophan [10]. TSPO, at a subcellular level, is present mainly on the outer membrane of mitochondria, specialy at contact sites between the inner and outer membrane, where the translocator protein is particularly enriched. These sites are known as the mitochondrial permeability transition pore (MPTP) and are formed by at least three different subunits on the mitochondrial outer membrane (Figure 1.2): (1) the isoquinoline binding protein of $18 \mathrm{kDa}$ (TSPO); (2) a voltage-dependent anion channel of $32 \mathrm{kDa}$ (VDAC); and (3) an adenine nucleotide transporter of $30 \mathrm{kDa}(\mathrm{ANT})[5,25]$. 


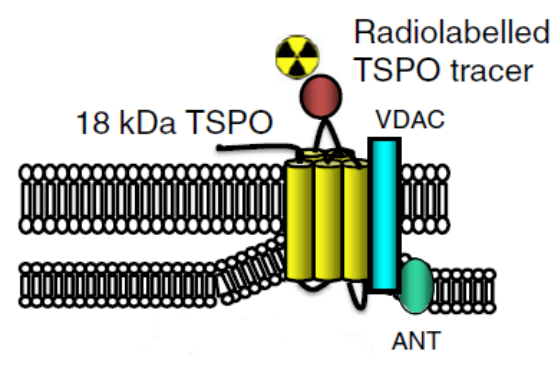

Figure 1.2 Structures of TSPO as a hetero-oligomeric complex. This multimeric complex consists at least of three different subunits, including the isoquinoline binding protein of $18 \mathrm{kDa}$ (TSPO), a voltage-dependent anion channel of $32 \mathrm{kDa}(\mathrm{VDAC})$ and an adenine nucleotide transporter of $30 \mathrm{kDa}$ (ANT) Adapted from [5].

Thus, TSPO has a putative five transmembrane helical structure (Figure 1.2) forming a hetero-oligomeric complex present in mitochondria of astrocytes and microglia (Figure 1.3). In association with the VDAC and the ANT contains inner and outer membrane contact sites to enable the passage of lipophilic molecules through the intermembrane space [21].

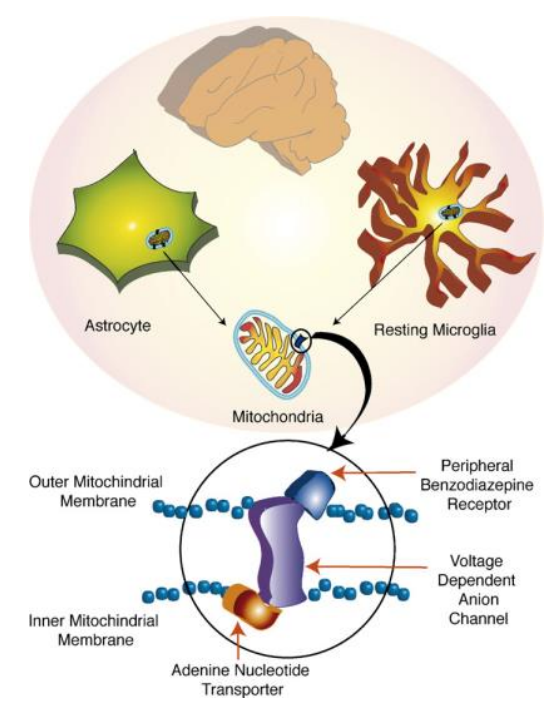

Figure 1.3 Schematic diagram of the hetero-oligomeric complex localized on the outer mitochondrial membrane of astrocytes and microglia. Obtained from [4].

\subsubsection{Function}

Decades of studies of TSPO in mammals showed many physiological functions that can be attributed to TSPO such as cell grow and proliferation, steroidogenesis, bile acid synthesis, calcium flow, chemotaxis and cellular immunity, heme biosynthesis, and mitochondrial respiration and apoptosis [24]. Amongst the physiological functions of TSPO, steroidogenesis is the best well-known. TSPO is enriched in steroid synthesising tissues such as the adrenal gland 
and the testis, where TSPO mediates cholesterol transport from the outer to the inner mitochondrial membranes [26]. Its presence at the mitochondrial permeability transition pore (MPTP) also implicates TSPO in the regulation of necrotic and apoptotic cell dead as ligands that are able to cause opening of the MPTP result in the induction of apoptosis [27]. Cell proliferation in cancer cell lines is also inhibit by TSPO ligands, which cause an arrest of the cells at the $G_{1} / G_{0}$ phase of the cell cycle, leading to the inhibition of the progression of the cells to the $S$ and $G_{2} / M$ phase, where cell proliferation occurs [28]. Due to TSPO expression on microglia and other immune cells, this protein also plays a role in immune regulation.

The functions of TSPO in the CNS are not clearly known [29]. Under normal physiological conditions, the levels of TSPO in the CNS are very low and limited to glial cells (astrocytes and microglia). But, it is thought that this receptor is involved in neurosteroid synthesis [30], regulation of mitochondrial function [10] and modulation of neuroinflammation in microglial cells [4]. Even though the function of TSPO in CNS is not yet entire clear, several studies have focused on changes in TSPO expression in a number of CNS disorders [3, 4, 25, 31].

\subsubsection{TSPO in neuroinflammation}

As mentioned before, TSPO is present at very low levels in normal brain, limited to glial cells, but it is upregulated at sites of injury and inflammation [32]. TSPO is expressed by the mitochondria of activated microglial cells in response to a diversity of insults and pathogens. This process is not exclusive of microglia and can also be found on macrophages in response to inflammation throughout the body, e.g. associated with tumoral activity [5, 32]. Similarly to macrophages, microglial cells respond to any pathological event, through the production and release of pro-inflammatory cytokines (Figure 1.4). 


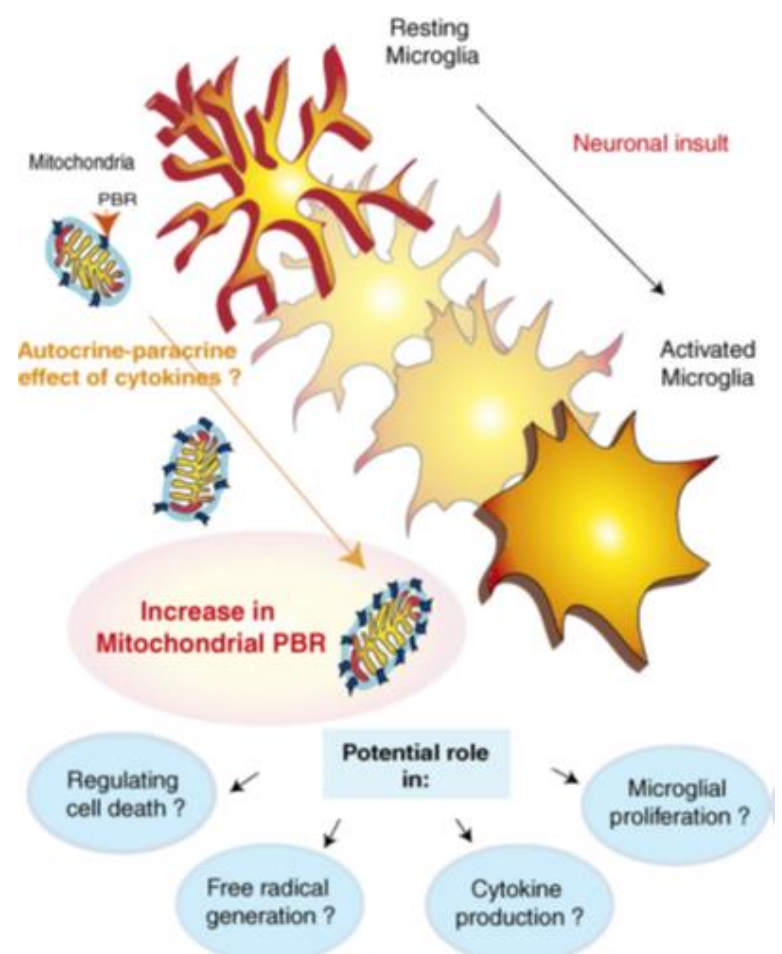

Figure 1.4 Schematic diagram of function and mechanism of $18 \mathrm{kDa}$ translocator protein (TSPO). Obtained from [4].

There is a range of synthetic TSPO ligands whose binding profile will potentially aid in the understanding of the TSPO binding sites and should help to determine any conformational changes in the TSPO protein that may occur in neuroinflammation and in various CNS disease states. TPSO ligands have the potential to be used in vivo and post-mortem analyses of a variety of CNS diseases including AD, PD, HD, multiple sclerosis, and mood disorders. It makes TSPO as an ideal and sensitive biomarker for microglial activation in neuroinflammatory processes.

These outcomes have encouraged researchers to develop radioligands for TSPO. Although new probes are currently being developed to visualize this receptor, $\left[{ }^{11} \mathrm{C}\right] \mathrm{PK} 11195$ remains the most widely used radiotracer for PET imaging of the TSPO benefiting from a significant clinical experience and important results in a number of neuroinflammatory and neurodegenerative diseases [5, 33].

\subsubsection{TSPO ligands}

As a consequence of the marked upregulation of TSPO in active disease states, it becomes an attractive target for in vivo imaging of disease progression using functional imaging modalities such as PET [4]. The TSPO is now considered a significant therapeutic and diagnostic target 
promoting a substantial effort in TSPO ligands development.

Radioligands for TSPO can be divided in seven chemical classes or entities [2], including benzodiazepines (1), isoquinoline carboxamides (2), indoleacetamides (3), vinca alkaloids (4), oxodihydropurines (5), phenoxyarylacetanides (6), and imidazopyridines and bioisoteric structures (imidazopyridines and pyrazolopyrimidines) (7). Examples of some TSPO-binding ligands from these classes are shown in Figure 1.5.

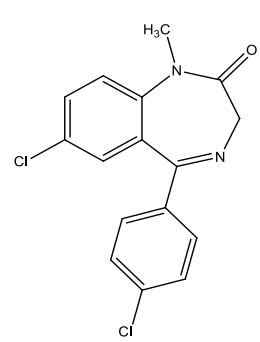

Ro5-4864 (1)<smiles>CCN(Cc1ccccc1)C(=O)Cn1c(=O)n(C)c2cnc(-c3ccccc3)nc21</smiles>

AC-5216 (5)<smiles>CC[C@H](C)N(C)C(=O)c1cc2ccccc2c(-c2ccccc2Cl)n1</smiles>

(R)-PK11195 (2)

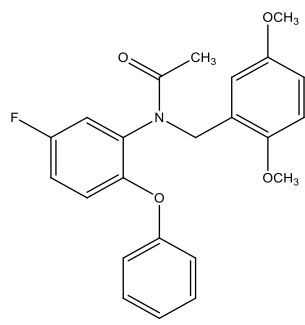

DAA1106 (6)

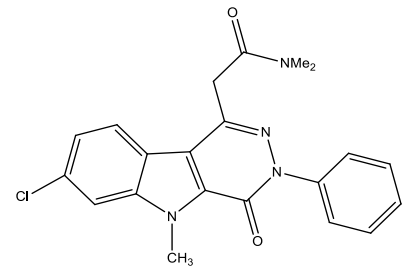

SSR180575 (3)

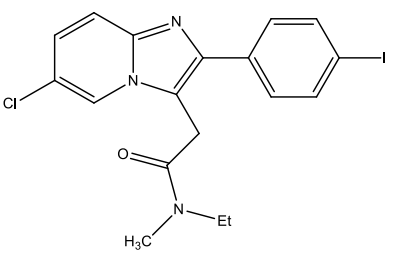

CLINME (7a)<smiles>[CH][C@]12C=C(C(=O)CO)n3c4c(c5ccccc53)CCN(CC1)[C@]42C</smiles>

Vinpocetine (4)

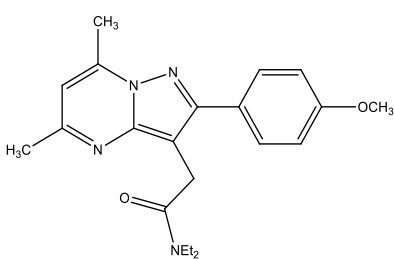

DPA-713 (7b)

Figure 1.5 Chemical structures of some TSPO-selective compounds, Ro5-4864 (1), (R) PK11195 (2), SSR180575 (3), Vinpocetine (4), AC 5216 (5), DAA1106 (6), CLINME (7a), and DPA 713 (7b).

Benzodiazepines are a class of drugs known for being extensively prescribed for the relieve of anxiety and insomnia. They are also considered sedative and anticonvulsant because of their pharmacological effects (e.g. diazepam). After the discovery that diazepam binds with relatively high affinity to both TSPO and $\mathrm{GABA}_{\mathrm{A}}$ receptors in rat brain, new benzodiazepine derivatives began to appear aiming at establishing the difference between these two types of receptors. The benzodiazepine derivative $\left[{ }^{11} \mathrm{C}\right]$ Ro5-4864 (4'-chlorodiazepam), was synthesised at the same year as $\left[{ }^{11} \mathrm{C}\right] \mathrm{PK} 11195$ and it was the first molecule able to discriminate "peripheral" from "central" benzodiazepine binding sites [2]. It was a 4'-chloro derivative of diazepam and was found to bind with high affinity to TSPO derived from rat kidney and with low affinity to $\mathrm{GABA}_{\mathrm{A}}$ [34]. 
In 1983, Lefur and co-workers detailed the isoquinoline carboxamides as a new class of TSPO radioligands in addition to benzodiazepines [35]. The isoquinoline carboxamides (Figure 1.6) are structurally different from benzodiazepines and have a higher affinity for TSPO than for $\mathrm{GABA}_{\mathrm{A}}$. The first isoquinoline carboxamide synthesised in 1984 was PK11195 (more information in section 1.6) and since then it has found numerous applications in a number of animal and clinical studies.

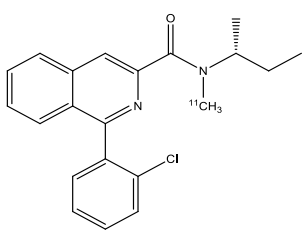

(R)-[ $\left[{ }^{11} \mathrm{C}\right] \mathrm{PK} 11195(2)$

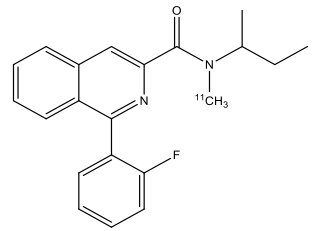

$\left[{ }^{11} \mathrm{C}\right] \mathrm{PK} 11211$

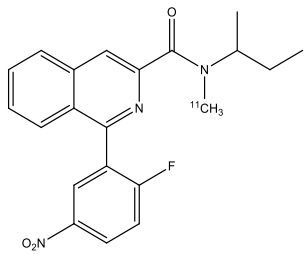

$\left[{ }^{11} \mathrm{C}\right] \mathrm{PK} 14105$

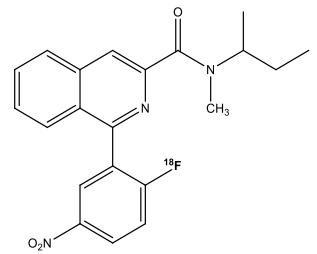

$\left[{ }^{18} \mathrm{~F}\right] \mathrm{PK} 14105$

Figure 1.6 Chemical structures of isoquinoline carboxamides.

There has been a wide range of ligands developed over the years that show high affinity to the TSPO binding site. All share some common features [36] including a fused bicyclic aromatic system containing two electronegative boundaries and a freely rotating aromatic ring. Moreover, many ligands also contain a third electronegative group surrounded by lipophilic substituents [36]. Development of new TSPO ligands is also underway with the aim of finding more selective and specific compounds based of those structures. From those, compounds with favourable in vivo binding properties and kinetics could be used to increase our understanding of the normal functioning of the TSPO and the chemical pathways underlying several pathological conditions.

\section{6. (R)-[ $\left.{ }^{11} \mathrm{C}\right] \mathrm{PK} 11195$}

PK11195 [1-(2-chlorophenyl)- $N$-methyl- $N$-(1-methylpropyl)-3-isoquinoline] was the first non-benzodiazepine high-affinity selective TSPO ligand $\left(K_{\mathrm{I}}=9.3 \mathrm{nM}\right)$ and was labelled with carbon-11 ([11 C]PK11195) as a probe for PET imaging [37]. It was discovered in 1984 and named after a French company, Pharmuka [38].

In 1994, Shah et al. [39] synthesised and compared in vivo the $\mathrm{R}$ and $\mathrm{S}$ enantiomer of $\left[{ }^{11} \mathrm{C}\right] \mathrm{PK} 11195$ (Figure 1.7) in rats with a cortical focal lesion. This study showed a twofold higher affinity of the (R)-[ $\left.{ }^{11} \mathrm{C}\right]$ PK11195 enantiomer, making it advantageous over the (S)- $\left[{ }^{11} \mathrm{C}\right] \mathrm{PK} 11195$ 
for imaging studies. With its nanomolar binding affinity, it remains today the most widely used ligand for TSPO imaging and is regarded as the prototypal reference for new compound development [5].

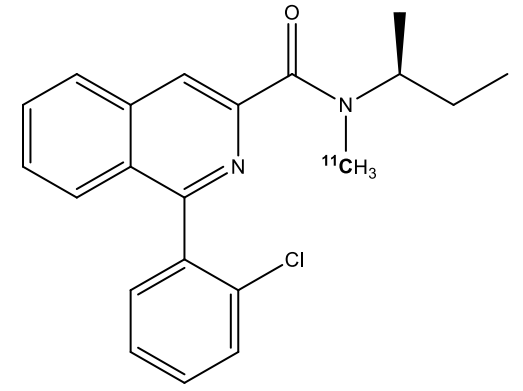

(S)- $\left[{ }^{11} \mathrm{C}\right] \mathrm{PK} 11195$<smiles>CC[C@H](C)N(C)C(=O)c1cc2ccccc2c(-c2ccccc2Cl)n1</smiles>

(R)- $\left[{ }^{11} \mathrm{C}\right] \mathrm{PK} 11195$

Figure 1.7 Chemical structures of $(R)$ - and $(S)-\left[{ }^{11} \mathrm{C}\right] \mathrm{PK} 11195$.

PK11195 presents favourable kinetic proprieties that allow its use as an in vivo ligand including the ability to permeate the blood brain barrier (BBB) by passive diffusion [37] with an extraction from blood to brain of over $90 \%$. Studies of whole-body distribution and metabolism of (R)- $\left[{ }^{11} \mathrm{C}\right] \mathrm{PK} 11195$ in humans [40], showed a large inter-individual variation in the amount radiolabelled metabolites in plasma. Whole-body distribution of (R)- $\left[{ }^{11} \mathrm{C}\right]$ PK11195 showed the highest radioactivity levels in urinary bladder, adrenal gland, liver, salivary glands, heart, kidneys and vertebral column. (R)- $\left[{ }^{11} \mathrm{C}\right] \mathrm{PK} 11195$ seems to be eliminated through both the renal and hepatobiliary systems.

(R)- $\left[{ }^{11} \mathrm{C}\right]$ PK11195 exhibits high affinity for the TSPO in all species [41], however newer radioligands are beginning to appear as an alternative to PK11195 [34, 42, 43]. They have, so far, failed to replace it due to inadequate pharmacokinetic proprieties, poor bioavailability toward brain tissue or a high level of nonspecific binding [33]. All these new ligands share some common features that allow researchers to have a better insight of the TSPO binding domain, thus opening the door for the development of better, more selective and specific tracers that could be available in the future. 


\subsubsection{PET imaging studies of TSPO in human diseases}

Overexpression of TSPO can be detected in vivo by PET imaging with selective radioligands such as $\left[{ }^{11} \mathrm{C}\right] \mathrm{PK} 11195[2,3,29,37]$. With the evidence that $\left[{ }^{11} \mathrm{C}\right] \mathrm{PK} 11195$ binding potential $\left(\mathrm{BP}_{\mathrm{ND}}\right)$ increases with the activation of microglia [44], this tracer has been used in a wide range of human CNS diseases that involve some degree of inflammation such as Parkinson's disease (PD), Huntington's disease (HD), multiple sclerosis , Alzheimer's disease (AD), Dementia, Rasmussen's encephalities, amyotrophic lateral sclerosis, infectious diseases (HIV and herpes encephalitis), and neuropsychiatric disorders such as schizophrenia [37]. Thus, the assessment of TSPO with PET provides an in vivo tool to monitor the progression and severity of neuroinflammation, providing a useful biomarker for several active CNS diseases.

\section{Parkinson's disease (PD)}

Parkinson's disease is the second most common neurodegenerative disorder of the aged and is associated with the motor symptoms of tremor, bradykinesia, and rigidity. PD is characterised by the extended loss of dopaminergic neurons in the substantia nigra pars compacta, resulting in a deficiency of dopamine in the striatum. PD is the most common of a group of parkinsonian movement disorders that also includes multiple system atrophy, corticobasal degeneration, and progressive supranuclear palsy [45].

Several studies suggest a close relationship between neurodegeneration and neuroinflammation in $\mathrm{PD}$, and further clues regarding the role of activated microglia has also come from in vivo PET imaging studies [3]. Inflammation through activated microglia can be measured directly using $\left[{ }^{11} \mathrm{C}\right] \mathrm{PK} 11195$ and this tracer has paved the road to in vivo animal and human PET studies for measuring neuroinflammation in PD [45].

Two PET studies have reported a significant increase in (R)- $\left[{ }^{11} \mathrm{C}\right] \mathrm{PK} 11195$ binding in both striatal and extrastriatal regions in PD patients when compared to normal controls (Figure 1.8) [46]. In one of these studies, levels of putamen dopamine transporter binding were inversely correlated with levels of midbrain microglial activation. 

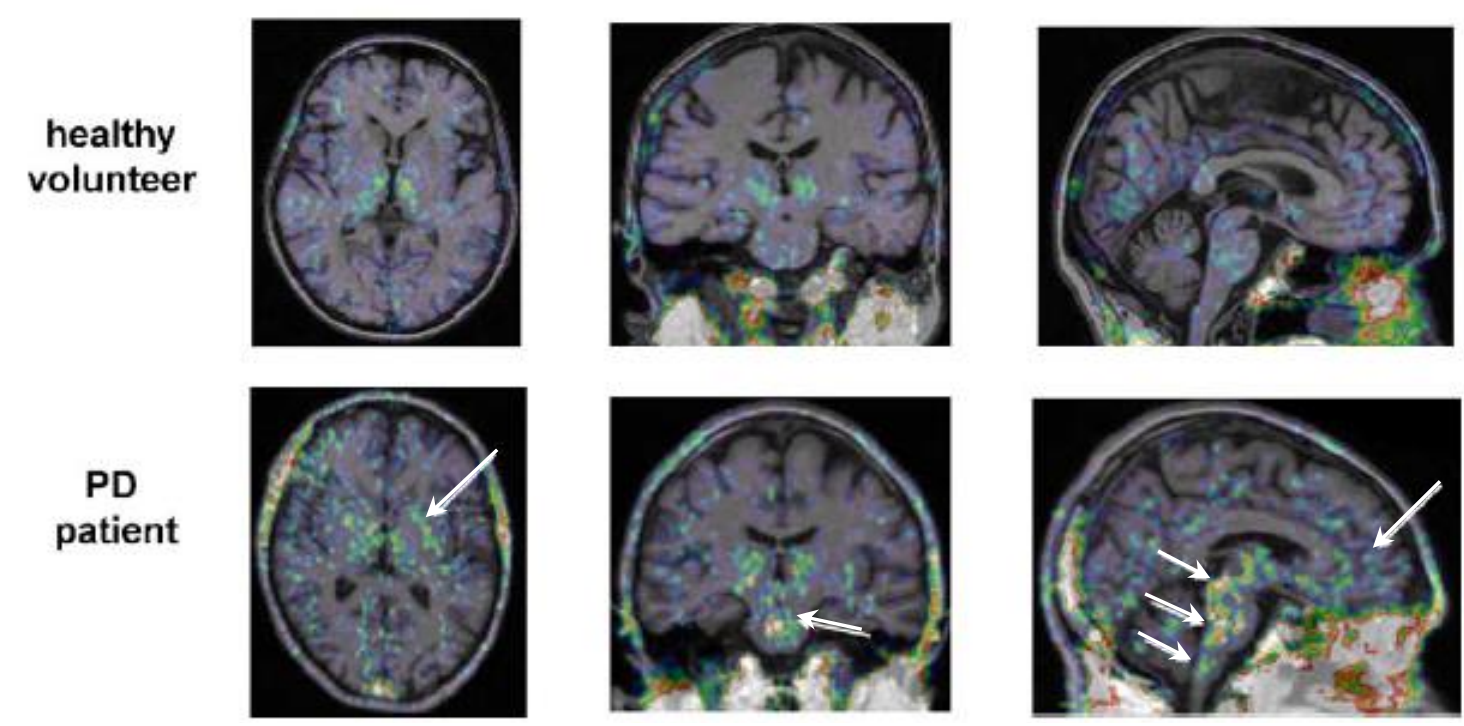

Figure 1.8 PET scans with $\left[{ }^{11} \mathrm{C}\right] \mathrm{PK} 11195$ of a healthy subject and a Parkinson's disease patient. Mild microglial activation is seen in the thalamus of the healthy control but a significantly raised activation is evident in the midbrain and striata of the PD patient. Obtained from [46].

Additional, extensive binding of (R)- $\left[{ }^{11} \mathrm{C}\right]$ PK11195 has been observed in patients with the atypical syndrome multiple system atrophy [47]. Taken together these findings support the hypothesis that neuroinflammatory responses, as evidenced by activation of microglia, contribute to neuronal loss in PD and other neurodegenerative diseases.

\section{Huntington's disease (HD)}

Huntington's disease is an autosomal, dominant inherited progressive neurodegenerative disorder associated with motor, cognitive, and psychiatric symptoms. HD is caused by an abnormal polyglutamine-repeat expansion on the IT15 gene that codes huntingtin, and involves the progressive loss of medium spiny dopaminergic receptor-bearing striatal GABA-ergic neurons [48].

In vivo studies evidence an increase in (R)- $\left[{ }^{11} \mathrm{C}\right] \mathrm{PK} 11195 \mathrm{BP}_{\mathrm{ND}}$ in the striatum and cortical regions in symptomatic HD patients when compared with healthy controls [49]. They suggests that in manifest HD patients, the observed significant increase of $(\mathrm{R})-\left[{ }^{11} \mathrm{C}\right] \mathrm{PK} 11195 \mathrm{BP} \mathrm{ND}_{\mathrm{N}}$ in the striatum, hypothalamus, and various cortical regions is correlated with greater disease burden and higher motor disability. More studies using this radioligand have also found increased microglial activation in symptomatic HD patients and in manifest HD patients when compared with healthy control ([3] and references inside), and interestingly, this microglial activation in the striatum and 
regions related to cognitive function has been shown to predict the 5-year disease clinical onset in pre-manifest HD patients.

These findings show that microglia activation is an early event in the HD disease course, and may have a pathogenic involvement that is associated with progression of the disease.

\section{Multiple Sclerosis}

Multiple sclerosis is a disease characterised pathological by inflammatory demyelination and axonal transection, being the most common cause of non-traumatic disability in young adults [50].

The presence of activated macrophages in areas of demyelination and the presence of myelin debris within the cytoplasm has been a strong argument for a direct role of this cell type in multiple sclerosis. Activated microglia involvement in the immune response of multiple sclerosis has long been proposed [51]. Consequently, pathological aspects of multiple sclerosis such as neuroinflammation, demyelination, and neurodegeneration may be explored in vivo by PET imaging studies with radiolabelled (R)- $\left[{ }^{11} \mathrm{C}\right] \mathrm{PK} 11195$ ligand. These studies have proved that the inflammatory processes and microglia are actively involved in multiple sclerosis (Figure 1.9) [3].

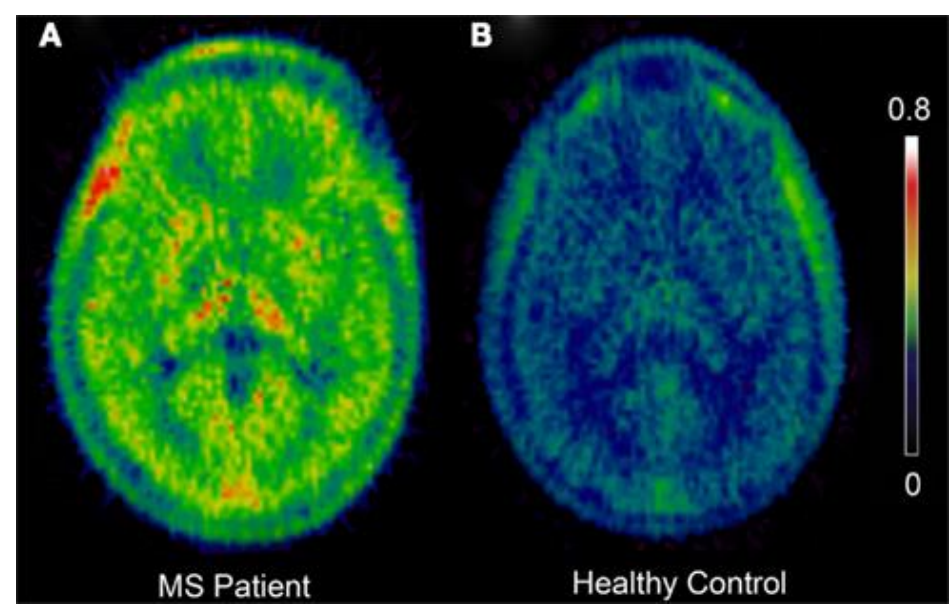

Figure 1.9 Increased $\left[{ }^{11} \mathrm{C}\right] \mathrm{PK} 11195$ binding potential $\left(\mathrm{BP}_{\mathrm{ND}}\right)$ in a Multiple Sclerosis patient $(\mathrm{A})$ when compared to a healthy normal control (B). Color bar represents intensity of [ $\left.{ }^{11} \mathrm{C}\right] \mathrm{PK} 11195$ tracer binding. Obtained from [3].

In conclusion, $\left[{ }^{11} \mathrm{C}\right] \mathrm{PK} 11195$ and PET are able to demonstrate inflammatory processes with microglial involvement in multiple sclerosis. 


\section{Alzheimer's disease (AD)}

Alzheimer's disease is defined neuropathologically by the presence of neurofibrillary tangles and plaques associated with tau and $\beta$-amyloid $(A \beta)$ protein deposition.

Over the last decades, there was increasing evidences that neuroinflammation represents a crucial part in the pathogenesis of $\mathrm{AD}$, such as in other neurodegenerative diseases. The localisation of microglia and $\beta$-amyloid plaques has been widely reported in pathological examination of $\mathrm{AD}$ suggesting that neuroinflammation may play a role in the pathogenesis and/or delay the progression of the disease. Activated microglia present at sites of aggregated A $\beta$ deposition in the brains of $\mathrm{AD}$ patients may contribute to $\mathrm{A} \beta$ removal [52]. Nevertheless, the secretion of cytokines associated to the activation of microglia also can contribute to tissue damage and apoptosis [53].

Other hypotheses suggest that microglial activation in $\mathrm{AD}$ occurs as a consequence of extracellular $A \beta$ deposition or that it serves as a triggering factor for $A \beta$ deposition in the initial stage of the disease.

$\left[{ }^{11} \mathrm{C}\right] \mathrm{PK} 11195$ has been used to image AD patients with PET but results, so far, have not been completely clear. One of the first study of $\mathrm{AD}$ with $\left[{ }^{11} \mathrm{C}\right] \mathrm{PK} 11195$ was negative must probably due to the relatively high level of non-specific binding, that resulted in non-favourable signal strength [54]. A more recently study using the R-enantiomer of this ligand, (R)- $\left[{ }^{11} \mathrm{C}\right] \mathrm{PK} 11195$ [55], showed a moderately increased binding potential (Figure 1.10).

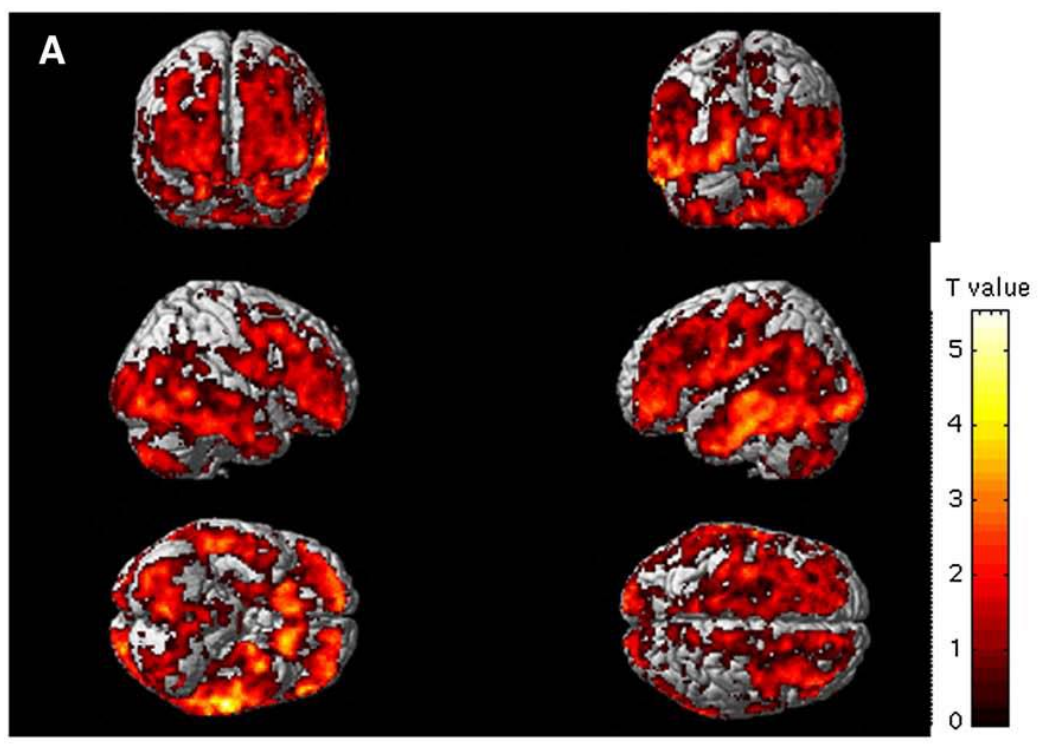

Figure 1.10 Significant increase of $(R)-\left[{ }^{11} \mathrm{C}\right]$ PK11195 uptake in Alzheimer's Disease patients when compared with control. Adapted from [55] 
However, more research with longitudinal assessment of microglial activation in humans is needed to understand its role as a consequence or an influence factor for the progression of the disease.

\subsubsection{PK11195 limitations}

With the exception of the earliest studies, the vast majority of PET imaging studies on TSPO in human diseases have been performed with the (R)-enantiomer of $\left[{ }^{11} \mathrm{C}\right] \mathrm{PK} 11195$, Although it is recognised that (R)- $\left[{ }^{11} \mathrm{C}\right] \mathrm{PK} 11195$ and even $\left[{ }^{11} \mathrm{C}\right] \mathrm{PK} 11195$ shows increase uptake in a wide array of neurodegenerative disorders, there are several methodological and kinetic unresolved issues that limit the interpretation and potential use of this TSPO radioligand.

There is a lower than desirable binding potential that has attributed to the low receptor affinity and relatively low total brain uptake, which results from substantial binding of the tracer to other parts of the body. It suffers from high plasma protein binding and high non-specific binding related to its high lipophilic nature $(\log \mathrm{P}=3.4)[56]$. Less than ideal penetration of the $\mathrm{BBB}$ and low brain uptake leads to a poor signal-to-noise ratio on PET imaging. Other complicating factors are the highly variable kinetic behaviour, and sensitivity and specificity issues which have precluded the development of a standard quantitative method for analysis applicable to all subjects. Therefore, the research field is open to find alternatives to PK11195 that can perform better for the quantification of TSPO expression in vivo. [5]

In addition to these disadvantages, the short half-life of ${ }^{11} \mathrm{C}$ (20.4 minutes) limits its use in routine clinical practice of PET imaging in centres without an on-site cyclotron facility.

\subsection{Molecular Imaging}

Advanced diagnostic techniques in the field of biomedical research aim to identify and quantify in vivo biological and biochemical processes at the cellular and molecular level. The intense research effort being made in this area has prompted for a new field called molecular imaging (MI) that includes techniques so diverse as magnetic resonance imaging (MRI), computed tomography (CT), ultrasound (US), optical and nuclear imaging [57, 58]. Each modality has its own advantages and disadvantages, but nuclear imaging has unrivalled properties when compared with other techniques as it can directly visualize molecular events at nanomolar level with high sensitivity and specificity [59]. In recognition to this, nuclear imaging techniques 
such as positron emission tomography (PET) and single photon emission tomography (SPECT) are increasingly being used in the clinical setting for applications in oncology, cardiology and, of course, neurology.

Particularly in neurology, PET can provide clinicians with the ability to image in vivo regional cerebral functions with radiotracers (radiopharmaceuticals) labelled with positronemission isotopes introduced into patients. As an important and useful technique for diagnosis, therapeutic planning and research, PET requires specific probes radiolabelled with short-lived positron-emitting nuclides. Therefore, the full potential of PET strongly depends on the availability of proper radioligands for the cellular and molecular processes that are of interest, as well as, on the development and optimisation of new ones when a suitable probe is not available.

\subsubsection{Molecular imaging probe concept}

The requirements for a successful probe for molecular imaging (MI) include high affinity and specificity for the intended molecular target as well as the ability to overcome the relevant biological barriers (Figure 1.11). Also important are the kinetics of binding to the target, blood clearance and the presence of metabolites that can access the specific compartment and make quantification impossible.
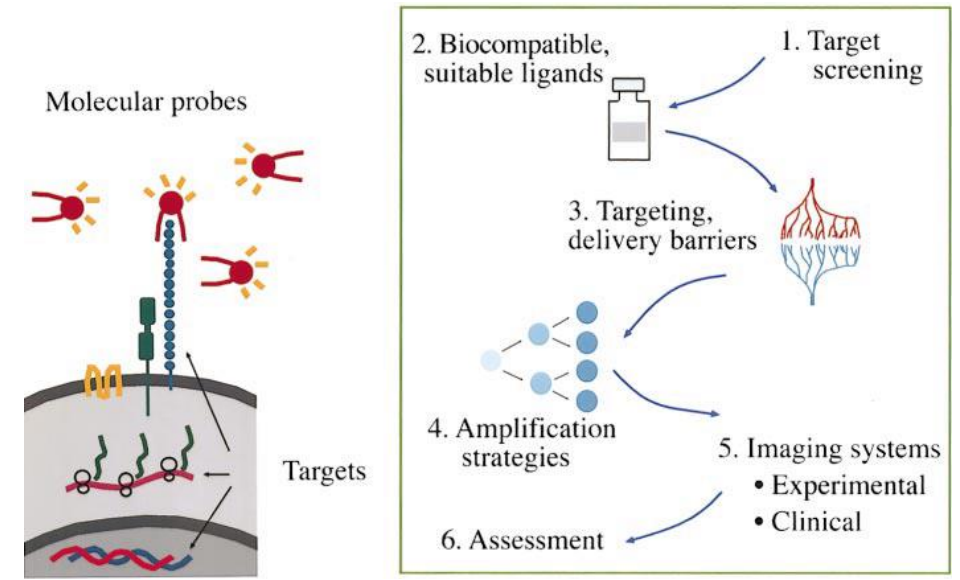

Figure 1.11 Several key criteria for probes in molecular imaging. Adapted from [58].

The choice of a molecular target with sufficient density to allow a strong specific signal and easy access for the MI probe is also fundamental. In PET, the selection of a suitable nuclide with an adequate half-life considering the synthesis time and the kinetics of the process being followed is a critical issue. Finally, the choice of labelling position is important as it has to maintain the 
physicochemical characteristics of the compound being labelled and also be resistant to metabolism that could remove the label from the probe and invalidate the study.

\subsubsection{Principles of Positron Emission Tomography}

Positron emission tomography (PET) is a powerful scientific and clinical tool and is one of the most sensitive techniques to image non-invasively, molecular pathways and interactions in vivo [60]. The full potential of PET is made possible by the availability of very specific and selective ligands for critical molecular targets that are relevant for a wide range of diseases [61]. The PET technique is based on intravenously administration in animals and/or humans a radiopharmaceutical compound labelled with a short-live positron-emitting radionuclide, in order to acquire 3D images of functional process by detecting and quantifying the distribution of the labelled tracer in the body [60]. Among the numerous short lived positron-emitting isotopes available, Carbon-11, Fluorine-18, Nitrogen-13 and Oxygen-15 (physical proprieties in Table 1.1) are the most important considering the prevalence of these elements in organic molecules making them very attractive to be incorporated into biomolecules. This allows the labelling to take place without affecting the physicochemical properties of the parent molecule a feature that is critical for the success of the study.

Table 1.1 Physical Proprieties of the most common short lived positron-emitting isotopes [62]: Carbon-11 ( $\left.{ }^{11} \mathrm{C}\right)$, Fluoride-18 $\left({ }^{18} \mathrm{~F}\right)$, Nitrogen-13 $\left({ }^{13} \mathrm{~N}\right)$ and Oxygen-15 $\left({ }^{15} \mathrm{O}\right) . *$ EC: Electron capture.

\begin{tabular}{|c|c|c|c|c|c|}
\hline Radioisotope & $\begin{array}{l}\text { Half-life } \\
\text { (minutes) }\end{array}$ & $\begin{array}{c}\text { Decay mode } \\
\text { Decay product }\end{array}$ & $\begin{array}{c}\text { Max. Energy } \\
(\mathrm{MeV})\end{array}$ & $\begin{array}{c}\text { Mean Energy } \\
(\mathrm{MeV})\end{array}$ & $\begin{array}{c}\text { Max. Range } \\
(\mathrm{mm})\end{array}$ \\
\hline Carbon-11 & 20.4 & $\begin{array}{l}100 \% \beta^{+} \\
\text {Boron-11 }\end{array}$ & 0.96 & 0.386 & 4.1 \\
\hline Fluorine-18 & 109.8 & $\begin{array}{c}97 \% \beta^{+} 3 \% \text { EC } \\
\text { Oxygen-18 }\end{array}$ & 0.69 & 0.250 & 2.4 \\
\hline Nitrogen-13 & 9.98 & $\begin{array}{c}100 \% \beta^{+} \\
\text {Carbon-13 }\end{array}$ & 1.19 & 0.492 & 5.4 \\
\hline Oxygen-15 & 2.05 & $\begin{array}{c}100 \% \beta^{+} \\
\text {Nitrogen-15 }\end{array}$ & 1.70 & 0.735 & 8.0 \\
\hline
\end{tabular}

\subsubsection{Production of radiolabelled compounds for PET}

The production of radiolabelled compounds for positron emission tomography with short- 
lived positron-emitting radionuclides (e.g. Carbon-11, Fluorine-18, Nitrogen-13 and Oxygen-18) is limited to sites with on-site cyclotron because of their short half-life. In fact, inside the list of radionuclides mentioned above (Table 1.1), only the Fluorine-18 $\left({ }^{18} \mathrm{~F}\right)$ can be used in PET sites without on-site cyclotron through registered ${ }^{18} \mathrm{~F}$-labelled radiopharmaceuticals distributions. For the other three, the production has to be performed in a medical cyclotron on-site, requiring dedicated equipment and specially trained and qualified personnel.

\subsubsection{The detection principle}

Positron emission tomography relies on the use of positron emitting atoms bond to organic molecules as tracers for endogenous physiological activity. Positron emitters are characterized by an excess of positive charges in their nuclei, and decay towards a stable state. This leads to a transformation of a proton into a neutron, having emission of a neutrino ( $\mathrm{n}$ ) and a positron $\left(\beta^{+}\right)$.

The imaging of regional tracer concentration is associated to the unique properties of positron decay and annihilation. Because of the energy released by the electronic transition, when emitted, the energetic positron travels a few millimetres through the tissue until becomes thermalized by electrostatic interaction between the electrons and the atomic nuclei of the media and combines with a free electron to form a positronium. The positronium decays by annihilation, generating a pair of gamma rays which travel in nearly opposite directions with an energy of $511 \mathrm{keV}$ each (Figure 1.12, A). The simultaneous and coincidence detection of both photons makes it possible the definition of a virtual axis on which the positron is annihilated with an electron of the medium, a few milimeters from the place of issue (Figure 1.12, B). The generation of these gamma rays is the basis of positron emission tomography. 


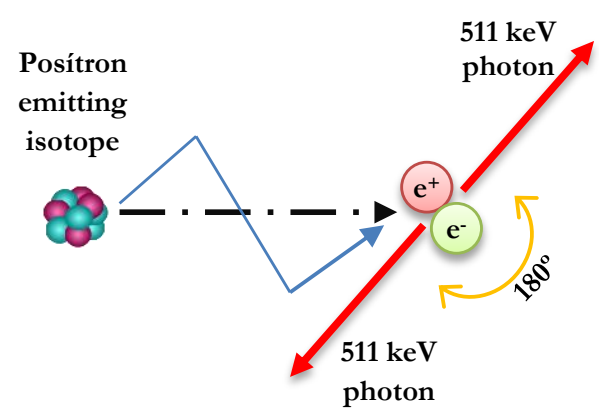

A

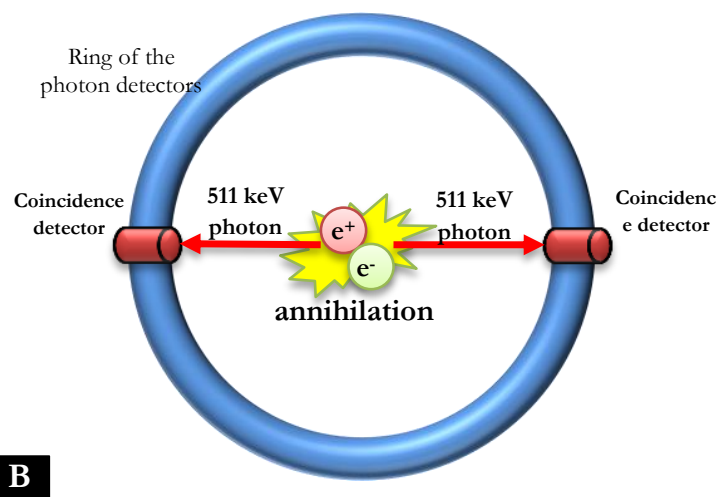

B

Figure 1.12 Principle of PET detection. Radioactive probes emitting positively charged anti-electrons (positrons) are used as imaging agents for PET. The positron travels a short distance before it annihilates with any electron to give two photons of $511 \mathrm{keV}$ travelling under a mutual angle of $180^{\circ}$. The simultaneous detection of these two gamma ray photons is behind of PET principle and allows in vivo quantitative 3D imaging acquisition.

Thereby, when a probe containing a positron emitter is administered to an organism, highenergy gamma rays are produced, which have a high penetration power, are able to escape from the body, and can be detected by an external ring of detectors as a coincident event. The simultaneous detection of many thousand pairs of gamma photons (511 keV each) allows the reconstruction of a 3D image containing information about the distribution of the radiolabelled probe in the organism.

\subsubsection{Cyclotron: high energy particle accelerator}

"Dr Livingston has asked me to advise you that he has obtained 1,100,000 volt protons. He also suggested that I add 'Whoopee'!' Telegram to Lawrence, 3 August 1931.

A cyclotron (Figure 1.13) is a particle accelerator capable of animating particles to energies that are high enough to promote nuclear reactions. The idea to curve the path of the particle beam of a linear accelerator (LINAC) into a spiral path and use over and over again the same electrode system to accelerate the particles, came from E. Lawrence. The first model was built in 1930, and in 1931 the proof of particle acceleration was performed by Livingston [62]. This notable idea of these two American physicists is the base of all modern cyclotrons, making the cyclotron the most widely used type of particle accelerator.

Currently, most radionuclides used for labelling PET radiopharmaceuticals are produced by bombardment in a cyclotron. 

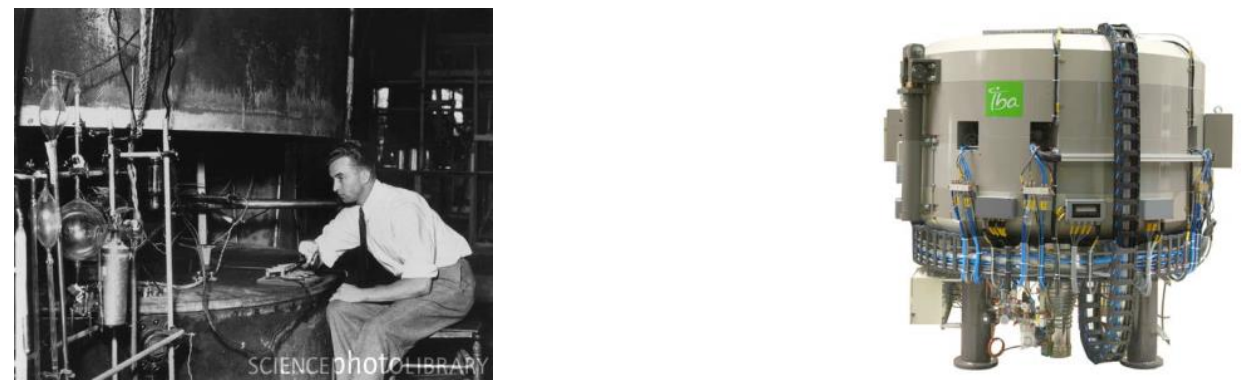

Figure 1.13 General views of two cyclotrons from different eras First Livingston cyclotron in 1931 (left) and an IBA Cyclone 18/9 cyclotron (right).

\subsection{Principles of operation}

The basic operating principles of the cyclotron are showed in Figure 1.14. In a cyclotron, an electrical field is used to accelerate ions, such as $\mathrm{H}$ - or D-, and a magnetic field is applied to bend the moving charges into a spiral path.

From a structural point of view, a cyclotron is composed by two hollow copper electrodes, called dees (or D's) due to their shape, inside a vacuum chamber. The two dees are connected to a high radiofrequency power supply that provides a sinusoidal alternating electric field between the two electrodes, being the electric field null inside the two dees. The dees and their vacuum chamber are placed between the poles of a big magnet, fed by a coil, to produce an approximately uniform magnetic field perpendicular to the radial plane of dees. The negative ions are generated by applying a high voltage to hydrogen or deuterium gas in the ion source at the centre of the cyclotron, getting a constant increase in energy for each passage across the gap between dees.

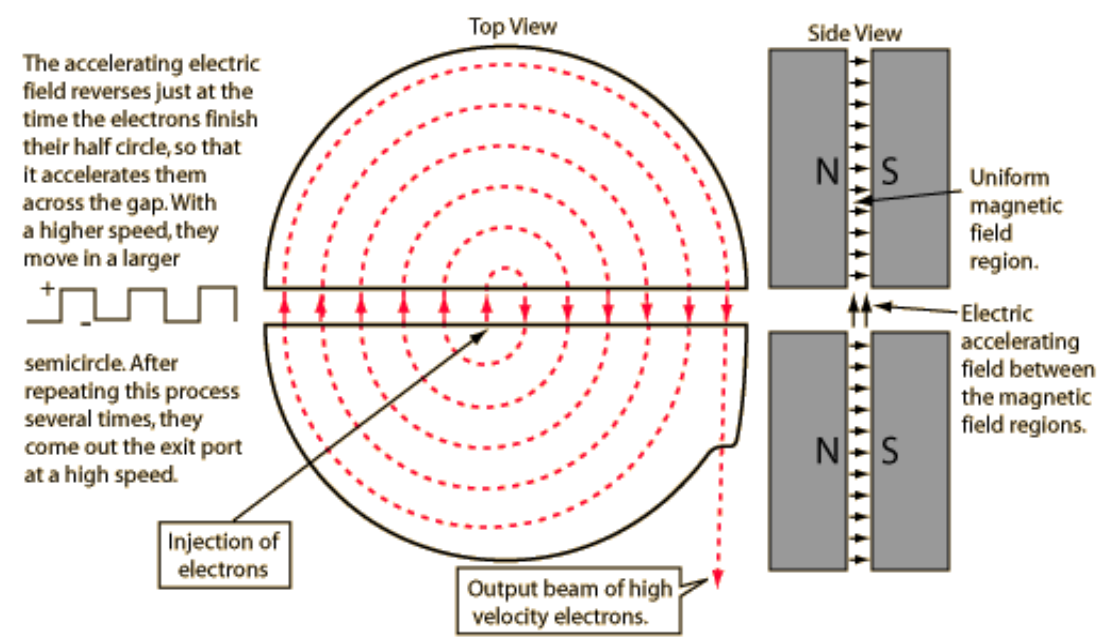

Figure 1.14 Schematic structure of cyclotron showing the 'dee' structure, the ion source and the magnet. Obtained from [62]. 
The acceleration of particles (protons or deuterons) in the so-called central region begins in the centre, where negative ions are generated by applying high voltage to a gas (hydrogen or deuterium). By applying an electrical field, the negative ions are extracted from the centre of cyclotron (ion source) and are accelerated towards the dee and counter dee by the electrical field. As the ions pass through the hole of the dees, they are only subjected to the magnetic field. When the dee is positively charged, the counter dee is negatively charged therefore when the ion leaves the dee is accelerated to the counter dee, because of the reversed polarity. This process is the same in other dee, but the speed and the orbit radius of the ion are higher. The acceleration process only ends when the ion reaches the border of magnetic field, being extracted by stripping the electrons off the negatively charged ions and allowing the magnetic field to reverse the curvature of the resulting positively charged paths and to transport the particles towards the target. The charged ion, now positive, leaves the magnetic field and continues to target position, where collides with specific substances (liquid or gas), to generate the nuclear reaction. 


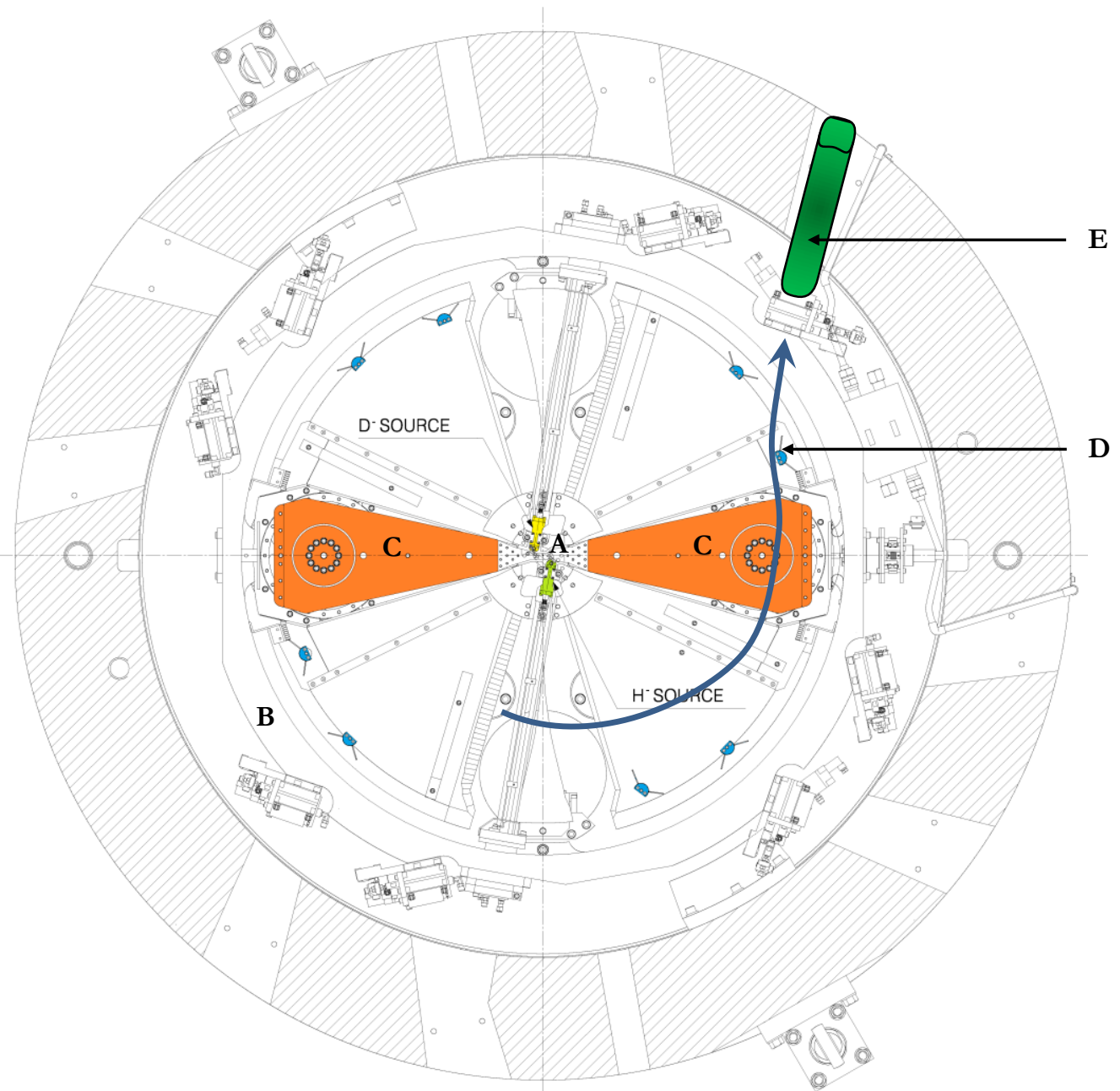

Figure 1.15 Schematic top view of the main body of an IBA Cyclone 18/9 cyclotron. Negative ions are generated in ion source (A). The electrical current passing through the coils (B) creates the magnetic field and surrounds the four wedge-shaped steel sectors. The two electrodes, also called dees $(\mathrm{C})$, are placed between steel sectors and the counter dees are placed on the edges of four steel sectors close to the dees. The negative ions are accelerated until they hit a stripper foil (usually graphite; E) which removes the electrons and charge positively the ion leaves the cyclotron and strikes the selected target (placed on F) to produce the radioisotope. Adapted from: IBA user manual.

After acceleration and before the collision with the target, the projectiles energy is related with the radius path of the ions inside the dees. As the projectiles acquire energy, the radius of their path within the dees increases, with the energy of projectile expressed by the follow equation:

$$
E_{k i n}=\frac{1}{2} \frac{q^{2}}{m} B^{2} r^{2}
$$


where $q$ and $m$ are the charge and the mass, respectively, of an ion, $B$ is the modulus of the magnetic field vector and $r$ is the radius of a circular path described by the ion under the effect of the magnetic field force. Thus, the sum of all individual accelerations in the gaps between dees is the energy achieved by the ion. This energy is kinetic energy and is dependant on the nature of the ion and the size of the magnet.

The actual production of radioisotopes happens at the same moment in which the beam of accelerated particles collides against the target nucleus resulting in the desired nuclear reaction.

\subsection{Targets}

Generally, the target materials (usually gas or liquid but can also be solid) are contained in special containers called target chambers, which are irradiated by the beam of accelerated particles. Because of the heat produced by the beam, the target is continuously cooled with water and helium to counterbalance this heating. The target can be made up from different materials (e.g. silver, aluminium). All materials must be chemically and physically inert and be able to resist high temperatures and pressures. Target materials can be in the solid, liquid or gaseous physical state, operating as a target for the nuclear reaction. It is essential that these materials (composed by a stable isotope) are in the most pure form. This avoids side reactions, caused by the impurities present.

Targets designed for the production of the most common shot-live positron emitters (carbon-11, fluorine-18, nitrogen-13 and oxygen-15), have been developed over the years and are readily implemented in all commercial available cyclotrons.

\subsection{Radiochemistry}

Positron emission tomography has numerous applications in the understanding of biological processes in living systems. It plays an important role in understanding disease pathology, progression and diagnosis, and also in drug development. Fundamental for this technique is the production of molecules labelled with short-lived positron emitting radionuclides. These labelled compounds are called radioligands or radiotracers, and their production (synthesis) forms the basis of radiochemistry.

Considering its ubiquity in organic molecules, carbon-11, is one of the most commonly used PET radionuclides. It has a short-live half-life (20.4 minutes) and, due to the versatility of 
carbon chemistry, this radioisotope can be incorporated into virtually any organic molecule without significant effect on biological activity. In addition, the short half-life of ${ }^{11} \mathrm{C}$ allows for repeated injections in the same subject and day. Therefore, ${ }^{11} \mathrm{C}$ radiopharmaceuticals are being applied in an increasing number of applications in non-invasive investigations in humans. The ability to study in vivo biochemistry processes, and eventually also to follow the fate of certain atom in a molecule, provides science and clinical practice with important new information [63].

\subsubsection{Carbon-11}

Radiochemistry with carbon-11 $\left({ }^{11} \mathrm{C}\right)$ brings considerable challenges to radiosynthesis, due to the short half-life of this positron emitter. Compared to the almost $2 \mathrm{~h}$ half-life of fluorine-18, the shorter half-life of ${ }^{11} \mathrm{C}$ provides the advantage to perform repeated PET studies while maintaining low doses on the patients.

Carbon-11 has a 20.4 minutes half-life and decays $99.8 \%$ by positron emission and only $0.2 \%$ by electron capture. It decays to stable boron- 11 . More characteristics of ${ }^{11} \mathrm{C}$ are showed in Table 1.2.

Table 1.2 Characteristics of carbon-11 as a PET isotope.

\begin{tabular}{l} 
Carbon-11 $\left({ }^{11} \mathrm{C}\right)$ \\
\hline Half-life: 20.4 minutes \\
Decay Mode: $99.8 \% \beta^{+}, 0.2 \% \mathrm{EC}$ \\
Max. Energy: $0.96 \mathrm{MeV}$ \\
Most Prob. Energy: $0.326 \mathrm{MeV}$ \\
Max. Range: $4.1 \mathrm{~mm}$ \\
Max. Specific Activity (theoretical): $9220 \mathrm{Ci} / \mu \mathrm{mol}$
\end{tabular}

Due to its favourable decay characteristics (Table 1.2), ${ }^{11} \mathrm{C}$ is considered one of the most interesting labelling agents for clinical as well as research use with PET. Over the last 3 decades, thousands of ${ }^{11} \mathrm{C}$ labelled compounds were developed and many ${ }^{11} \mathrm{C}$ labelling precursors have been used to incorporate ${ }^{11} \mathrm{C}$-isotopes to various and different molecules.

Figure 1.16 lists the chemical synthesis of some of the most important carbon-11 precursors. In the present work, we are mainly focused of the pathways steaming from the 
precursors $\left[{ }^{11} \mathrm{C}\right]$ methyl iodide $\left(\left[{ }^{11} \mathrm{C}\right] \mathrm{CH}_{3} \mathrm{I}\right)$ and $\left[{ }^{11} \mathrm{C}\right]$ methyl triflate $\left(\left[{ }^{11} \mathrm{C}\right] \mathrm{CH}_{3} \mathrm{OTf}\right)$.

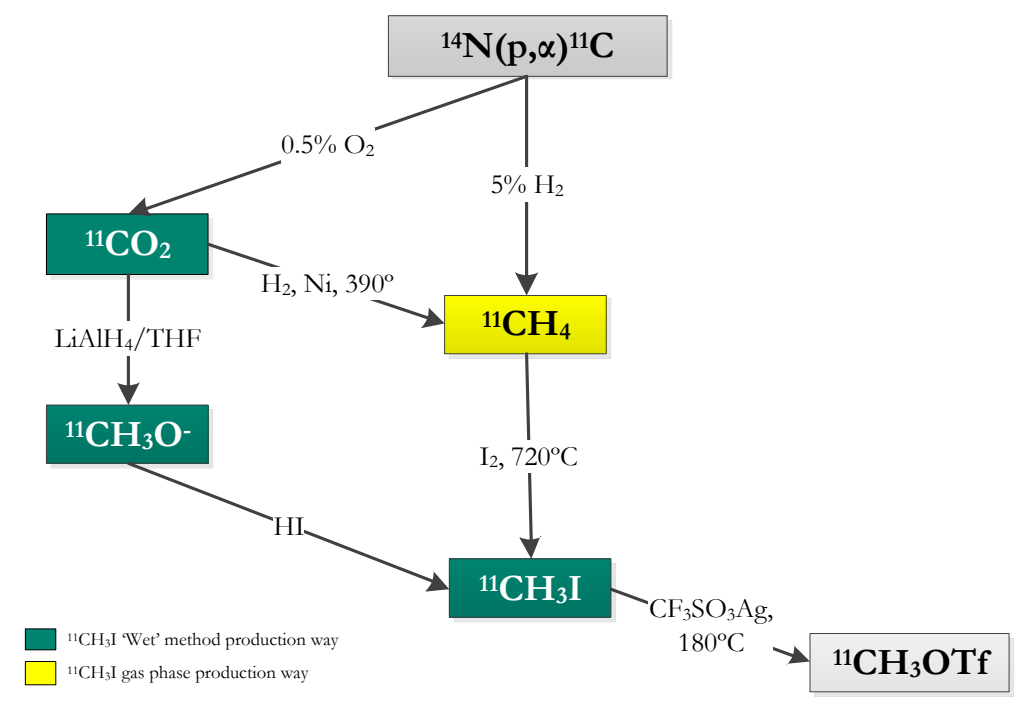

Figure 1.16 Pathways to produce ${ }^{11} \mathrm{C}$-labelling precursors. $\left[{ }^{11} \mathrm{C}\right]$ methyl iodide, the most common, can be synthesised by two different methods: the so called 'wet' method with reduction of ${ }^{11} \mathrm{CO}_{2}$ to methanol by lithium aluminium hydride (green) and the "gas phase" by the ${ }^{11} \mathrm{CH}_{4}$ pathway, or by the reduction of $\mathrm{CO}_{2}$ to $\mathrm{CH}_{4}$ (yellow).

\subsubsection{Production of ${ }^{11} \mathrm{C}$}

The first production of the short-lived positron emitting radionuclide carbon-11 was made by Crane and Lauritsen in 1934 [63]. Their work aimed to investigate the physical properties of ${ }^{11} \mathrm{C}$ and demonstrated that this radionuclide decays by positron emission to the stable nuclide boron-11 $\left({ }^{11} \mathrm{~B}\right)$. Due to its short half-life, radiopharmaceuticals labelled with ${ }^{11} \mathrm{C}$ are not easy to transport from manufacturing centres to surrounding hospitals. Consequently, this nuclide began to receive increasing attention in medical application only when cyclotrons and PET scanners begun to be installed at the same site.

Several nuclear reactions can be used to produce ${ }^{11} \mathrm{C}$ (Table 1.3), amongst these the ${ }^{14} \mathrm{~N}(\mathrm{p}, \alpha){ }^{11} \mathrm{C}$ reaction, using nitrogen gas as target material (irradiated material), is by far the most commonly used. High yields of ${ }^{11} \mathrm{C}$ production are obtained by this reaction if a small amount of oxygen $(<2 \%)$ or hydrogen $(5-10 \%)$ is available in the target gas. The primary precursors $\left[{ }^{11} \mathrm{C}\right]$ carbon dioxide $\left(\left[{ }^{11} \mathrm{C}\right] \mathrm{CO}_{2}\right)$ and $\left[{ }^{11} \mathrm{C}\right]$ methane $\left(\left[{ }^{11} \mathrm{C}\right] \mathrm{CH}_{4}\right)$ are, respectively, formed.

The in-target production of $\left[{ }^{11} \mathrm{C}\right] \mathrm{CO}_{2}$ is generally achieved with higher radiochemical yields, while the specific activity is lower compared to the production of $\left[{ }^{11} \mathrm{C}\right] \mathrm{CH}_{4}[64]$. 
Table 1.3 Nuclear reactions used to produce carbon-11. Natural abundance of the irradiated stable isotope is listed in the last column. Obtained from [65].

\begin{tabular}{ccc}
\hline Nuclear Reaction & Useful Energy Range (MeV) & \% Natural Abundance \\
\hline${ }^{11} \mathrm{~B}(\mathrm{p}, \mathrm{n}){ }^{11} \mathrm{C}$ & $5-20$ & 80.1 \\
${ }^{10} \mathrm{~B}(\mathrm{~d}, \mathrm{n})^{11} \mathrm{C}$ & $3-12$ & 19.9 \\
${ }^{12} \mathrm{C}(\mathrm{p}, \mathrm{pn}){ }^{11} \mathrm{C}$ & $20-50$ & 98.9 \\
${ }^{14} \mathrm{~N}(\mathrm{p}, \boldsymbol{\alpha}){ }^{11} \mathrm{C}$ & $7-15$ & $\mathbf{9 9 . 6}$ \\
${ }^{14} \mathrm{~N}\left(\mathrm{~d}, \mathrm{n}^{4} \mathrm{He}\right){ }^{11} \mathrm{C}$ & $10-15$ & 99.6 \\
${ }^{12} \mathrm{C}\left({ }^{3} \mathrm{He},{ }^{4} \mathrm{He}\right){ }^{11} \mathrm{C}$ & $7-15$ & 98.9 \\
\hline
\end{tabular}

Although there are several ways to produce ${ }^{11} \mathrm{C}$ described in literature [63], the most widely used is based on the so-called 'wet' method in which the $\left[{ }^{11} \mathrm{C}\right] \mathrm{CO}_{2}$ is reduced to a $\left[{ }^{11} \mathrm{C}\right]$ lithium methoxide salt with lithium aluminium hydride solution $\left(\mathrm{LiAlH}_{4}\right)$ and then by addition of hydiodic acid $(\mathrm{HI})\left[{ }^{11} \mathrm{C}\right]$ methyl iodide $\left(\left[{ }^{11} \mathrm{C}\right] \mathrm{CH}_{3} \mathrm{I}\right)$ is produced and then distilled to produce the ${ }^{11} \mathrm{C}$-methylating agent.

The $\left[{ }^{11} \mathrm{C}\right] \mathrm{CO}_{2}$ is produced, as mentioned above, using the ${ }^{14} \mathrm{~N}(\mathrm{p}, \alpha){ }^{11} \mathrm{C}$ reaction by irradiation of a material target composed by nitrogen and small amounts of oxygen. This was the procedure used for this work for the optimisation of the ${ }^{11} \mathrm{C}$-labelling of $\left[{ }^{11} \mathrm{C}\right] \mathrm{PK} 11195$.

\subsection{Half-life of the radionuclide}

As mentioned above, the half-life of the radionuclide is a key factor in the production of PET radiopharmaceuticals. Overall, the half-life of the radionuclide should be long enough for the radiolabelling process and the time frame of the imaging procedure and, ideally, the radiolabelled compound should be produced within 2-3 half-lives of the radionuclide. This is important to maintain high radiochemical yields and high specific activity.

Furthermore, the stoichiometric ratio between the precursor for labelling material and the radioactive precursor should be chosen in the range between 10000 and 10, due to the low mass of radioactive agent. As a result, the starting radiolabelled reagent is rapidly consumed in a pseudo-first order reaction kinetics, independently of its concentration. 


\subsection{Specific Activity}

Medical applications of radiopharmaceuticals labelled with short-live positron emitters require high specific activity (SA) of the compounds, i.e. they should have a high concentration of radioactivity per unit mass. Specific activity is arguably one of the most important parameter associated with the development and production of ${ }^{11} \mathrm{C}$ labelled compounds where 'cold' carbon can contaminate the preparation at various steps in the synthesis. With advances in PET applications, there is an increasing demand for novel more specific labelled radioligands, mainly with carbon-11 and fluorine-18, and specific activity has become an important issue. This is particularly important when the radionuclide is incorporated into a radiolabelled compound that is used to probe some physiological process that has low density of target molecules in the body such as receptors, enzymes, gene expression, monoclonal antibodies, etc. [65].

The specific activity of a radiopharmaceutical can be defined as the ratio between radioactivity of an isotope and the amount of carrier (which is normally the non-radioactivity counterpart of the isotope or labelled compound). According to the more updated terminology that is recommended by the IUPAC [66], the concept of specific activity for a certain nuclide, or a mixture of nuclides, is defined as the activity of a radionuclide divided by the mass of all radioactive and stable nuclides isotopic with the element involved. Although the theoretical specific activity (or specific radioactivity) for Carbon-11 is $341.14 \mathrm{TBq} / \mu \mathrm{mol}$ $\left(9220 \mathrm{Ci} / \mathrm{mmol}^{1}\right)[65]$, these values are usually very high compared with SA values of radiopharmaceutical obtained at end of synthesis (EOS). This decrease of SA is due to the dilution process with non-radioactive isotope $\left({ }^{\mathrm{x}} \mathrm{C}\right)$, that occurs not only during radionuclide production and their incorporation in a compound (radiosynthesis), but also in reagents, gases, impurities in target materials and many others factors. It is also noted that, if it is possible to decrease SA by diluting the radioligand with non-radioactive compound, the opposite (SA increase) is not possible. Thus, if high specific activities values are obtained during radiosynthesis, a radioligand with a pre-determined SA can be prepared by simple addition of the accurate amount of non-radiolabelled compound. It is important to note that these non-radioactive isotopes undergo the same chemical transformations of their radioactive conterparts.

When this 'cold' contamination of labelled compound is significant and the SA is far from the theoretical value, the physical decay of the ${ }^{11} \mathrm{C}$ radionuclide affects the specific activity by a factor of two for every 20.4 minutes $\left({ }^{11} \mathrm{C}\right.$ half-life). Consequently, synthesis time becomes an important factor for obtain good specific activities, since it declines rapidly with time. The total

\footnotetext{
${ }^{1} 1 \mathrm{Ci}=3.7 \times 10^{10} \mathrm{~Bq}$
} 
amount of radioactivity injected is also related with SA, due to the total quantity of radiolabelled and non-radiolabelled compound administrated.

This competition between radiolabelled and non-radiolabelled compounds may have a negative effect on the concentration of radioactivity in the target tissue, and it can produce undesired pharmacodynamic and/or toxic effects, as well as the receptor saturation and internalization. Hence, high SA is crucial to provide sufficient contrast in images between the target tissue and its surrounding.

As mentioned above, SA decreases rapidly with time considering that, as time passes, the number of non-radioactive isotopes remains constant while radioactivity decays by a factor of two, in case of carbon-11, for each 20 minutes. For this reason, it is mandatory to calculate the SA by decay correction to a specific time point such as end of bombardment (EOB), end of synthesis (EOS), or time of injection (TOI). Therefore, radiopharmaceutical synthesis and quality control with carbon-11 labelled compounds must be carried out in the shortest possible time.

In summary, the specific activity values of cyclotron produced radioisotopes depend on several factors, such as:

- Materials that these radioisotopes are in contact during irradiation and target transfer to the synthesis hot-cells;

- The quality of the irradiated material and the amount of radioactivity produced during irradiation;

- Sources of stables isotopes from the surface of the target chamber and tubing;

- Contamination of stable isotopes from the irradiated material;

- Quality and quantity of reagents used in the chemical transformations;

- Low purity of inert gases (helium or nitrogen) used in synthesis steps.

All these factors affect the final SA values of a radiopharmaceutical. In particular for carbon-11, those factors assume great importance because of its short half-life and the competition by side reactions with environmental carbon-12 $\left({ }^{12} \mathrm{C}\right)$ sources (especially when the radioactive precursor used is $\left[{ }^{11} \mathrm{C}\right]$ carbon dioxide $\left.\left(\left[{ }^{11} \mathrm{C}\right] \mathrm{CO}_{2}\right)\right)$. This is why the main goal of the present work - optimisation of specific activity of radiolabelled compounds with carbon-11, most particularly $\left[{ }^{11} \mathrm{C}\right] \mathrm{PK} 11195$ - is a relevant and most important challenge for the successful use of these compounds for in vivo molecular imaging with PET. 



\section{CHAPTER 2}

Materials and Methods

\subsection{Background}

The Radiochemistry and Cyclotron Laboratory of ICNAS, enables this multidisciplinary institute to produce a variety of pharmaceuticals labelled with short-lived positron emitters. Production operations are assigned to a University owned company ICNAS-Produção Unipessoal, Lda (ICNAS-P) that holds all necessary licences for GMP pharmaceutical manufacturing and has achieved Marketing Authorization for its first commercial product (Fluodesoxiglucose $\left[{ }^{18} \mathrm{~F}\right]$ UC) in December 2011. Besides distribution at national level for hospitals and imaging centres, ICNAS-P also produces positron emitting tracers for internal use at ICNAS to support ongoing pre-clinical and clinical research studies as well as its own R\&D projects. ICNAS-P has state-of-the-art equipment for radiopharmaceutical production, dispensing and packaging including an IBA Cyclone 18/9 cyclotron, 2 fully-equipped GMP Class C production labs, 4 hot-cells and 5 modules and one robotic arm for automatic production/dispensing of radiopharmaceuticals. The production facility is completed by a full 
Quality Control lab that includes 2 high performance liquid chromatography (HPLC) systems, 1 gas chromatograph (GC), 1 radio thin layer chromatograph (radio-TLC) system 1 dose calibrator and a High-Purity Germanium (HPGe) gamma spectrometer.

The synthesis optimization of (R)-[N-Methyl- $\left.{ }^{11} \mathrm{C}\right] \mathrm{PK} 11195$ is well in-line with the R\&D strategy of ICNAS as outlined by its Scientific Council and is expected to provide researchers with a crucial tool for in vivo molecular imaging of inflammation both in animal models as well as in human studies. The project fits well the objectives of the Integrated Master in Biomedical Engineering and is expected to take advantage of the scientific knowledge accumulated by the candidate during the course of the studies.

\subsubsection{The captive solvent loop}

A particular method for the ${ }^{11} \mathrm{C}$-methylation of precursors with $\left[{ }^{11} \mathrm{C}\right] \mathrm{CH}_{3} \mathrm{I}$ was developed by Wilson et al. [67] as a part of the synthesis of $\left[{ }^{11} \mathrm{C}\right]$ raclopride $\left(\mathrm{a}_{2}\right.$-like dopamine receptor ligand). The originality of this method is to use of an HPLC injection loop which serves as reactor for radiosynthesis (Figure 2.1).

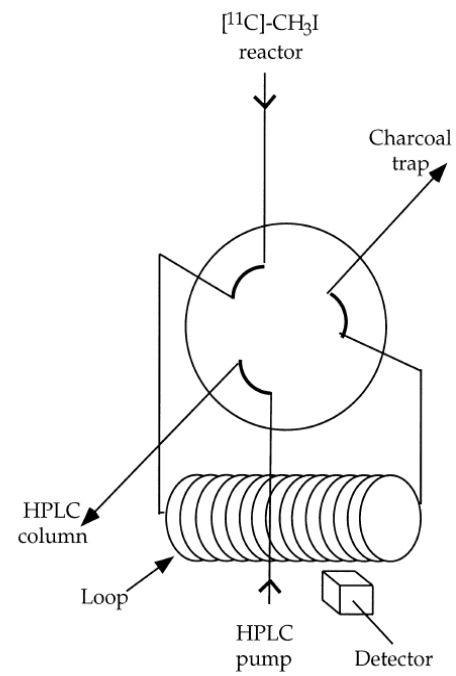

Figure 2.1 Apparatus and flow diagram for trapping [ $\left.{ }^{11} \mathrm{C}\right]$ methyl iodide on HPLC loop, pre-charged (coated) with a non-radioactive precursor. The labelling reaction takes place instantly before injection into an HPLC semi-preparative column for purification. Obtained from [67].

The non-radioactive (cold) precursor is dissolved in a small volume of solvent $(80 \mu \mathrm{l})$, and then slowly injected into a $2 \mathrm{ml}$ stainless steel loop enabling it to coat the inner surface of the 
tube. $\left[{ }^{11} \mathrm{C}\right]$ methyl iodide is then swept into the HPLC loop with the precursor solution by a stream of $\mathrm{N}_{2}$ gas $(8 \mathrm{ml} / \mathrm{min})$ at room temperature as it becomes efficiently trapped by the cold precursor solution and enables the reaction to take place. Once the reaction is complete, the mixture is readily injected into a semi-preparative HPLC column to purify the synthesised products. Since no vials, transfer lines, cooling, heating, or sealing valves are required, this technique simplifies handling and minimizes losses permitting the achievement of significantly higher yields.

\subsubsection{Quality control of PET radiolabelled compounds}

Before a PET radiolabelled compound can be administrated to a patient, there is the requirement to produce a compound that is of pharmaceutical quality. Care must be taken to ensure that the radiolabelled compound is suitably labelled, purified, formulated and sterilized. Quality control procedures for radiopharmaceuticals [68] are similar to those applied to non-radioactive pharmaceuticals, and are separated into two categories of tests: physicochemical tests and biological tests. The physicochemical tests establish the level of chemical, radiochemical and radionuclidic purity and determine the $\mathrm{pH}$, osmolality, activity, concentration and other physical properties. The biological tests establish the sterility, apyrogenicity, and toxicity of the sample.

\subsection{Aims}

The aim of this work is the automation and optimisation of the radiosynthesis for (R)-[N-Methyl- $\left.{ }^{11} \mathrm{C}\right] \mathrm{PK} 11195$. Full automation, i.e. synthesis, purification and reformulation of $\left[{ }^{11} \mathrm{C}\right] \mathrm{PK} 11195$ (notation used from this point, which refers to (R)-enantiomer; (R)-[N-Methyl- $\left.{ }^{11} \mathrm{C}\right]$ PK11195) with quality for human injection in the shortest possible amount of time, is required. Also important is the optimisation of the synthesis parameters to ensure the reproducibly and reliability of several successive radiosynthesis per day. The study of main sources of stable isotopes (non-radioactive) of carbon in the production of $\left[{ }^{11} \mathrm{C}_{\mathrm{CH}} \mathrm{CH}_{3} \mathrm{I}\right.$ through the 'wet' method, and their 'elimination' from the synthesis is a critical issue to be optimized, to ensure that the final product has the best possible specific activity. This effort is important in establishing general guidelines for the optimisation of SA values in the production of (R)- $\left[{ }^{11} \mathrm{C}\right] \mathrm{PK} 11195$ and others ${ }^{11} \mathrm{C}$-labelled compounds methylated via this method.

To achieve a final preparation of $\left[{ }^{11} \mathrm{C}\right] \mathrm{PK} 11195$ suitable for human injection, several steps 
are required: 1) production of carbon-11 in a cyclotron by irradiation of a $\mathrm{N}_{2}+0.5 \%$ target; 2) conversion of the $\left[{ }^{11} \mathrm{C}\right] \mathrm{CO}_{2}$ formed in the cyclotron to $\left[{ }^{11} \mathrm{C}\right]$ methyl iodide $\left(\left[{ }^{11} \mathrm{C}\right] \mathrm{CH}_{3} \mathrm{I}\right)$ or $\left[{ }^{11} \mathrm{C}\right]$ methyl triflate $\left(\left[{ }^{11} \mathrm{C}\right] \mathrm{CH}_{3} \mathrm{OTf}\right) ; \quad 3{ }^{11} \mathrm{C}$-methylation of the precursor ((R)-[N-Desmethy]PK11195) in a captive solvent loop; 4) purification in a HPLC reverse-phase system and 5) reformulation in $10 \% \mathrm{EtOH}+90 \% \mathrm{NaCl} 0.9 \%$ injectable solution.

\subsection{Automation of radiosynthesis for $(R)-\left[N\right.$-methyl- $\left.{ }^{11} \mathrm{C}\right] \mathrm{PK} 11195$}

\subsubsection{General}

All irradiations were performed on a IBA Cyclone 18/9 cyclotron (IBA, Louvain-la-neuve, Belgium) using high energy (18 MeV) protons.

Production of $\left[{ }^{11} \mathrm{C}\right] \mathrm{CH}_{3} \mathrm{I}$ and conversion to $\left[{ }^{11} \mathrm{C}\right] \mathrm{CH}_{3} \mathrm{OTf}$ was carried out using a Bioscan MeI-Plus (Bioscan Inc., Washington DC, USA) and the methylations occurred in a specially designed loop (Autoloop system, Bioscan Inc., Washington DC, USA). The reaction products were purified using a semi-preparative HPLC system composed by a HPLC K-501 pump

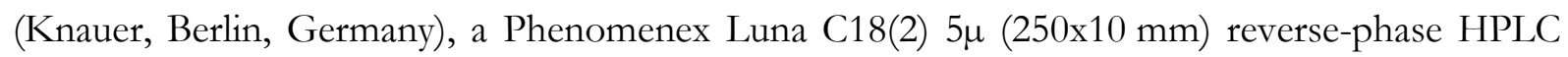
column (Phenomenex, Le Pecq Cedex, France), a UV K-200 detector set at $254 \mathrm{~nm}$ (Knauer, Berlin, Germany), and a suitable radiation detector. On the last step of the synthesis, the desired fraction was collected and formulated using a ReFORM-Plus system (Bioscan Inc., Washington DC, USA)ReFORM-Plus system. Cold precursors ((R)-[N-Desmethyl]PK11195 and others) were purchased from ABX (Advanced Biochemical Compounds, Radeberg, Germany) and all other reagents and solvents used in the syntheses were purchased from local suppliers are were of Pharm. Eur. grade, when available.

Quality control (QC) of all radiotracers for PET synthesised during this work, in special $\left[{ }^{11} \mathrm{C}\right] \mathrm{PK} 11195$, were performed to verify their purity and safety for injection. For that purpose, an Agilent 1200 Series HPLC system (variable wavelength detector) with a Raytest Gabi Star 1207 radiometric detector (RaytestGmbh, Straubenhardt, Germany) and a Rheodyne (IDEX H\&S, Wertheim-Mondfeld, Germany) model $7125 \mathrm{i}$ syringe-loading sample injector valve with a $20 \mu \mathrm{l}$ loop was used. The chromatographic separation was performed using an analytical reverse-phase Agilent Zorbax Eclipse XDB-C18 column (150x4.5 mm; 5 $\mu$ ). A dose calibrator (ISOMED 1010; Elimpex-Medizintechnik GesmbH, Mödling, Austria) was used to measure the radioactivity concentration and the physical half-life of radioisotope. A gas chromatography (GC) system (GC Agilent 6850; RaytestGmbh, Straubenhardt, Germany) was used to monitor residual solvents 
concentration in final product. The $\mathrm{pH}$ was measured using a $\mathrm{pH}$ meter (JENWAY $3510 \mathrm{pH}$; Bibby Scientific Limited, Staffordshire, UK).

\subsubsection{Automated synthesis module}

\subsubsection{Methyl iodide production system}

The methyl iodide production system is a commercial synthesiser optimised for the production of $\left[{ }^{11} \mathrm{C}\right] \mathrm{CH}_{3} \mathrm{I}$ and $\left[{ }^{11} \mathrm{C}\right] \mathrm{CH}_{3} \mathrm{OTf}$, the workhorses of $\left[{ }^{11} \mathrm{C}\right]$-labelling of PET radiopharmaceuticals. The system includes automated procedures for loading of reagents, production and cleaning as well as in-process-controls that allow detailed viewing and reporting in accordance with modern GMP procedures. At the end of synthesis, the methyl iodide production system runs a cleaning procedure which removes all radioactivity and residual chemicals. The system is ready to another production.

This system is composed of multiple hardware modules (Figure 2.2): the main module: the solvent delivery module; and the waste delivery module.

The main module contains electronic and mechanical control circuitry, three temperature controlled ovens (molecular sieve, reactor and triflate), electromagnetic valves, a reactor vessel, and reagent stations to control the entire process of methyl iodide production.

The solvent delivery module controls the introduction of cleaning solvents and inert gases (nitrogen or helium) into the system. As this module is never exposed to radioactivity, it is positioned outside of the shielded cell. This module has 4 solvent bottle positions which are filled with ethanol (position 1), acetone (position 2), diethyl ether (position 3) and distilled water (position 4). The unit provides solvents and inert gas not only for this system, but also for the $\left[{ }^{11} \mathrm{C}\right]$-methylation module described on section 2.3.2.2.

The waste recovery module is the recipient of waste gas and solvents during the synthesis and cleaning processes. It contains both a liquid waste reservoir and an ascarite ${ }^{\circledR}$ column to trap any radioactive $\left[{ }^{11} \mathrm{C}\right] \mathrm{CO}_{2}$ that is not trapped in the molecular sieve columns or in the reactor. 


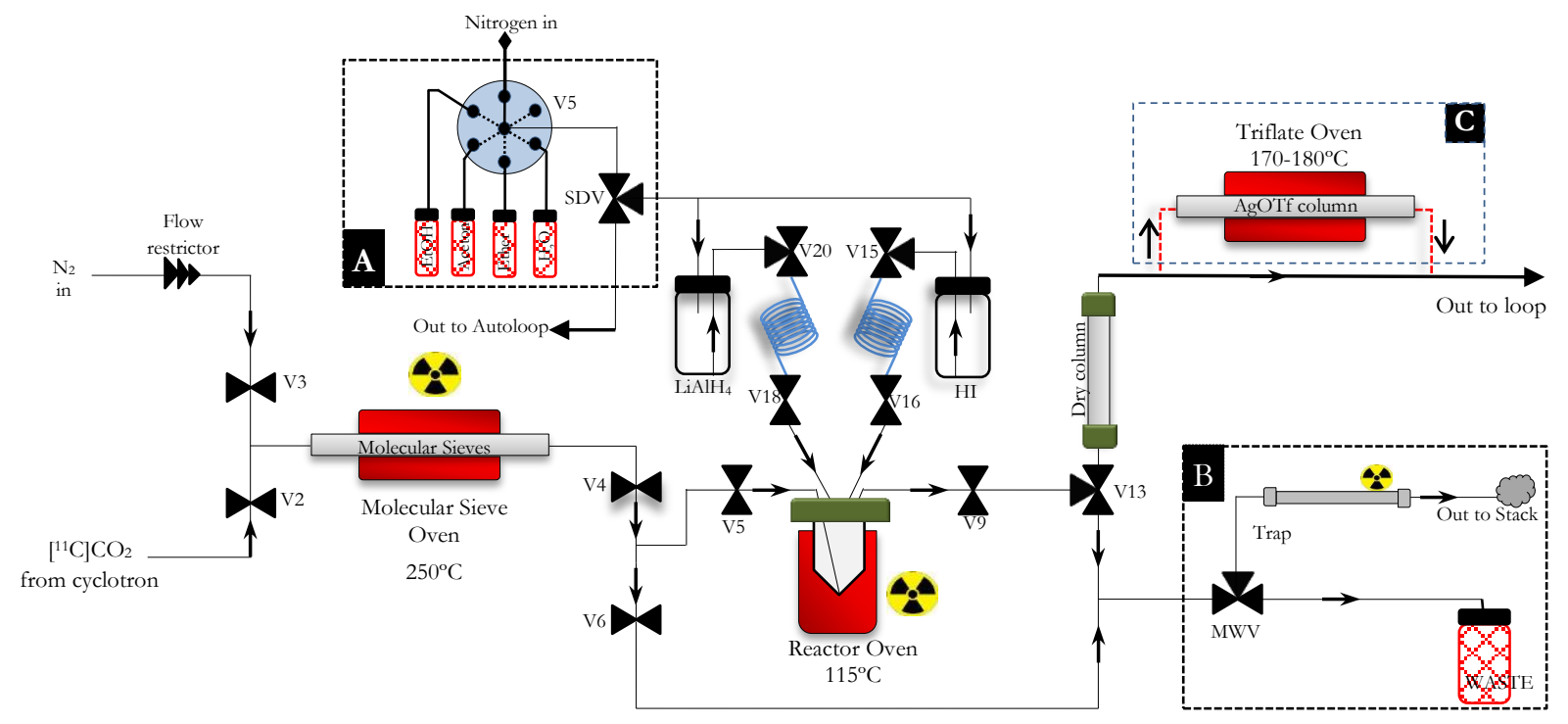

Legend:

2-way valve
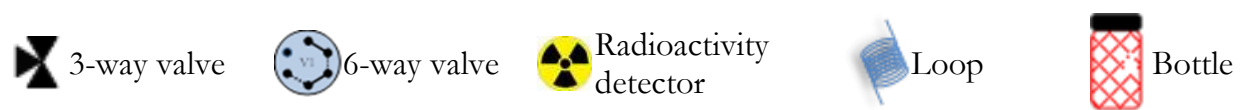

Figure 2.2 Schematic diagram of the $\left[{ }^{11} \mathrm{C}\right]$ methyl iodide production system. Solvent delivery module (A) and waste recovery module $(\mathbf{B})$ is represented too. A mixture of graphite and silver triflate is placed on a copper column, and heated up to $170-180^{\circ} \mathrm{C}$ for instantaneous conversion of $\left[{ }^{11} \mathrm{C}\right] \mathrm{CH}_{3} \mathrm{I}$ to $\left[{ }^{11} \mathrm{C}\right] \mathrm{CH}_{3} \mathrm{OTf}\left(\left[{ }^{11} \mathrm{C}\right]\right.$ methyl triflate) (C). This is used to convert $\left[{ }^{11} \mathrm{C}\right] \mathrm{CH}_{3} \mathrm{I}$ to $\left[{ }^{11} \mathrm{C}\right] \mathrm{CH}_{3} \mathrm{OTf}$, when needed.

\subsubsection{2. $\left[{ }^{11} \mathrm{C}\right]$ methylation system}

Based on the method development by Wison et al. (2000) [67], the $\left[{ }^{11} \mathrm{C}\right]$ methylation labelling system is designed to automate the labelling process by using a captive solvent HPLC loop (stainless steel; $2 \mathrm{ml}$ ).

Before the synthesis, the precursor solution is coated on the internal surface of this loop. The $\left[{ }^{11} \mathrm{C}\right]$-labelling agent carried by the inert gas is then made to flow through the loop where the solvent is trapped and made to react with the cold precursor. After the reaction, the mixture is introduced into a semi-preparative HPLC column for purification.

The $\left[{ }^{11} \mathrm{C}\right]$ methylation system, described on Figure 2.3, is made-up by a commercial HPLC injection valve (V1 valve; Rheodyne 7725i; IDEX Health \& Science; Wertheim-Mondfeld; Germany) that is equipped with a stainless steel loop $(2 \mathrm{ml})$ and an injection port for introducing the precursor solution. A 3-way commercial valve (V2 valve; NResearsh; USA) is used to introduce the $\left[{ }^{11} \mathrm{C}\right]$-labelled gas into the HPLC loop, as well as to introduce the wash solvents on beginning of day and on the end of each synthesis. This allows multiple radiosynthesis in one day, because an automated wash cycle is performed after each synthesis. There is also a selector valve 
way (V3) between V2 and the loop which selects the introduction of the $\left[{ }^{11} \mathrm{C}\right]$-labelled gas (or wash solvents) into the loop, and directs the movement of reacted products from the loop and into the HPLC system.

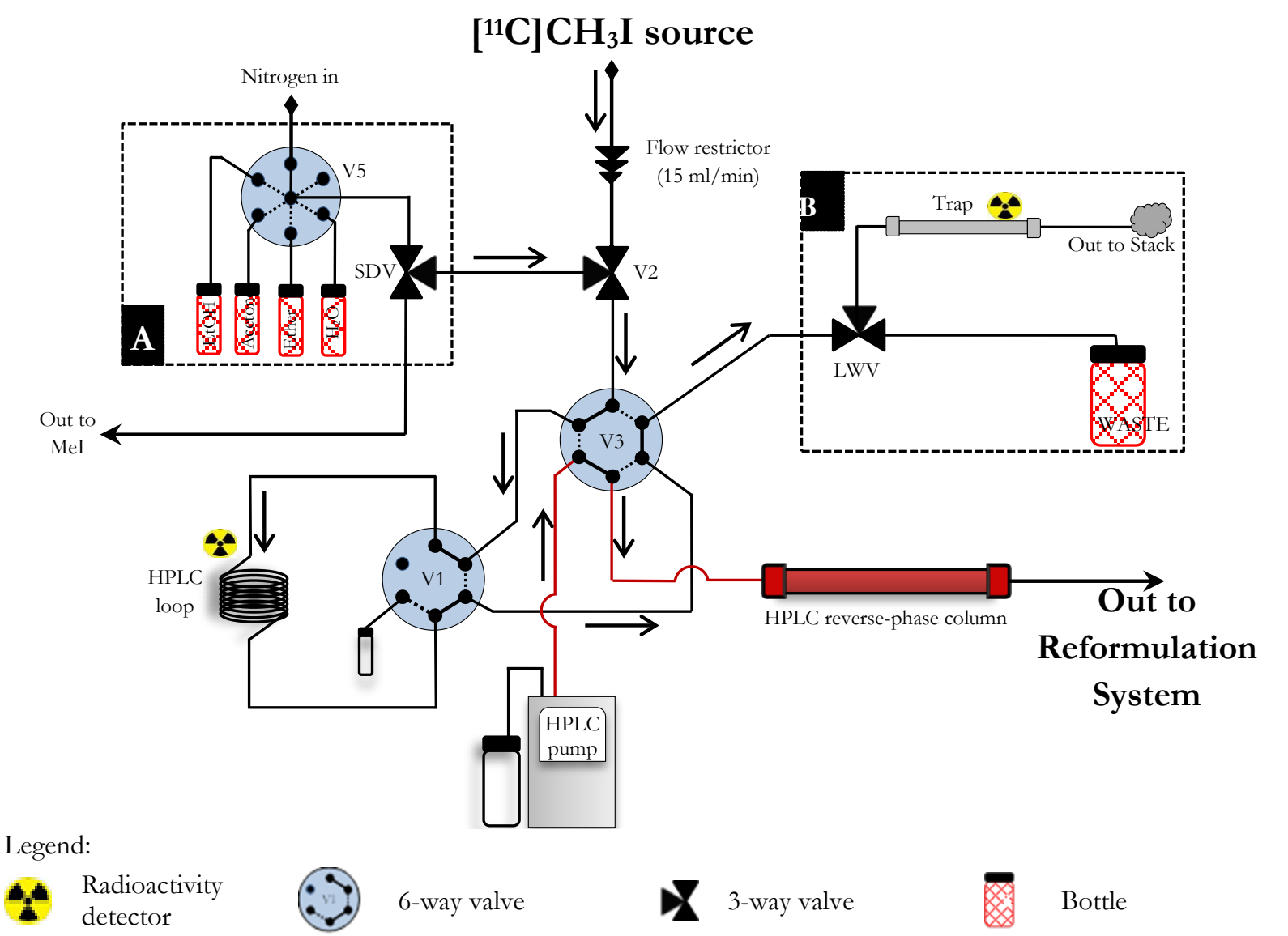

Figure 2.3 Schematic diagram of the $\left[{ }^{11} \mathrm{C}\right]$ methylation system. A: solvent delivery system. B: Waste recovery system.

\subsubsection{Reformulation system}

The reformulation system is an automated module with the main propose of reformulating radiopharmaceuticals from the HPLC mobile phase, into a ready-to-inject dose for clinical use. At the front panel, this module has an array of 5 rotary valves adapted to a stopcock cassette manifold. A dual pinch valve controls the final product/waste flows. Luer fittings connect the hardware cassette tubing to the HPLC input and vacuum and gas pressure ports.

The disposable reformulation kit, was optimised during this project and is shown in Figure 2.4 . 


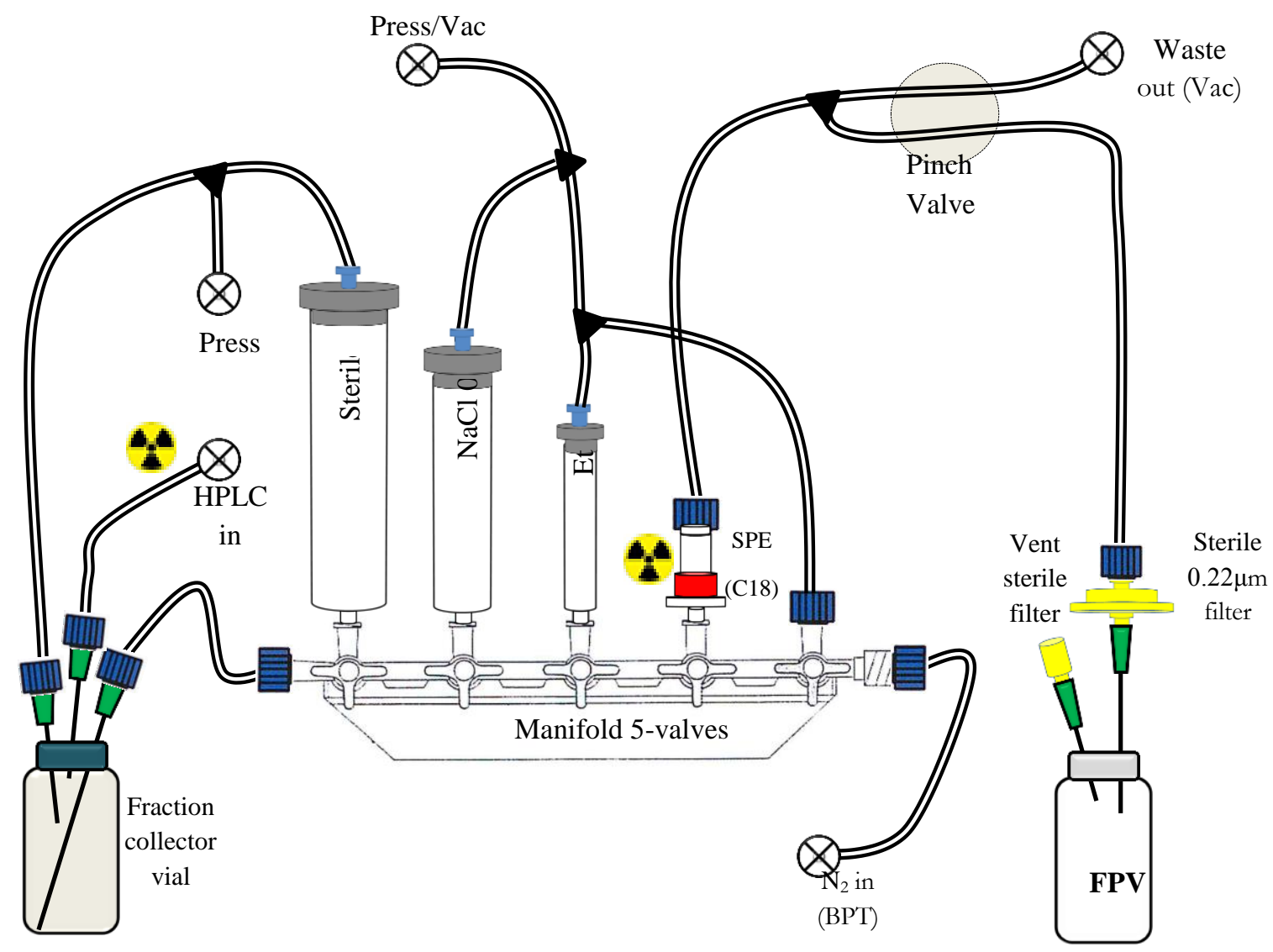

Legend:
Luer connector
Y connector
Sterile vial
뭄 SPE cartridge
Radioactivity detctor

Figure 2.4 Schematic diagram of the disposable reformulation kit for product formulation used on reformulation system.

\subsubsection{Preparation of system}

On the day of production and before each synthesis, a group of steps are essential to prepare the system in order to obtain at the end a product with the quality needed to be ready-toinject, with a high radiochemical yield and the highest specific activity possible.

\subsection{Preparation of methyl iodide production system}

In the beginning of each day, a cleaning process ('full system cleaning' option in 'System preparation' tab of system software) should be done. The $\mathrm{LiAlH}_{4}$ and HI positions should be filled with ethanol $(9 \mathrm{ml}$ each). When the system is stopped for a long period of time, it is recommended to clean the system the same way, but the vial in the LiAlH4 position filled with $\mathrm{EtOH}(8 \mathrm{ml})$ and $0.1 \mathrm{M} \mathrm{HCl}(1 \mathrm{ml})$, and the vial in the HI position with $9 \mathrm{ml}$ of EtOH. All parts 
of the system are rinsed with ethanol, acetone and diethyl ether using a stream of inert gas (nitrogen or helium). When the production of $\left[{ }^{11} \mathrm{C}\right] \mathrm{CH}_{3} \mathrm{OTf}$ is needed, the AgOTf column is pre-heated to $180^{\circ} \mathrm{C}$.

Before the beginning of the synthesis, the molecular sieve column is conditioned at $250^{\circ} \mathrm{C}$ for a minimum of 20 minutes with a stream of inert gas $\left(\mathrm{N}_{2}\right.$ or $\left.\mathrm{He}\right)$.

\subsection{Preparation of the $\left[{ }^{11} \mathrm{C}\right]$ methylation system}

The $\left[{ }^{11} \mathrm{C}\right]$ methylation system is cleaned at the beginning of the day and in the end of each synthesis. All parts of the module (lines, valves and loop) are rinsed with distilled water and acetone, and then purged with a stream of inert gas (nitrogen or helium). Before the injection of the precursor solution in the loop, the injection port of HPLC injection valve should be purged. For that purpose, the 'Dry injector valve' on 'System preparation' tab in the system software window, should be executed.

\subsection{Preparation for reformulation}

After insertion of the kit, a solid phase extraction C18 cartridge (tC18 short) is pre-conditioned using $10 \mathrm{ml}$ of ethanol and $10 \mathrm{ml}$ of sterile water, dried and connected to its designated position. The fraction collection vial is filled with $20 \mathrm{ml}$ of sterile water. The 3 reservoirs are filled with sterile water $(25 \mathrm{ml})$, physiological saline $(0.9 \% ; 9 \mathrm{ml})$ and ethanol $(1 \mathrm{ml})$ respectively.

\subsubsection{Production of $\left[{ }^{11} \mathrm{C}\right] \mathrm{CO}_{2}$}

All irradiations were performed on a IBA Cyclone 18/9 cyclotron (described on section 1.7.2.3) using $18 \mathrm{MeV}$ protons. The $\left[{ }^{11} \mathrm{C}\right]$ carbon dioxide $\left(\left[{ }^{11} \mathrm{C}^{-} \mathrm{CO}_{2}\right)\right.$ target was a $50 \mathrm{~cm}^{3}$ aluminium target. The target gas used was nitrogen of scientific grade purity $(99.9999 \%)$ with $0.5 \%$ oxygen. Process gases used were nitrogen, hydrogen and helium of scientific grade (99.999\%). The gases were purchased from Praxair Portugal Gases, S.A (Maia, Portugal).

The radioactive starting material, $\left[{ }^{11} \mathrm{C}\right] \mathrm{CO}_{2}$, was produced by the nuclear reaction ${ }^{14} \mathrm{~N}(\mathrm{p}, \alpha){ }^{11} \mathrm{C}$ on the cyclotron target. It was then transferred to a shielded hot-cell (MIP1-1P, Comecer S.p.A., Castel Bolognese, Italy) and trapped on a molecular sieve at room temperature. This trapped method allows purification of the incoming flow. 


\subsubsection{Production of $\left[{ }^{11} \mathrm{C}\right] \mathrm{CH}_{3} \mathrm{I}$}

Starting from in-target produced $\left[{ }^{11} \mathrm{C}\right] \mathrm{CO}_{2},\left[{ }^{11} \mathrm{C}\right] \mathrm{CH}_{3} \mathrm{I}$ was synthesised using the chemical reaction described by Crouzel et al. in 1987 [69].

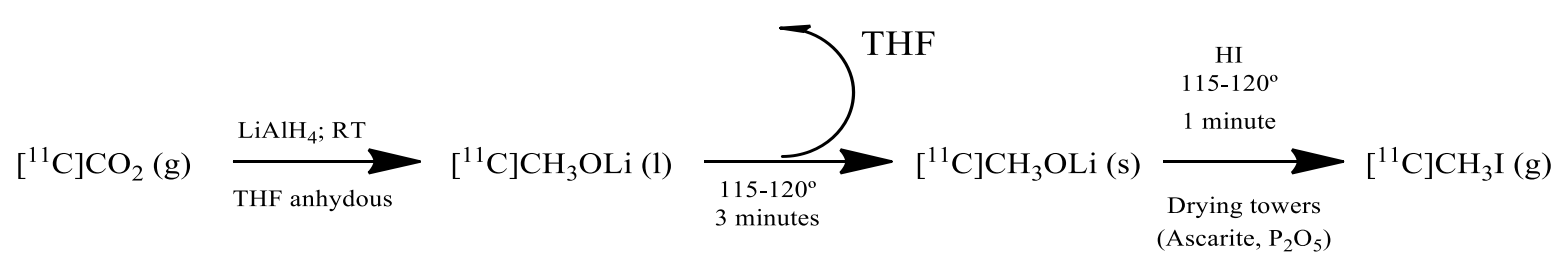

Figure 2.5 Reaction scheme for the synthesis of $\left[{ }^{11} \mathrm{C}\right]$ methyl iodide.

The $\left[{ }^{11} \mathrm{C}\right] \mathrm{CO}_{2}$ produced on cyclotron is trapped on the molecular sieve (MS) at room temperature, that allows a purification of the input stream. After all $\left[{ }^{11} \mathrm{C}_{C} \mathrm{CO}_{2}\right.$ is trapped, the MS is heated at $250^{\circ} \mathrm{C}$ to release $\left[{ }^{11} \mathrm{C}\right] \mathrm{CO}_{2}$. Then, it is trapped in a solution of lithium aluminium hydride $\left(\mathrm{LiAlH}_{4}\right)$ in tetrahydrofuran $(\mathrm{THF})$ and reduced to a lithium $\left[{ }^{11} \mathrm{C}\right]$ methoxide. The medium is then heated to $115-120^{\circ} \mathrm{C}$ to evaporate the THF. After the evaporation of the solvent, white salt of lithium $\left[{ }^{11} \mathrm{C}\right]$ methoxide is visible in the reactor. In the following step, hydriodic acid (HI) is added to form $\left[{ }^{11} \mathrm{C}\right]$ methyl iodide $\left(\left[{ }^{11} \mathrm{C}\right] \mathrm{CH}_{3} \mathrm{I}\right)$ and then distilled off at $115-120^{\circ} \mathrm{C}$ temperature in a stream of nitrogen or helium.

The production of $\left[{ }^{11} \mathrm{C}\right] \mathrm{CH}_{3} \mathrm{I}$ from $\left[{ }^{11} \mathrm{C}\right] \mathrm{CO}_{2}$ can then be summarised in 6 steps:

Table 2.1 Steps for production of $\left[{ }^{11} \mathrm{C}\right] \mathrm{CH}_{3} \mathrm{I}$ from $\left[{ }^{11} \mathrm{C}\right] \mathrm{CO}_{2}$ by the 'wet method'.

\begin{tabular}{|c|c|c|}
\hline STEP & Description & Info \\
\hline S1 & $\begin{array}{l}\text { Production of }\left[{ }^{11} \mathrm{C}\right] \mathrm{CO}_{2} \text { in a cyclotron via the }{ }^{14} \mathrm{~N}(\mathrm{p}, \alpha){ }^{11} \mathrm{C} \text { nuclear reaction by bombarding a target of } \\
\mathrm{N}_{2}+0.2^{2} \% \mathrm{O}_{2} \text { with high energy protons }\end{array}$ & \\
\hline S2 & $\begin{array}{l}\text { Unload the target content to the shielded cell (through the shielded transfer line) and trap it on a } \\
\text { molecular sieve column at room temperature }\end{array}$ & $\sim 1.5 \min$ \\
\hline S3 & Pre-fill the reactor with $\mathrm{LiAlH}_{4}$ & $\sim 150 \mu \mathrm{l}$ \\
\hline S4 & $\begin{array}{l}\text { Release }\left[{ }^{11} \mathrm{C}\right] \mathrm{CO}_{2} \text { from molecular sieves (by increasing the temperature of column; } 250^{\circ} \mathrm{C} \text { ) and bubble } \\
\text { it on the reactor with nitrogen stream }\end{array}$ & $\sim 1.3 \mathrm{~min}$ \\
\hline S5 & $\begin{array}{l}\text { After complete trapping, the solvent }(\mathrm{THF}) \text { is evaporated; and } \mathrm{HI} \text { is added to generate }\left[{ }^{11} \mathrm{C}\right] \mathrm{CH}_{3} \mathrm{I} \\
\text { which is distilled by heating the reactor }\left(115^{\circ} \mathrm{C}\right) \text { under a continuous nitrogen (or helium) stream }\end{array}$ & $\begin{array}{l}2.5 \mathrm{~min} ; \\
\mathrm{HI}: \sim 350 \mu \mathrm{l}\end{array}$ \\
\hline S6 & $\begin{array}{l}\left.\left[{ }^{11} \mathrm{C}\right] \mathrm{CH}_{3} \mathrm{I} \text { passes through a dry column (ascarite and } \mathrm{P}_{2} \mathrm{O}_{5}\right) \text { to remove unreacted }\left[{ }^{11} \mathrm{C}_{C} \mathrm{CO}_{2} \text { and dry. }\right. \\
\text { Then }\left[{ }^{11} \mathrm{C}\right] \mathrm{CH}_{3} \mathrm{I} \text { is trapped in a loop pre-filled with precursor solution, where methylation reaction } \\
\text { takes place }\end{array}$ & $\sim 3 \mathrm{~min}$ \\
\hline
\end{tabular}




\subsubsection{Conversion of $\left[{ }^{11} \mathrm{C}\right]$ methyl iodide into $\left[{ }^{11} \mathrm{C}\right]$ methyl triflate}

When $\left[{ }^{11} \mathrm{C}\right]$ methyl triflate $\left(\left[{ }^{11} \mathrm{C}\right] \mathrm{CH}_{3} \mathrm{OTf}\right.$ or $\left.\left[{ }^{11} \mathrm{C}\right] \mathrm{MeOTf}\right)$ is required, it is converted from $\left[{ }^{11} \mathrm{C}\right] \mathrm{CH}_{3} \mathrm{I}$ by passing it through a column of silver triflate (AgOTf) heated at $175^{\circ} \mathrm{C}$ (Figure 2.6).

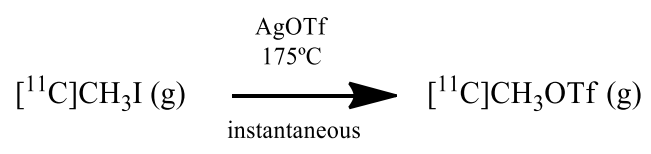

Figure 2.6 Reaction scheme for the convertion of $\left[{ }^{11} \mathrm{C}\right]$ methyl iodide into $\left[{ }^{11} \mathrm{C}\right]$ methyl triflate.

\subsubsection{Radiosynthesis of $(R)-\left[N\right.$-methyl- $\left.{ }^{11} C\right]$ PK11195}

\subsubsection{Preparation of precursor solution}

The PK11195 precursor ((R)-[N-Desmethyl]PK11195; 0.25, 0.5 and $1 \mathrm{mg})$ is dissolved in $150 \mu \mathrm{l}$ of DMSO, DMF or MEK and vortexed vigorously for 1 minute. After that, the precursor solution is transferred to a vial with a strong base (e.g. $\mathrm{KOH} ; 10,20 \mathrm{or} 30 \mathrm{mg}$ ) and vortexed again for about 5 minutes. When the base is an aqueous solution (e.g. $8 \mathrm{~N} \mathrm{KOH}$ ) or methanol (e.g. $1 \mathrm{M}$ TBAOH), a small volume of base solution is added to precursor solution and vortexed for a few more minutes. The selection of the solvent is important for an efficient trapping of the $\left[{ }^{11} \mathrm{C}\right]$-methylation agent and their action (or interference) in the methylation reaction. For that reason, the solvents must be polar and aprotic as appropriate for a $\left[{ }^{11} \mathrm{C}\right]$-methylation reaction by nucleophilic substitution. The N-alkylation reaction of (R)-[N-desmethyl]PK11195 precursor with $\left[{ }^{11}\right] \mathrm{CH}_{3} \mathrm{I}$ or $\left[{ }^{11} \mathrm{C}\right] \mathrm{CH}_{3} \mathrm{OTf}$ requires the presence of a strong base for deprotonation.

After preparation, the precursor solution (solvent $+(\mathrm{R})-[N$-desmethyl]PK11195 + base) is slowly injected into the HPLC loop.

\subsubsection{Labelling reaction}

Once produced, the $\left[{ }^{11} \mathrm{C}\right]$-methylation agent $\left(\left[{ }^{11} \mathrm{C}\right]\right.$ methyl iodide or $\left[{ }^{11} \mathrm{C}\right]$ methyl triflate $)$ is swept into the HPLC stainless steel loop previously coated with the precursor solution by a stream of nitrogen $(<15 \mathrm{ml} / \mathrm{min})$ at room temperature.

After the methylation agent is trapped in loop, the nitrogen flow is stopped and the reaction is allowed to proceed for a few minutes $(1-5 \mathrm{~min})$. The reaction proceedes (Figure 2.7) by the N-methylation of (R)-[N-Desmethyl]PK11195 with a methyl group labelled with 
carbon-11 via nucleophilic substitution.

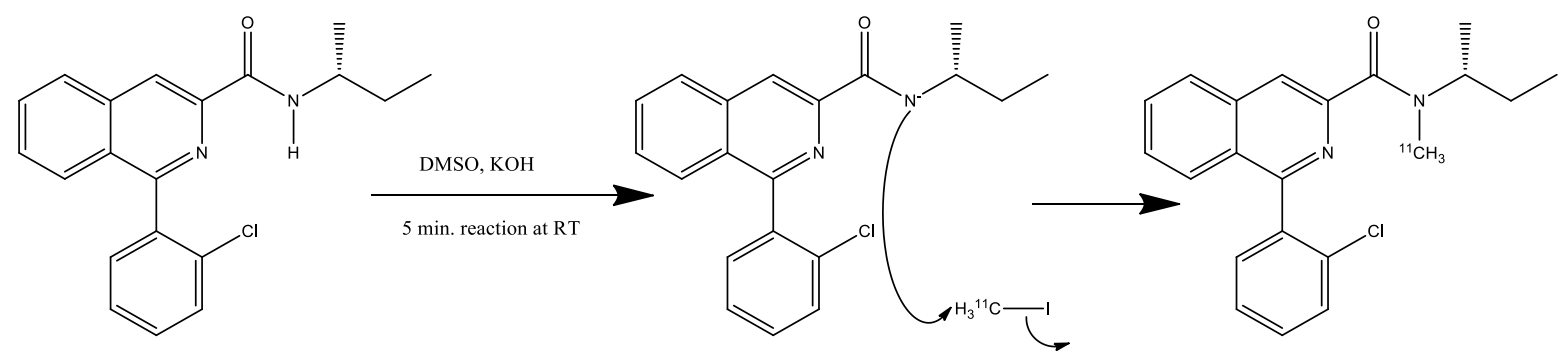

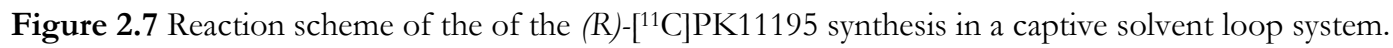

\subsubsection{Purification of (R)- $\left[N\right.$-methyl- $\left.{ }^{11} \mathrm{C}\right] \mathrm{PK} 11195$}

After the reaction on the loop is completed, the mixture is directly injected into a semi-preparative HPLC column for purification. The reverse-phase column (Phenomenex, Luna C18(2), 5 $\mu, 250 \times 10 \mathrm{~mm}$ ) is coupled to a ultra-violet detector (UV) at $254 \mathrm{~nm}$ (Knauer K-200) and a radioactivity detector. The chosen eluent is $0.1 \mathrm{M}$ ammonium formate aqueous solution/acetonitrile $(40 / 60)$ at flow rate of $6 \mathrm{ml} / \mathrm{min}$. The elution time of (R)-[N-methyl- $\left.{ }^{11} \mathrm{C}\right] \mathrm{PK} 11195$ is about 11.6 minutes with the best conditions listed above.

\subsubsection{Product reformulation}

After purification of labelled compounds by HPLC, they must be reformulated into ready-to-inject doses for clinical use. This is because the eluent of the HPLC is rarely compatible with injection to animals or humans. Reformulation is then needed to remove any organic solvent that may be present. For (R)-[ $\left.{ }^{11} \mathrm{C}\right] \mathrm{PK} 11195$ the method used is solid phase extraction (SPE) [70].

The product reformulation step is carried out on a reformulation system using a sterile disposable kit optimised during this project and suitable reagents, following a sequence of steps which are determined by the user selected method. The method uses an SPE (C18) cartridge to trap the (R)- $\left[{ }^{11} \mathrm{C}\right]$ PK11195 from the diluted HPLC mobile phase, rinses any residual organic solvents, and releases the compound in a small volume of ethanol followed by dilution with $\mathrm{NaCl} 0.9 \%$ and filtration through a sterile $0.22 \mu \mathrm{m}$ filter SLGV033NS (Millex-GV, Millipore). In summary, the following steps are involved in the process:

1. Receiving the product fraction from HPLC purification and dilution in sterile water; 
2. Mixing the product with aqueous phase (sterile water);

3. Passing the diluted product fraction through the SPE (C18) cartridge, where the product (lipophilic) is retained;

4. Rinsing the SPE cartridge with sufficient sterile water to effectively remove any residual organic solvents;

5. Drying the SPE cartridge with a stream of inert gas (nitrogen);

6. Eluting the product from SPE cartridge with a small volume of ethanol $(<10 \%$ of total final product volume);

7. Diluting the product in the final product vial (FPV) with buffered saline to have the correct osmolarity and acceptable ethanol concentration;

8. During steps 6 . and 7. the solutions passes through an sterile $0.22 \mu \mathrm{m}$ filter to FPV;

9. After removal of the vial with the (R)- $\left[{ }^{11} \mathrm{C}\right] \mathrm{PK} 11195$ solution, a bubble point test is performed on the sterilization filter to ensure the integrity of the membrane.

At the end of the reformulation process, the product is prepared for quality control.

\subsubsection{Quality control}

Authentic samples of the compound and precursor of (R)- $\left[{ }^{11} \mathrm{C}\right] \mathrm{PK} 11195$ were obtained commercially from ABX (Advanced Biochemical Compounds, Radeberg, Germany) and were used without further purification. All other chemicals were of reagent or HPLC grade unless otherwise stated. The standard solutions were prepared in acetonitrile and water and then further diluted with water to the desired concentrations.

Chemical and radiochemical impurities were detected and quantified using analytical radio-HPLC. Acetonitrile and $0.1 \mathrm{M}$ ammonium formate $(75 / 25 ; \mathrm{v} / \mathrm{v})$ were used as mobile phase with a flow rate of $2 \mathrm{ml} / \mathrm{min}$ on a reverse-phase C18 (Agilent Zorbax Eclipse XDB-C18;

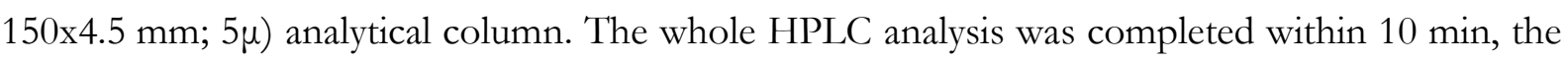
retention time of the precursor $\left((\mathrm{R})-\left[\mathrm{N}\right.\right.$-methyl- $\left.\left.{ }^{11} \mathrm{C}\right] \mathrm{PK} 11195\right)$ was 2.5-3.1 $\mathrm{min}$ and the product $\left[{ }^{11} \mathrm{C}\right]$ PK11195 was eluted with a retention time of 1.8-2.4 minutes. The chemical identity of $\left[{ }^{11} \mathrm{C}\right] \mathrm{PK} 11195$ was determined by co-injection of the unlabelled reference compound, (R)-[N-methyl- $\left.{ }^{12} \mathrm{C}\right]$ PK11195 (sample chromatogram is shown in Figure 2.8). For calculation of radiochemical purity, the portion of $\left[{ }^{11} \mathrm{C}\right] \mathrm{PK} 11195$ in relation to total radioactivity was determined (threshold $\geq 95 \%$ ). Residual solvents were analysed by gas chromatography (GC 
Agilent 6850; RaytestGmbh, Straubenhardt, Germany). The radiochemical purity was assessed by measurement of the physical half-life on dose calibrator (ISOMED 1010; ElimpexMedizintechnik GesmbH, Mödling, Austria). pH was measured on a pH meter (JENWAY 3510 pH; Bibby Scientific Limited, Staffordshire, UK).

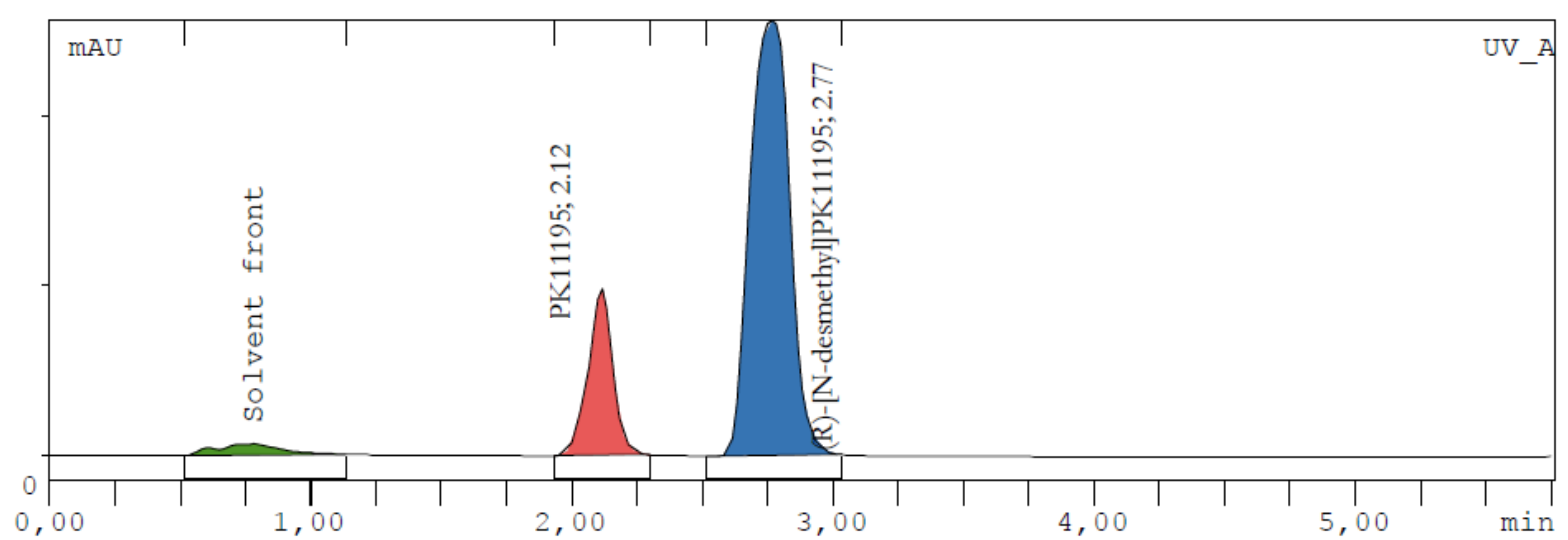

Figure 2.8 Analytical UV HPLC trace for co-injection of (R)-[N-methyl-12C]PK11195 standard solution and (R)-[N-desmethyl]PK11195 precursor solution. 


\section{CHAPTER 3}

Results

A full $\left[{ }^{11} \mathrm{C}\right] \mathrm{PK} 11195$ synthesis process was optimised for routine in about 35 minutes from EOB.

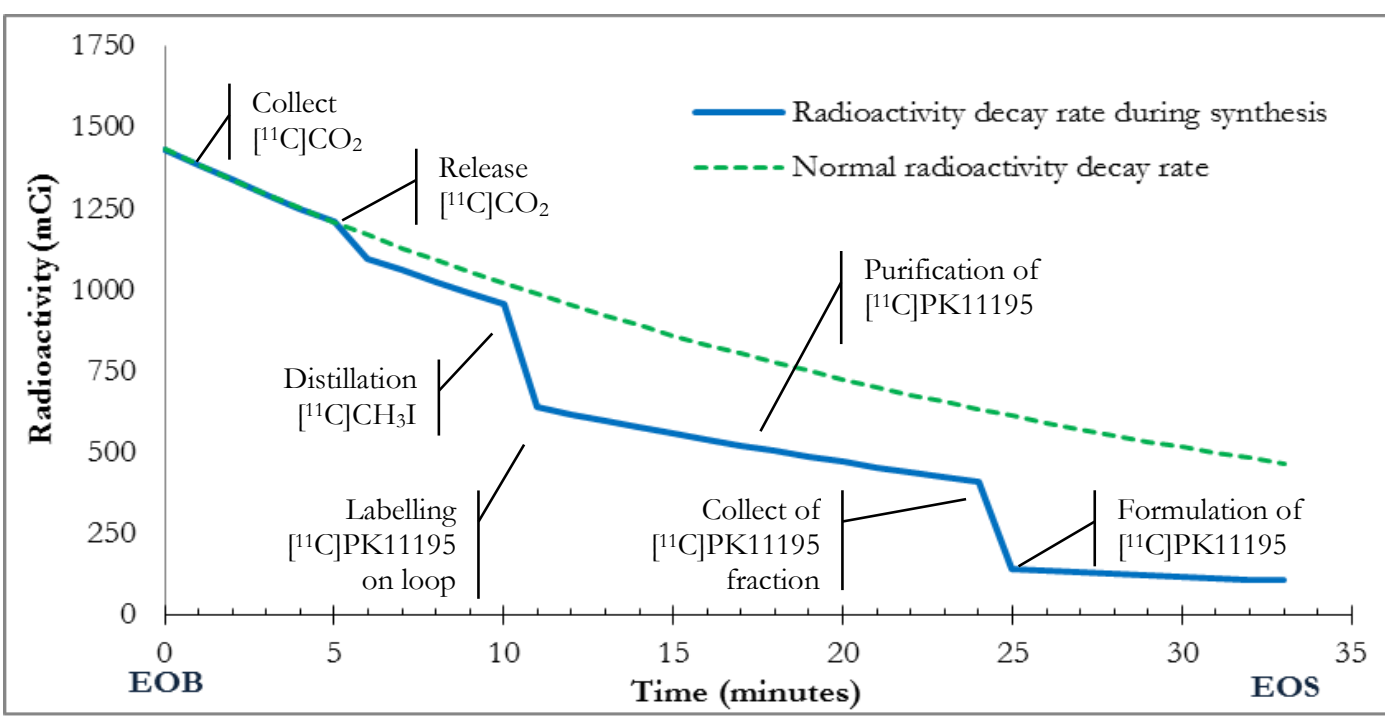

Figure 3.1 Radiosynthesis progress of (R)-[N-methyl- $\left.{ }^{11} \mathrm{C}\right] \mathrm{PK} 11195$ from EOB to EOS. 


\subsection{Production of $\left[{ }^{11} \mathrm{C}\right]$ methyl iodide: initial optimisations}

The main parameters for $\left[{ }^{11} \mathrm{C}\right]$ methyl iodide production were optimised to achieve the highest possible yields and insure reliability and reproducibility. The optimal settings are showed on Table 3.1.

Table 3.1 Production conditions for $\left[{ }^{11} \mathrm{C}\right] \mathrm{CH}_{3} \mathrm{I}$.

\begin{tabular}{ll}
\hline Setting & Value \\
\hline Timer for LaH dispensing (milliseconds) & 150 \\
Timer for HI dispensing (milliseconds) & 700 \\
$\mathrm{CO} 2$ trapping time (mm:ss) & $01: 30$ \\
$\mathrm{CO}_{2}$ release time (mm:ss) & $01: 20$ \\
THF evaporation time (mm:ss) & $02: 30$ \\
$\mathrm{CH}_{3} \mathrm{I}$ distillation time (mm:ss) & $03: 00$ \\
Molecular sieve oven temperature $\left({ }^{\circ} \mathrm{C}\right)$ & 250 \\
Reactor oven temperature $\left({ }^{\circ} \mathrm{C}\right)$ & 115 \\
Methyl triflate oven temperature $\left({ }^{\circ} \mathrm{C}\right)$ & 175 \\
\hline
\end{tabular}

With these settings, $\left[{ }^{11} \mathrm{C}\right] \mathrm{CH}_{3} \mathrm{I}$ production is completed in $11.39 \pm 0.76$ minutes (from EOB; Figure 3.2). The radiochemical yield and specific activity of $\left.{ }^{[11} \mathrm{C}\right] \mathrm{CH}_{3} \mathrm{I}$ produced were $70.79 \pm 7.6 \%$ (non-decay corrected) and 499.32 $\pm 72.77 \mathrm{mCi} / \mu \mathrm{mol}(18.47 \pm 2.69 \mathrm{GBq} / \mu \mathrm{mol})$, respectively.

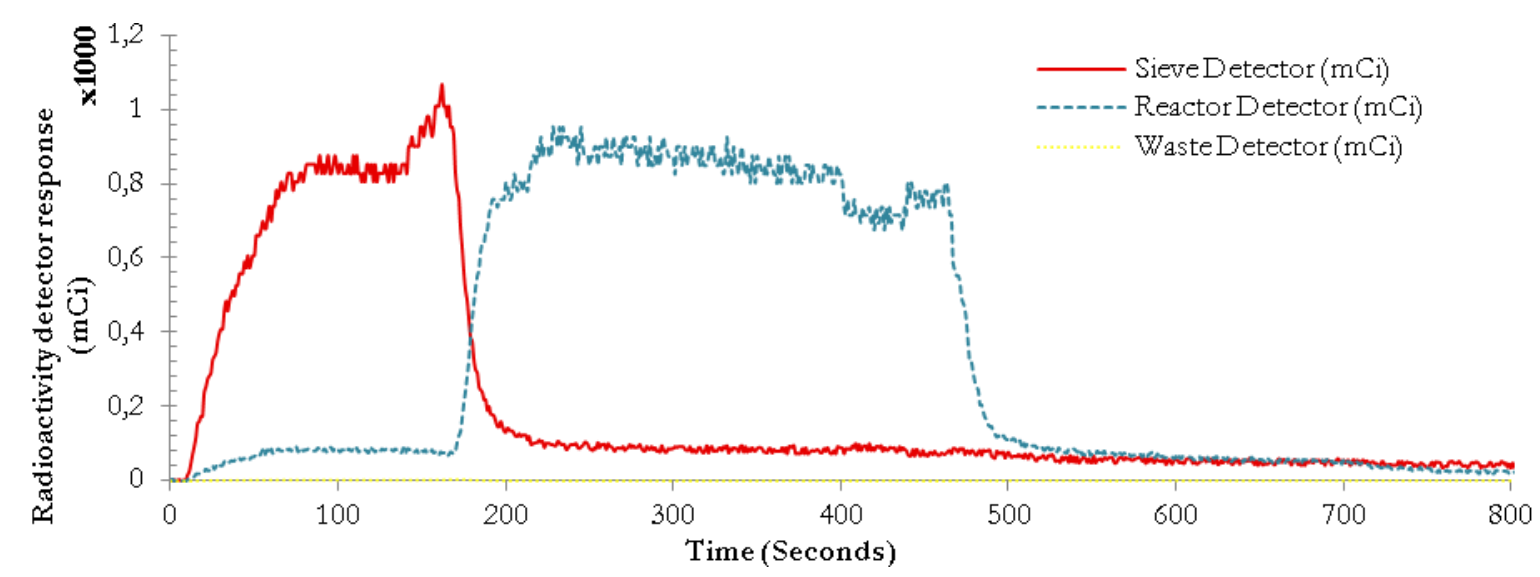

Figure 3.2 Diagram of in-process controls during $\left[{ }^{11} \mathrm{C}\right] \mathrm{CH}_{3} \mathrm{I}$ production..

The production of $\left[{ }^{11} \mathrm{C}\right]$ methyl iodide is a critical step for specific activity optimisation. The

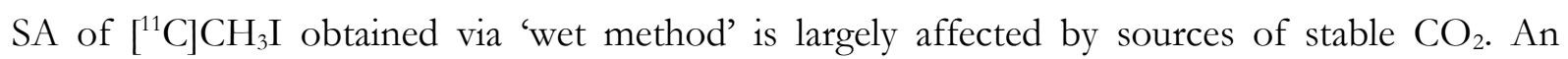
evaluation and identification of the main sources of ${ }^{12} \mathrm{C}$ involved in the $\left[{ }^{11} \mathrm{C}\right] \mathrm{CH}_{3} \mathrm{I}$ production using this method is the subject of the following section. 


\subsubsection{Specific activity optimisation}

\subsubsection{Evaluation of molecular sieve pre-conditioning influence on amount of $\left[{ }^{12} \mathrm{C}\right] \mathrm{CH}_{3} \mathrm{I}$ generated}

A molecular sieve is a material that can adsorb carbon dioxide at low temperature (room temperatures), and released it when heated to high temperatures $\left(250^{\circ} \mathrm{C}\right)$. In our tests we used two different scenarios: 1) synthesis without pre-conditioning the molecular sieves before; and 2) synthesis with pre-conditioning molecular sieves at $250^{\circ} \mathrm{C}$ during 20 minutes just before the beginning of synthesis. Both tests were done without unloading the cyclotron target to the molecular sieve.

The amount of $\mathrm{CH}_{3} \mathrm{I}$ formed in two scenarios was measured by HPLC. The results showed that without pre-conditioning of MS, the production of stable methyl iodide increases $315 \%$. The production of $\mathrm{CH}_{3} \mathrm{I}$ under scenario 1 was $530.56 \pm 340.88 \mathrm{nmol}$ and $168.10 \pm 36.51 \mathrm{nmol}$ under scenario 2 (Figure 3.3).

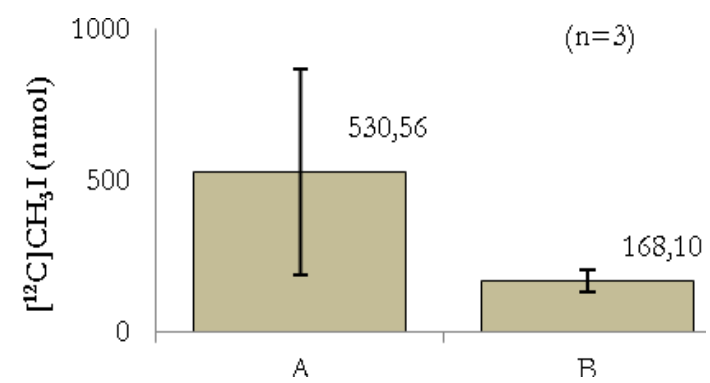

Figure 3.3 Amount of 'cold' $\mathrm{CH}_{3} \mathrm{I}$ formed without pre-conditioning of molecular sieves before synthesis (A) and with pre-conditioning just before the synthesis (B).

\subsubsection{Sources of ${ }^{12} \mathrm{C}$ from the inert gas purity}

Aiming to investigate the influence of potential impurities in the gas supply in the final amount of $\mathrm{CH}_{3} \mathrm{I}$ produced, we developed an in-house filter by preparing a column with ascarite and phosphorus pentoxide. The results show that the final amount of $\mathrm{CH}_{3} \mathrm{I}$ was

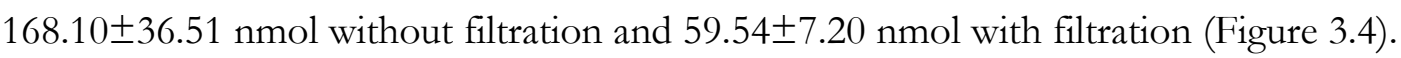




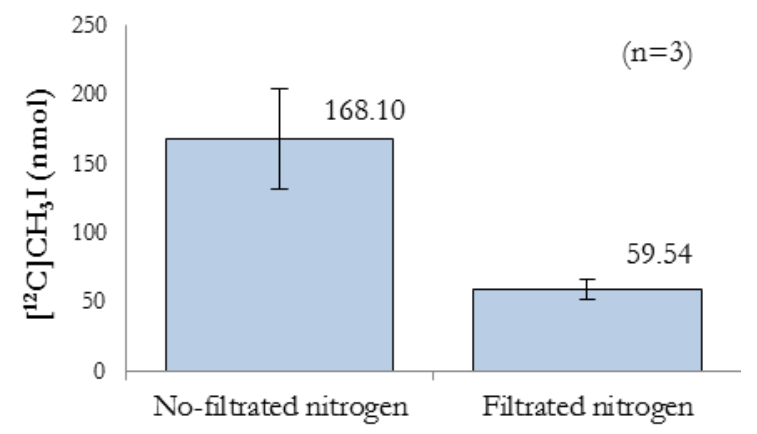

Figure 3.4 Amount of 'cold' $\mathrm{CH}_{3} \mathrm{I}$ formed without filtration of inert gas supplier of methyl iodide system and with filtration.

\subsubsection{Sources of ${ }^{12} \mathrm{C}$ involved on $\left[{ }^{11} \mathrm{C}\right] \mathrm{CH}_{3} \mathrm{I}$ production from reagents, materials, and}

\section{load-unload of the target}

Three different tests were performed to evaluate the source of ${ }^{12} \mathrm{C}$ from the gases, materials and reagents used on methyl iodide production process. Results were obtained from 3 scenarios (Figure 3.5A):

Scenario Sc1: Synthesis was carried out by executing step S3 and S5 (Table 2.1) of the general procedure. Transference of the target material and the $\mathrm{CO}_{2}$ release from the molecular sieves were skipped.

Scenario Sc2: Synthesis was carried out by executing step S3, S4 and S5 (Table 2.1) of the general procedure. Transference of the target material was skipped.

Scenario Sc3: Synthesis was carried out by executing step S2, S3, S4 and S5 (Table 2.1) of the general procedure.

The nitrogen input was filtered on all scenarios. 

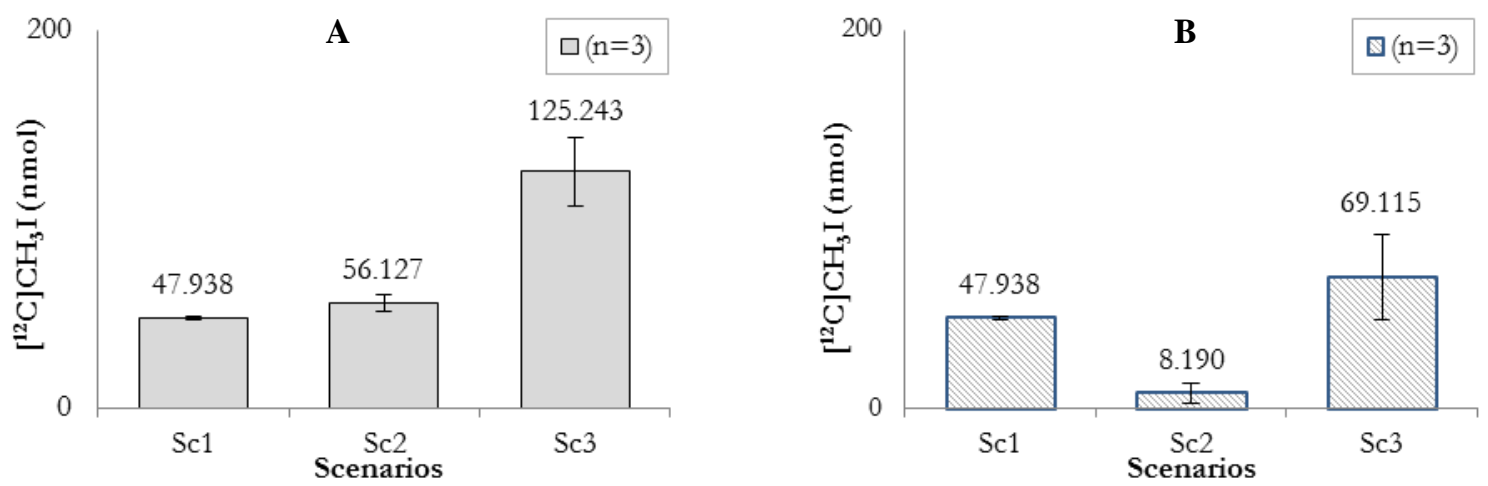

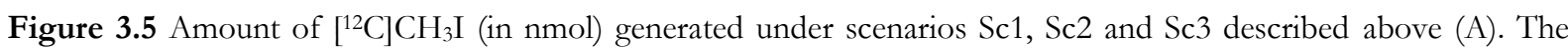
influence of $\left[{ }^{12} \mathrm{C}\right] \mathrm{CO}_{2}$ source by $\mathrm{LiAlH}_{4}(\mathrm{Sc} 1)$, release of $\mathrm{CO}_{2}$ from MS (Sc2) and the load-unload of the target (Sc3) was shown on graph of the right (B).

The individual contribution of each source of ${ }^{12} \mathrm{C}$ involved on the $\mathrm{CH}_{3} \mathrm{I}$ production is shown on Figure 3.5B. Under scenario $S_{c 1} 47.938 \pm 0.841 \mathrm{nmol}$ of stable methyl iodide were generated. This is expected to come from the $\mathrm{CO}_{2}$ on the $\mathrm{LiAlH}_{4}$ solution, absorbed from the atmosphere, or from methanol formed from THF remaining on $\mathrm{LiAlH}_{4}$ after evaporation. Under scenario Sc2 $8.190 \pm 5.262 \mathrm{nmol}$ of stable methyl iodide were generated, by the contribution of $\mathrm{CO}_{2}$ adsorbed to the molecular sieves even after conditioning. Finally under scenario $\mathrm{Sc} 3$ $69.115 \pm 22.597 \mathrm{nmol}$ of stable methyl iodide were generated, by the contribution of $\mathrm{CO}_{2}$ from load-unload target processes, such as from $\mathrm{CO}_{2}$ adsorbed on the target chamber, in the stainless-steel tubing that connect target to the synthesis module, or from its presence in the target gas.

\subsubsection{Sources of ${ }^{12} \mathrm{C}$ involved on $\left[{ }^{11} \mathrm{C}\right] \mathrm{CH}_{3} \mathrm{I}$ production: from effect of bombarding time}

Finally, we tested the contribution of bombarding time for the final amount of stable methyl iodide. As showed on Figure 3.6, the longer the bombarding time, the higher stable methyl iodide produced. 


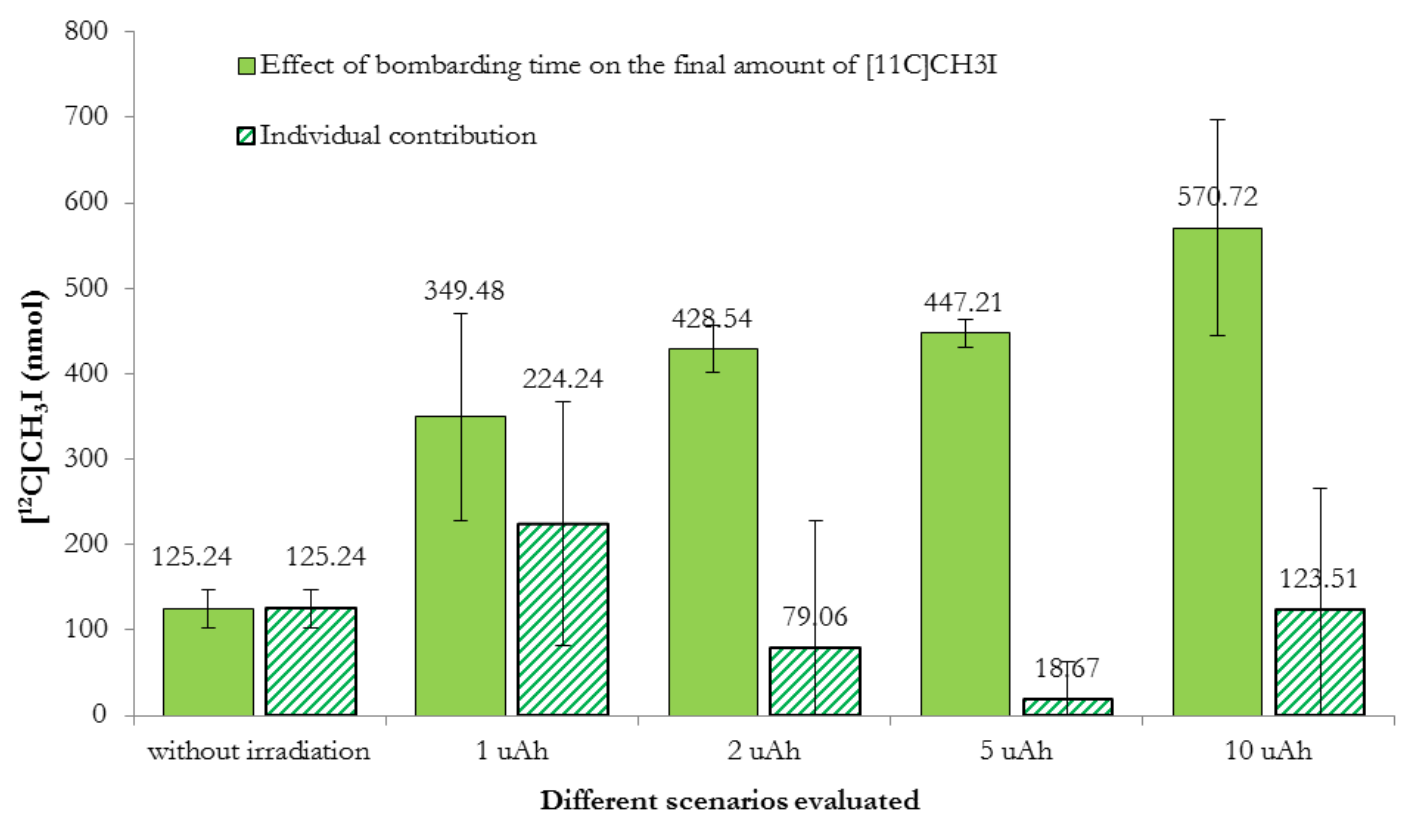

Figure 3.6 Effect of the bombarding time on the final amount of $\left[{ }^{12} \mathrm{C}\right] \mathrm{CH}_{3} \mathrm{I}$ (in nmol). 


\subsection{Captive solvent loop methylation: initial optimisations}

\subsubsection{Solvents and bases chosen}

The right choice of the polar aprotic solvent for the synthesis is important not only because of its effect on the nucleophilic substitution $\left[{ }^{11} \mathrm{C}\right]$-methylation reaction on a loop, but also because of the the trapping efficiency in $\left[{ }^{11} \mathrm{C}\right]$-methylation precursor on the loop. For that purpose, we compared the trapping efficacy of three different solvents. DMF (dimethylformamide) and DMSO (dimethyl sulfoxide), both anhydrous, were used on the synthesis with $\left[{ }^{11} \mathrm{C}\right]$ methyl iodide. MEK (methyl ethyl ketone) and DMSO were tested too, in their trapping efficacy, when $\left[{ }^{11} \mathrm{C}\right]$ methyl triflate was used as a methylation agent. These solvents were selected according to their ability to dissolve the (R)-[N-desmethyl]PK11195 precursor. In each test, $0.5 \mathrm{mg}$ of precursor was dissolved in $100 \mu \mathrm{l}$ of solvent, and then injected into captive solvent loop. The experimental results of precursor solvent efficiency on trapping are shown on Figure 3.7, and the trap efficacy of DMSO $\left(56.09 \%\right.$ with $\left[{ }^{11} \mathrm{C}\right] \mathrm{CH}_{3} \mathrm{OTf}$ and $93.83 \pm 3.90 \%$ with $\left.\left[{ }^{11} \mathrm{C}\right] \mathrm{CH}_{3} \mathrm{I}\right)$ is a good indication that it is close to ideal as a precursor solvent.

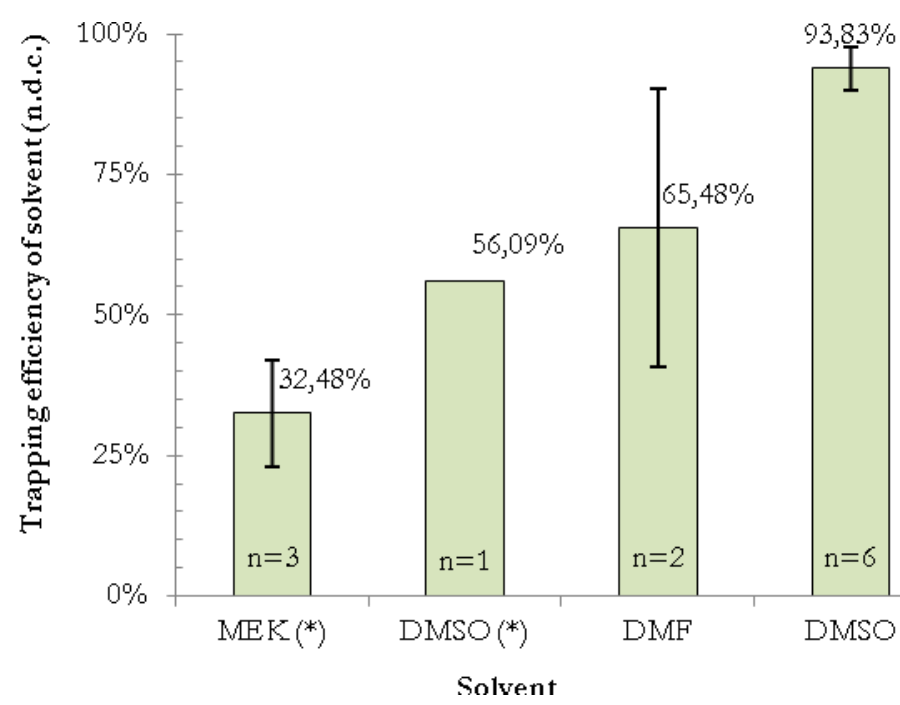

Figure 3.7 Influence of precursor solvent (MEK, DMSO and DMF) on the trapping efficacy of $\left[{ }^{11} \mathrm{C}\right] \mathrm{CH}_{3} \mathrm{I}$ and $\left[{ }^{11} \mathrm{C}\right] \mathrm{CH}_{3} \mathrm{OTf}(*)$ on the captive solvent loop.

R)-[N-methyl- $\left.{ }^{11} \mathrm{C}\right] \mathrm{PK} 11195$ is labelled with ${ }^{11} \mathrm{C}$ by an $\mathrm{N}$-alkylation reaction, that is aided by a strong base for deprotonation. Two different strong bases were used with various concentration, to evaluate their efficacy on N-deprotonation. Summary of the results are shown on Table 3.2. 
Table 3.2 Summary of the results of influence of different solvents and bases in the synthesis of (R)-[N-methyl$\left.{ }^{11} \mathrm{C}\right] \mathrm{PK} 11195$.

\begin{tabular}{|c|c|c|c|c|c|c|}
\hline Solvent & Base & $\begin{array}{l}{\left[{ }^{11} \mathrm{C}\right] \text {-methylation }} \\
\text { agent }\end{array}$ & $\begin{array}{l}\text { Average } \\
\text { trapping } \\
\text { efficiency of } \\
{\left[{ }^{11} \mathrm{C}\right] \mathrm{CH}_{3} \mathrm{I}(\%)} \\
(\operatorname{mean} \pm \sigma)\end{array}$ & $\begin{array}{l}\text { Average } \% \text { of } \\
\text { (R)-[N-methyl-11 C]PK } \\
11195 \text { RCY (DC) } \\
(\text { mean } \pm \sigma)\end{array}$ & $\begin{array}{l}\text { (R)-[N-methyl-11C]PK } \\
11195 \text { at EOS (mCi) } \\
(\text { mean } \pm \sigma)\end{array}$ & $\mathrm{n}$ \\
\hline MEK & $\mathrm{TBAOH}^{\mathbf{a}}$ & {$\left[{ }^{11} \mathrm{C}\right] \mathrm{CH}_{3} \mathrm{OTf}$} & $32.48 \pm 9.40$ & $5.11 \pm 2.56$ & $6.90 \pm 1.41$ & 3 \\
\hline DMSO & $\mathrm{KOH}^{\mathrm{b}}$ & {$\left[{ }^{11} \mathrm{C}\right] \mathrm{CH}_{3} \mathrm{OTf}$} & 56.09 & 2.14 & 1.90 & 1 \\
\hline DMF & $\mathrm{TBAOH}^{\mathbf{a}}$ & {$\left[{ }^{11} \mathrm{C}\right] \mathrm{CH}_{3} \mathrm{I}$} & 40.87 & 0 & 0 & 1 \\
\hline DMF & $\mathrm{KOH}^{\mathbf{b}}$ & {$\left[{ }^{11} \mathrm{C}\right] \mathrm{CH}_{3} \mathrm{I}$} & 90.09 & 0.83 & 2.13 & 1 \\
\hline DMSO & $\mathrm{KOH}^{\mathrm{b}}$ & {$\left[{ }^{11} \mathrm{C}\right] \mathrm{CH}_{3} \mathrm{I}$} & $93.83 \pm 3.90$ & $31.58 \pm 9.97$ & $107.85 \pm 52.13$ & 10 \\
\hline DMSO & $\mathrm{KOH}^{\mathrm{c}}$ & {$\left[{ }^{11} \mathrm{C}\right] \mathrm{CH}_{3} \mathrm{I}$} & $62.74 \pm 18.06$ & $4.41 \pm 2.78$ & $5.45 \pm 2.73$ & 3 \\
\hline
\end{tabular}

a TBAOH (1M) in methanol (TBAOH: tetrabutylammonium bydroxide); $10 \mu \mathrm{l}$

${ }^{b} \mathrm{KOH}$ (potassium hydroxide); precursor solution was saturated with $30 \mathrm{mg}$ of $\mathrm{KOH}$

${ }^{c} \mathrm{KOH}(8 \mathrm{~N})$ aqueous solution; $2 \mu \mathrm{l}$

\subsubsection{Precursor concentration: influence on RCY}

The amount of precursor (concentration) in the synthesis of $\left[{ }^{11} \mathrm{C}\right] \mathrm{PK} 11195$ is an important issue not only for the radiochemical yield (RCY), but also in the ratio $\left[{ }^{11} \mathrm{C}\right] \mathrm{PK} 11195 /\left[{ }^{11} \mathrm{C}\right] \mathrm{CH}_{3} \mathrm{I}$. The total activity amount of $\left[{ }^{11} \mathrm{C}\right] \mathrm{PK} 11195$ at the EOS was evaluated too, and correlated with precursor concentration.

The synthesis conditions were: the desired amount of precursor was dissolved in $100 \mu \mathrm{l}$ of DMSO, and saturated with $30 \mathrm{mg}$ of $\mathrm{KOH}$; and reacted $5 \mathrm{~min}$ on loop. All loop preparation processes were made just before the injection of the precursor solution. The experimental results are summarised on Table 3.3.

Table 3.3 Influence of precursor concentration in the synthesis of $\left[{ }^{11} \mathrm{C}\right] \mathrm{PK} 11195$.

\begin{tabular}{|c|c|c|c|c|c|}
\hline $\begin{array}{l}\text { Precursor } \\
\text { concentratio } \\
\mathrm{n} \\
(\mathrm{mg} / 100 \mu \mathrm{l})\end{array}$ & $\begin{array}{l}\text { Average amount of } \\
{\left[{ }^{11} \mathrm{C}\right] \mathrm{CH}_{3} \mathrm{I} \text { activity }} \\
\text { produced (mCi) } \\
(\text { mean } \pm \sigma)\end{array}$ & $\begin{array}{l}\text { Average amount of } \\
{\left[{ }^{11} \mathrm{C}\right] \mathrm{PK} 11195} \\
\text { activity produced } \\
(\mathrm{mCi})(\text { mean } \pm \sigma)\end{array}$ & $\begin{array}{l}\text { Average } \% \text { of } \\
{\left[{ }^{11} \mathrm{C}\right] \mathrm{PK} 11195 \mathrm{RCY}} \\
\text { (n.d.c.) }(\text { mean } \pm \sigma)\end{array}$ & $\begin{array}{l}{\left[{ }^{11} \mathrm{C}\right] \mathrm{PK} 11195 /\left[{ }^{11} \mathrm{C}\right] \mathrm{CH}_{3}} \\
\text { I ratio }(\text { mean } \pm \sigma)\end{array}$ & $\mathrm{n}$ \\
\hline 0.25 & $37.82 \pm 31.82$ & $13.70 \pm 9.70$ & $6.6 \pm 1.4$ & $0.5 \pm 0.17$ & \multirow{3}{*}{4} \\
\hline 0.5 & $73.92 \pm 56.97$ & $96.32 \pm 13.31$ & $17.8 \pm 5.2$ & $2.6 \pm 2.05$ & \\
\hline 1 & $39.40 \pm 16.81$ & $131.73 \pm 67.99$ & $20.9 \pm 4.0$ & $3.2 \pm 0.52$ & \\
\hline
\end{tabular}

Thus, increasing the amount of precursor, will increase not only the RCY of $\left[{ }^{11} \mathrm{C}\right] \mathrm{PK} 11195$ but also the total amount of activity at EOS (Figure 3.8). 

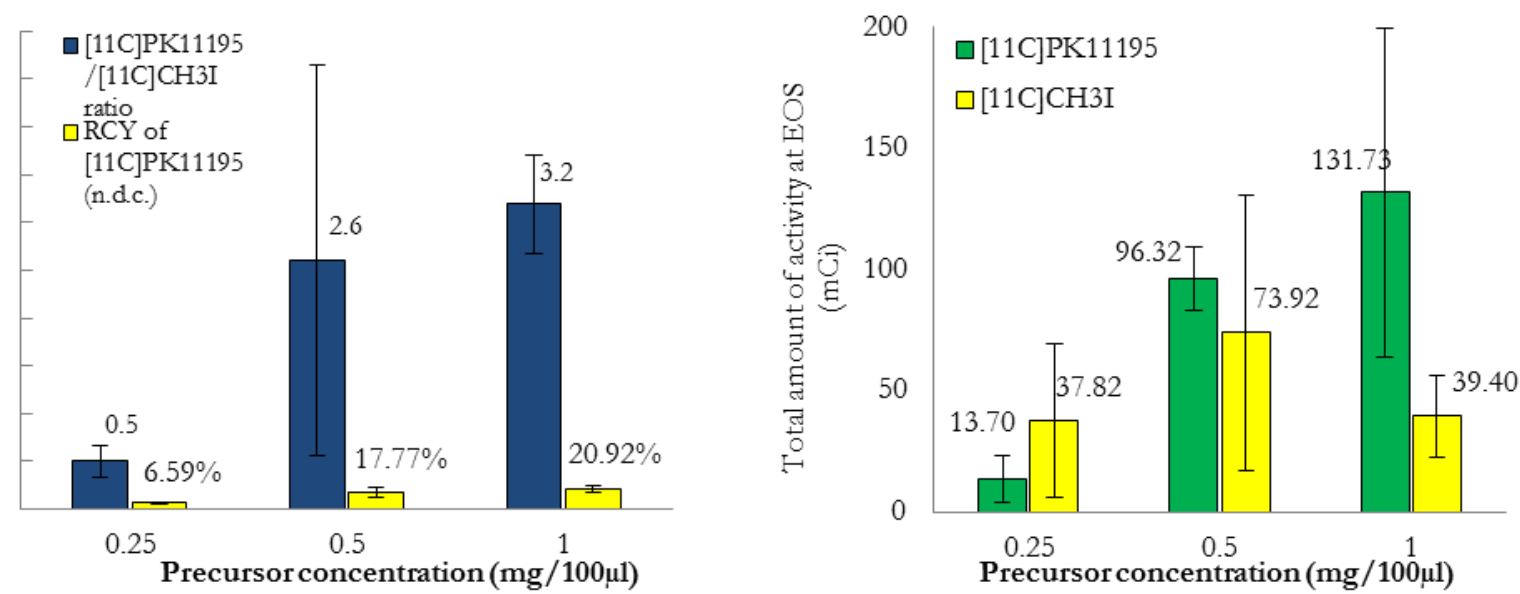

Figure 3.8 Influence of precursor ((R)-[N-desmethyl]PK11195) concentration in radiochemical yield (RCY) and in the ratio $\left[{ }^{11} \mathrm{C}\right] \mathrm{PK} 11195 /\left[{ }^{11} \mathrm{C}\right] \mathrm{CH}_{3} \mathrm{I}$ (left) and total amount of radioactivity of both at EOS affected by precursor concentration (right). $(\mathrm{n}=4)$.

\subsubsection{Reaction time}

We also evaluated the influence of reaction time on the synthesis of $\left[{ }^{11} \mathrm{C}\right] \mathrm{PK} 11195$, with $0.5 \mathrm{mg}$ of precursor dissolved in $100 \mu \mathrm{l}$ of DMSO, and saturated with $30 \mathrm{mg}$ of $\mathrm{KOH}$. All loop preparation processes were made just before the injection of the precursor solution. The results show that increasing the reaction time of $1 \mathrm{~min}$ to $3 \mathrm{~min}$, and then to 5 minutes, results in an increase of RCY of the $\left[{ }^{11} \mathrm{C}\right] \mathrm{PK} 11195$ product. Productions of $\left[{ }^{11} \mathrm{C}\right] \mathrm{PK} 11195$ were 58.4, 118.3 and $234.3 \mathrm{mCi}$ with 1, 3 and 5 minutes of reaction, respectively (Figure 3.9).
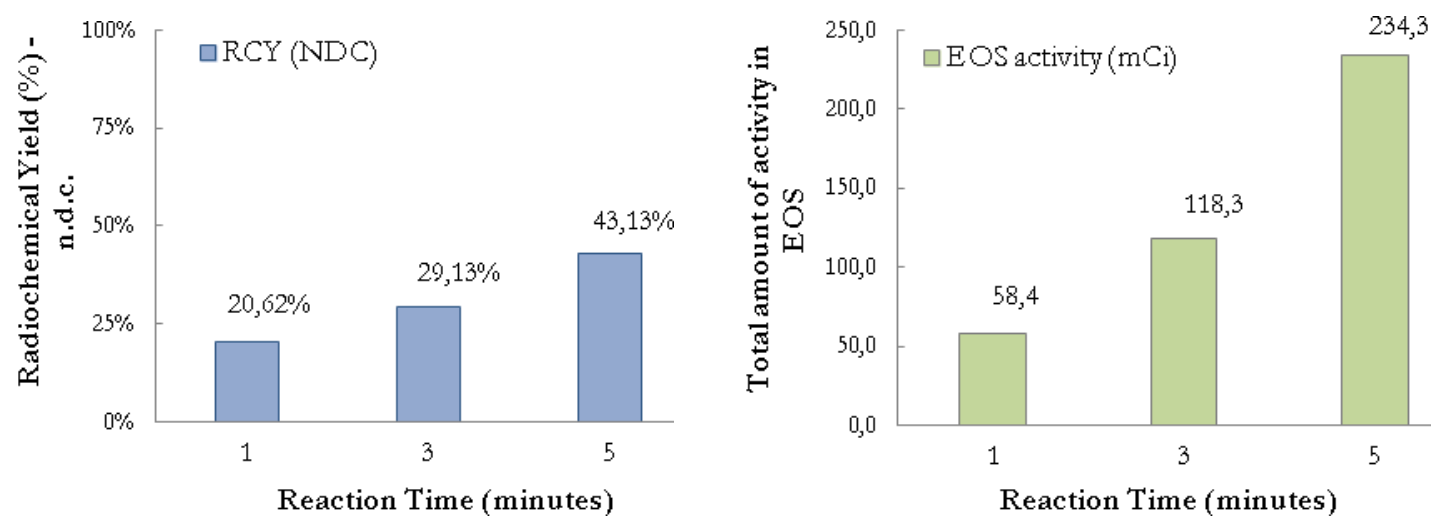

Figure 3.9 Effect of reaction time in $\left[{ }^{11} \mathrm{C}\right] \mathrm{PK} 11195$ production. Radiochemical yields (left) and total activity of $\left[{ }^{11} \mathrm{C}\right]$ PK11195 at the end of synthesis (mCi; right); $(\mathrm{n}=1)$. 


\subsection{Purification and formulation of $(R)-\left[{ }^{11} \mathrm{C}\right] \mathrm{PK} 11195$}

After the reaction in the loop, the crude mixture is injected into a semi-preparative HPLC column for purification.

The retention times were 10.8-12.5 minutes for (R)- $\left[\mathrm{N}\right.$-methyl- $\left.{ }^{11} \mathrm{C}\right] \mathrm{PK} 11195$ and 15.8-17.5 minutes for (R)-[N-desmethyl]PK11195 on the semi-preparative HPLC (Figure 3.10).

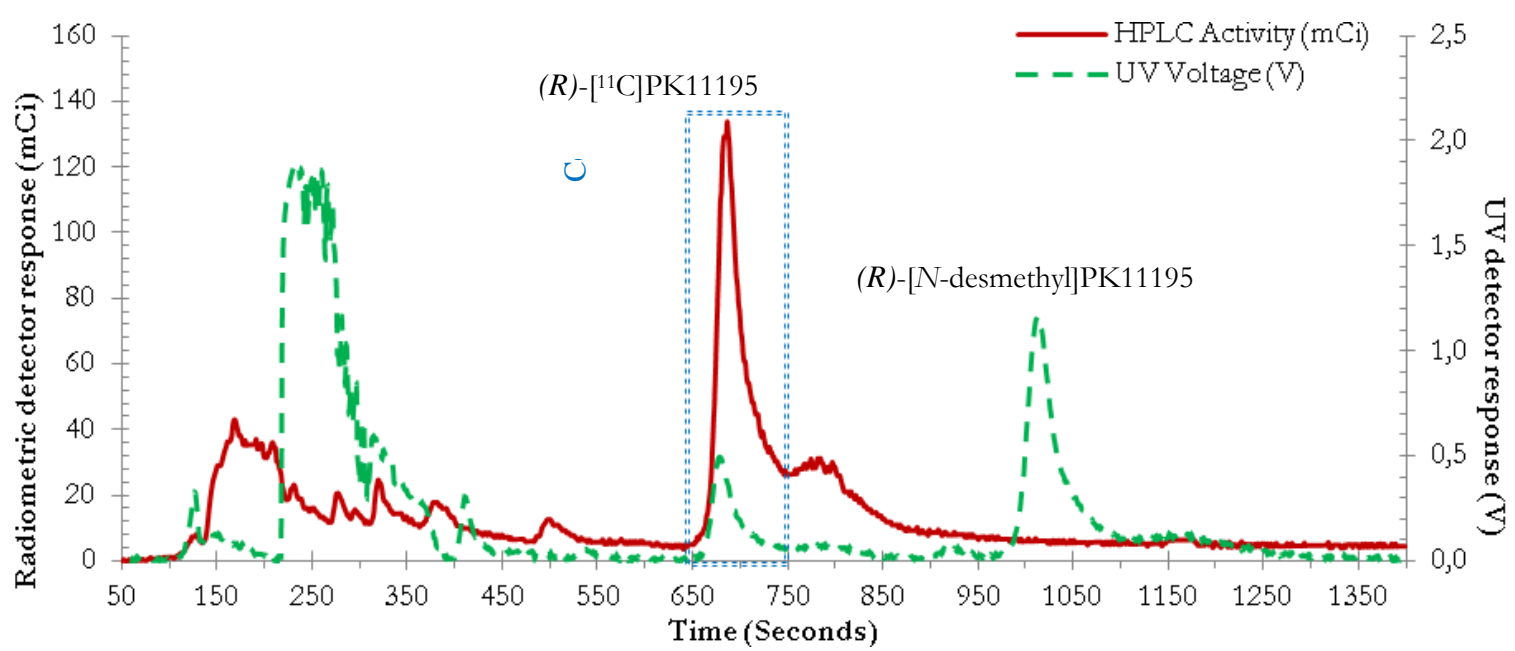

Figure 3.10 Semi-preparative HPLC separation of (R)-[N-methyl- $\left.{ }^{11} \mathrm{C}\right] \mathrm{PK} 11195\left(\mathrm{R}_{\mathrm{t}}: 11.7 \mathrm{~min}\right)$. HPLC conditionscolumn: Phenomenex Luna C18(2) $5 \mu(250 \times 10 \mathrm{~mm})$ reverse phase column; mobile phase: $0.1 \mathrm{~N}$ aqueous solution and acetonitrile (40:60); and flow rate: $5 \mathrm{ml} / \mathrm{min}$. (Decay corrected and background removed).

SPE purification resulted in a recovery of $>95 \%$ using $1 \mathrm{ml}$ of ethanol followed by $9 \mathrm{ml}$ of physiological saline solution $(\mathrm{NaCl} 0.9 \%)$ for the elution of $\left[{ }^{11} \mathrm{C}\right] \mathrm{PK} 11195$.

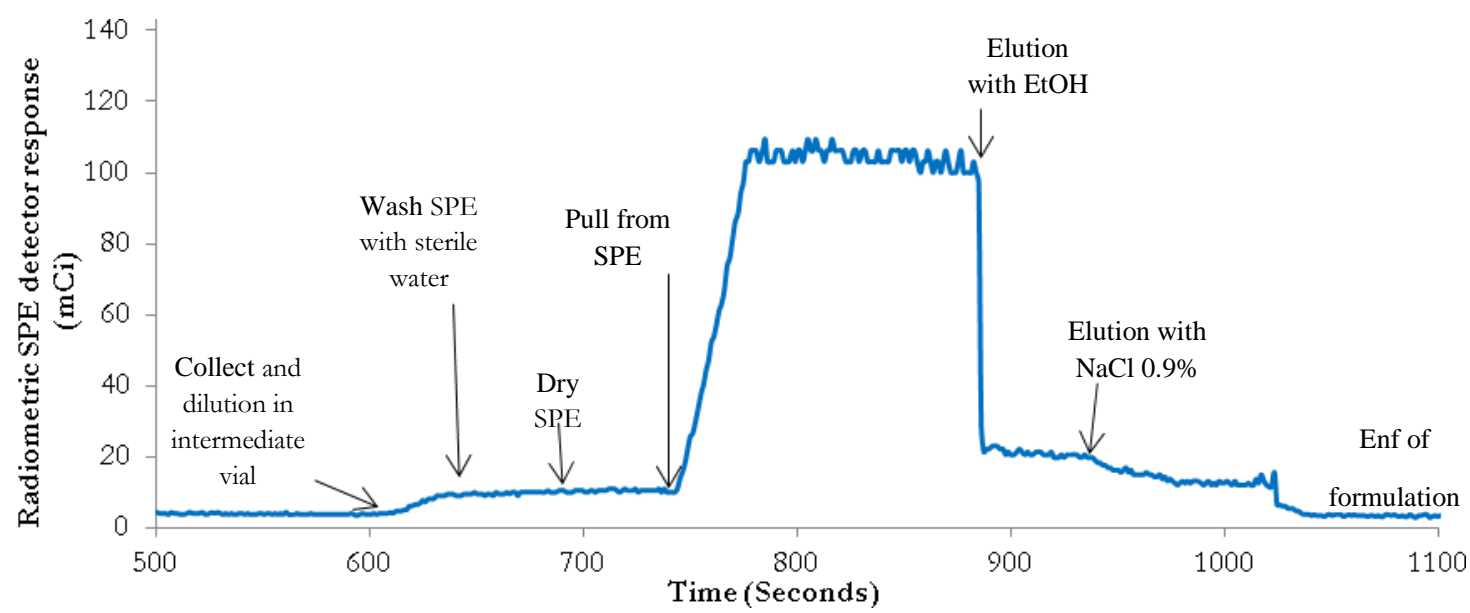

Figure 3.11 Formulation of $\left[{ }^{11} \mathrm{C}\right] \mathrm{PK} 11195$ by solid phase extraction on the reformulation system. 


\subsection{Product filtration}

A measure of the sterilization filter after reformulation, showed that a large amount of activity was trapped on the first filter used (Millex-GS; $0.22 \mu \mathrm{m}$ ). To confirm this result and make an evaluation of the problem, several filtration tests of the 'cold' product ((R)-PK11195) were made. Three different types of filter were used in these experiments (Figure 3.12).

The (R)-PK11195 standard was solubilised in a mixture of saline and ethanol (solution of saline with $10 \%$ of ethanol). From the concentration of the standard solution before injection and the measure by HPLC after injection, it was possible to evaluate the ratio of retention of the different filters.

Test 1 (GS): The standard solution of (R)-PK11195 was filtered with a Millex-GS Millipore $(0.22 \mu \mathrm{m})$ filter (mixed cellulose esters) and the filtrate was then subjected to injection into analytical HPLC.

Test 2 (GV): The standard solution of (R)-PK11195 was filtered with a Millex-GV Millipore $(0.22 \mu \mathrm{m})$ filter (polyvinylidene difluoride or PVDF) and the filtrate was then subjected to injection into analytical HPLC.

Test 3 (minisart): The standard solution of (R)-PK11195 was filtered with a Minisart ${ }^{\circledR}$ Sartorius Stedim $(0.2 \mu \mathrm{m})$ filter and the filtrate was then subjected to injection into analytical HPLC.

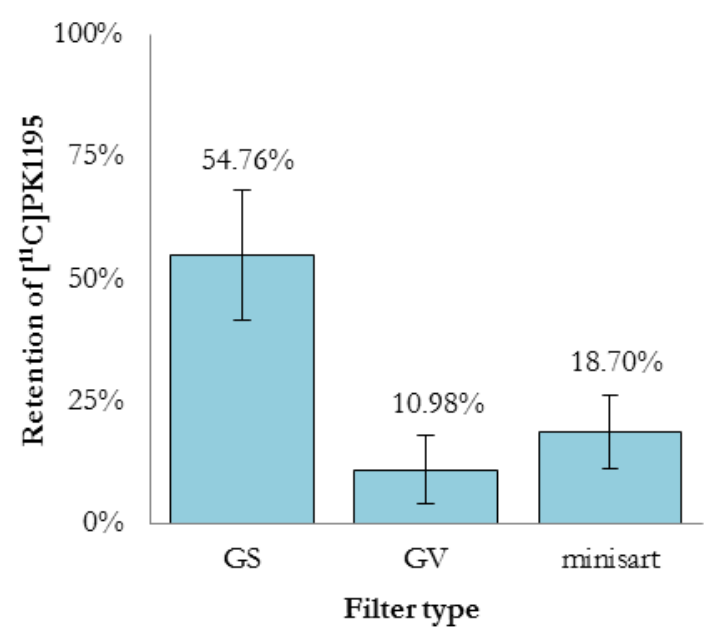

Figure 3.12 Filtration testes of (R)-PK11195 with $0.22 \mu \mathrm{m}$ sterile filters using a solution of saline at $10 \%$ of ethanol. $(\mathrm{n}=3)$. 
The results show that the Millex-GV column retains less product then the Millex-GS and the Minisart. Using a saline solution of (R)-PK11195 with 10\% EtOH, we obtained a filtered solution with a concentration of $89.02 \pm 6.92 \%$ of the initial value.

Hot tests with the labelled compound (R)-[N-methyl-11C]PK11195) confirmed this result and with a volume of $1 \mathrm{ml}$ of $\mathrm{EtOH}$, the labelled product was quantitatively recovered in the final vial.

\subsection{Routine radiolabelling of $(R)-\left[N\right.$-methyl $\left.-{ }^{11} \mathrm{C}\right] \mathrm{PK} 11195$}

The conditions for routine radiolabelling of $\left[{ }^{11} \mathrm{C}\right] \mathrm{PK} 11195$ involve an irradiation time of about 30 minutes on the cyclotron with an integrated current of about $12.8 \mu \mathrm{Ah}$. During the irradiation time, the molecular sieves (MeI-Plus) are pre-conditioned (heating at $250^{\circ} \mathrm{C}$ for about 20 minutes).

The reaction conditions are: $0.5 \mathrm{mg}$ of precursor ( $N$-desmethyl-PK11195) dissolved in $100 \mu \mathrm{l}$ of DMSO and then saturated with $30 \mathrm{mg}$ of $\mathrm{KOH}$; reaction in the loop for 5 minutes with $\left[{ }^{11} \mathrm{C}_{\mathrm{CH}_{3} \mathrm{I}}\right.$. DMSO as a solvent, $\mathrm{KOH}$ as the base, and the $\left[{ }^{11} \mathrm{C}\right] \mathrm{CH}_{3} \mathrm{I}$ as methylation precursor offered the best productions of $\left[{ }^{11} \mathrm{C}\right] \mathrm{PK} 11195$ (141.29 $\pm 57.15 \mathrm{mCi}$ at end of reformulation).

$\left[{ }^{11} \mathrm{C}\right] \mathrm{PK} 11195$ is easily separated from precursor, solvents and other products by the semipreparative HPLC.

Radiochemical purity exceeded $99 \%$ as determined by radio-HPLC. No contamination with $\mathrm{N}$-desmethyl-PK11195 precursor was observed (Figure 3.13). Residual solvents as determinate by GC were found to be $672.09 \mathrm{mg} / 10 \mathrm{ml}$ ethanol and $3.28 \mathrm{mg} / 10 \mathrm{ml}$ acetonitrile. $\mathrm{pH}$ was 6.19 . The specific activity of the final product $\left(\left[{ }^{11} \mathrm{C}\right] \mathrm{PK} 11195\right)$ was between $15-25 \mathrm{GBq} / \mu \mathrm{mol}$ and the radiochemical of about 10-16\% (non-decay corrected). 


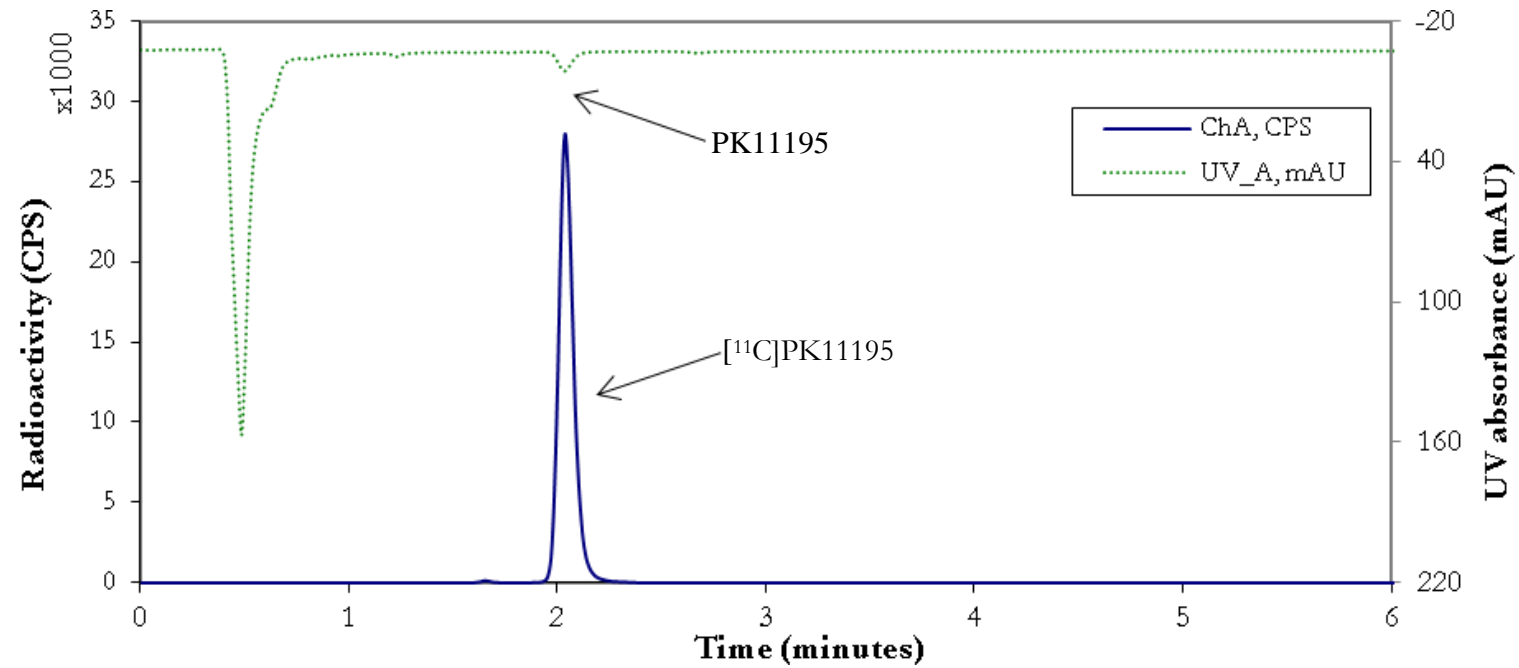

Figure 3.13 Analytical HPLC traces for a final (R)-[N-methyl- $\left.{ }^{11} \mathrm{C}\right] \mathrm{PK} 11195$ product sample $\left(\mathrm{R}_{\mathrm{t}}: 2.07\right.$ min). HPLC conditions: Agilent Zorbax Eclipse XDB-C18 (150x4.5 mm; $5 \mu)$ reverse phase column; mobile phase: water and acetonitrile (75:25); flow rate: $2 \mathrm{ml} / \mathrm{min}$. 



\section{CHAPTER 4}

Discussion

The radioligand $\left[{ }^{11} \mathrm{C}\right] \mathrm{PK} 1195$ was synthesised for the first time by the French company Pharmuka in 1984 [38]. The compound is a non-benzodiazepine high-affinity selective TSPO ligand and was labelled with carbon-11 as a PET imaging probe for neuroinflammation. Despite the limitations of carbon-11, related to its short half-life, PK11195 has remained the most widely used molecule for in vivo PET studies of TSPO.

The aim of this work was to optimise the synthesis, purification and reformulation of $\left[{ }^{11} \mathrm{C}\right] \mathrm{PK} 11195$ by the captive solvent method using a series of modules available at ICNAS for the production of methyl iodide, methylation in a captive solvent loop and reformulation by solid phase extraction. Automated radiosynthesis of compounds is common in PET production centres as it diminishes considerably doses on staff, provides a reliable and reproducible platform for production and facilitates record keeping and GMP compliance. A fundamental step of the process is the initial setup and optimisation of a synthesis that, considering there each installation is unique in its nature, requires substantial work in adapting production methods from the literature to the specific setup of each site. 


\subsection{Automation of $\left[{ }^{11} \mathrm{C}\right]$ methyl iodide production}

The first step of this work was dedicated to the $\left[{ }^{11} \mathrm{C}\right] \mathrm{CH}_{3} \mathrm{I}$ production optimisation parameters. The goal was to establish a rapid and reliable way to produce $\left[{ }^{11} \mathrm{C}\right] \mathrm{CH}_{3} \mathrm{I}$ with high radiochemical yields and with high specific activities. SA is a critical paramenter for a radiopharmaceutical and corresponds to the amount of radioactivity per unit mass of the compound. Thus, a low SA represents a higher mass of cold compound being injected with detrimental effects on image quality and possible pharmacotoxic effects on the subject.

In the production of methyl iodide at ICNAS, the labelled carbon-11 source comes from carbon dioxide labelled with ${ }^{11} \mathrm{C}$ produced on the cyclotron. This $\left[{ }^{11} \mathrm{C}\right] \mathrm{CO}_{2}$ is then used to produce $\left[{ }^{11} \mathrm{C}\right] \mathrm{CH}_{3} \mathrm{I}$. Any possible source of stable carbon (in form of $\mathrm{CO}_{2}$ ) present in lines of module, reagents, gas impurities and material of the target chamber, will also react with $\mathrm{LiAlH}_{4}$ and reduced to stable methanol salt. After evaporation of THF, and with addition of HI, stable methyl iodide is formed by distillation, which will decrease the specific activity of the final product. Therefore, the methyl iodide production system has to be optimised to potentiate the use of ${ }^{11} \mathrm{C}$ and to reduce, as much as possible, any potential sources of stable carbon $\left({ }^{12} \mathrm{C}\right)$.

The optimised parameters, as showed on Table 3.1, resulted in a production of $\left[{ }^{11} \mathrm{C}\right] \mathrm{CH}_{3} \mathrm{I}$ in about 10.57 minutes (from EOB) with radiochemical yields of $70.79 \pm 7.6 \%$ (NDC) and with very high reliability. In the end, more than $70 \%$ of the total activity received from the cyclotron (EOB) was converted to gaseous distilled $\left[{ }^{11} \mathrm{C}\right]$ methyl iodide.

\subsubsection{Specific Activity}

When the aim of identifying potential causes for the low specific activities associated with the production of methyl iodide by the so-called 'wet' method, we planned a series of experiments in order to assess the contribution of each individual element to the final amount of unlabelled carbon. For that purpose, we investigates the contribution to the SA of the synthesis module components (molecular sieves, pre-conditioning, volume of reagents and gas purity), the target, and the irradiation time.

When molecular sieves aren't pre-conditioned, values of $530.56 \pm 340.88 \mathrm{nmol}$ of stable methyl iodide were found, and $168.10 \pm 36.51 \mathrm{nmol}$ was found when pre-conditioning of molecular sieves been done before the start of synthesis (Figure 3.3). So, pre-conditioning of molecular sieves at $250^{\circ} \mathrm{C}$ for 20 minutes should always be performed, to release any absorbed $\mathrm{CO}_{2}$ before the beginning of a synthesis run. 
Next, were investigated the contribution of inert gas purity (nitrogen) in the final amount of stable methyl iodide. When $\mathrm{N}_{2}$ was used without any purification, values of $168.10 \pm 36.51 \mathrm{nmol}$ of stable methyl iodide were found. With the installation of an Ascarite ${ }^{\circledR} / \mathrm{P}_{2} \mathrm{O}_{5}$ column at the entrance of module, only $59.54 \pm 7.20 \mathrm{nmol}$ were found (Figure 3.4). Furthermore, we noticed that when drying the $\mathrm{N}_{2}$ with $\mathrm{P}_{2} \mathrm{O}_{5}$ the THF evaporation is more efficiently. We then concluded that a purification (filtration) of gases used in methyl iodide production is essential, and proceed to use then at every synthesis.

In a third step, the contribution from the reagents, the molecular sieves, the target chamber and the transfer line were investigated. The individual contribution of these factors was: $47.938 \pm 0.841 \mathrm{nmol}$ of stable methyl iodide was found due to the contribution of stable $\mathrm{CO}_{2}$ from the $\mathrm{CO}_{2}$ adsorbed on $\mathrm{LiAlH}_{4}$ solution, from the atmosphere due to lack or tightness of the synthesis module, or from methanol formed from THF remaining on $\mathrm{LiAlH}_{4}$ after evaporation; $8.190 \pm 5.262 \mathrm{nmol}$ of stable methyl iodide was found due to the contribution of stable $\mathrm{CO}_{2}$ adsorbed on molecular sieves; and $69.115 \pm 22.597 \mathrm{nmol}$ of stable methyl iodide were found due to the contribution of $\mathrm{CO}_{2}$ from load-unload target processes, such as from $\mathrm{CO}_{2}$ adsorbed on the target chamber, in the stainless-steel tubing that connect target to the synthesis module, or from presence in the target gas. Considering these results, it is clear that a reduction of LiAlH4 loaded volume and a purification of the nitrogen/oxygen mixture leads to a substantial increase of the specific activity.

Finally, were investigated the formation of stable $\mathrm{CO}_{2}$ during the bombarding processes. As it can be seen in Figure 3.6, methyl iodide production with $1 \mu \mathrm{Ah}$ of bombardment led to the production of $348.48 \pm 121.10 \mathrm{nmol}$ of stable $\mathrm{CH}_{3} \mathrm{I}$. When bombarding time was increased (integrated currents of 2, 5 and $10 \mu \mathrm{Ah}$ ), 428.54 $\pm 27.36,447 \pm 16.16$ and $570.72 \pm 125.82 \mathrm{nmol}$ of stable methyl iodide were found. These results show that the first minutes of bombardment contribute to a great amount of stable carbon dioxide formed during the target irradiation $(224.24 \pm 143.36 \mathrm{nmol}$ were found due to integrated of $1 \mathrm{uAh})$. The non-linear results of stable methyl iodide formation with increasing of bombarding time, suggests that the main source of non-radioactive (stable) carbon dioxide during the full synthesis of $\left[{ }^{11} \mathrm{C}\right] \mathrm{CH}_{3} \mathrm{I}$ is due to the presence of carrier carbon contamination in the target content and that the material is formed primarily during the first minutes of bombardment. This formation of stable $\mathrm{CO}_{2}$ (combustion) is greater and faster on the beginning of the bombardment because of the higher concentration of carrier carbon, which decreases as the combustion takes place. 
Considering the obtained results, was decided to implement a set of procedures in order to improve the radiochemical yield of the methyl iodide production and improved the specific activity of PK11195 labelled with carbon-11 via the 'wet' method. These procedures are:

1. Definitive modification:

a. Installation of a trap in nitrogen gas supply entry, for remove the introduction of stable carbon in lines;

b. Reduction of the volume of $\mathrm{LiAlH}_{4}$ loaded.

2. Preparation of the synthesis module:

a. Cleaning the system (EtOH, acetone and diethyl eter) and drying with nitrogen;

b. Loading the reagents into module;

c. Loading, bombarding the target (integrated current: $1 \mu \mathrm{Ah}$ ) and unloading to module, by running a simple methyl iodide production method; maintaining the target pressurised at $20 \mathrm{bar}$;

d. The system is cleaned automatically;

e. Pre-conditioning (at $250^{\circ} \mathrm{C}$ for 30 minutes) the molecular sieves column to eliminate residual $\mathrm{CO}_{2}$;

f. Maintaining the system pressurised.

3. Periodical check-ups to system to follow possible leaks on the system lines.

\subsubsection{Synthesis module: routine maintenance}

Following the experience acquired with the synthesis module, a set of procedures was established to maintain the high reliability of the production. This is summarised below.

1. Every day before the first synthesis, an inspection of the general conditions of the module should be performed (look for valves leaks; test operation of valves, ovens and reactor oven elevator);

2. In the end of the day, after the last production, the module should always be cleaned to avoid residues to build up and cause malfunctioning in subsequent productions;

3. Reagents needles should be changed every working day;

4. The molecular sieves should be replaced whenever there is an insufficient trapping of $\left[{ }^{11} \mathrm{C}\right] \mathrm{CO}_{2}$ gas. 
5. Drying column (with ascarite and $\mathrm{P}_{2} \mathrm{O}_{5}$ ) between methyl iodide production system and and loop should be replaced at the beginning of each production day.

6. Inert gas should be purified to improve radiochemical yields and specific activity.

\subsection{Radiolabelling $(R)-\left[{ }^{11} \mathrm{C}\right] \mathrm{PK} 11195$ on a captive solvent loop}

The production of radiopharmaceuticals with short-live positron emitters relies heavily on the use of semi-preparative HPLC systems for purification of the final reaction mixture. It is therefore of great convenience that we use the sample HPLC loop for the labelling reaction. This is the basis of the captive solvent loop developed by Wilson et al. work [67]. In this system, the methylation agent is trapped and made to react with the precursor solution pre-loaded onto the loop. Using this method, a large variety of PET radiopharmaceuticals labelled with carbon-11 can be produced. In this work we demonstrated that, with the right choice of solvent, base, time of reaction and eluents for HPLC purification, labelling of $\left[{ }^{11} \mathrm{C}\right] \mathrm{PK} 11195$ with this method is possible with good quality and reliability.

\subsubsection{Initial optimisation}

A critical parameter on a nucleophilic substitution reaction is the selection of an adequate polar aprotic solvent. We evaluated different solvents in the trapping efficiency of $\left[{ }^{11} \mathrm{C}\right] \mathrm{CH}_{3} \mathrm{I}$ or $\left[{ }^{11} \mathrm{C}\right] \mathrm{CH}_{3} \mathrm{OTf}$ after establishing their ability to dissolve the (R)-[N-desmethyl]PK11195 precursor.

The experimental results are shown on Figure 3.7, and DMSO proved to be the best choice on trapping efficacy $\left(56.09 \%\right.$ of $\left[{ }^{11} \mathrm{C}\right] \mathrm{CH}_{3} \mathrm{OTf}$ and $93.83 \pm 3.90 \%$ of $\left.\left[{ }^{11} \mathrm{C}\right] \mathrm{CH}_{3} \mathrm{I}\right)$. A strong base is also needed on the precursor solution for deprotonation (R)-[N-desmethyl]PK11195 for $\left[{ }^{11} \mathrm{C}\right]$-methylation reaction by an $N$-alkylation. According to the results showed on Table 3.2., radiochemical yields were higher when the precursor solution was saturated with $30 \mathrm{mg}$ of $\mathrm{KOH}$.

The amount of precursor injected into the loop should be sufficient to produce good radiochemical yields. However, it should not be excessive to ensure a good separation from $\left[{ }^{11} \mathrm{C}\right] \mathrm{PK} 11195$ by reverse-phase HPLC, and to help maintain the cost of the synthesis low. As it can be seen by the results, with $1 \mathrm{mg}$ of precursor, we obtained radiochemical yields of about $20.9 \pm 4.0 \%$ (non-decay corrected), whereas with $0.5 \mathrm{mg}$ were obtained RCY of $17.8 \pm 5.2 \%$ (NDC). Although the ratio between labelled $\left[{ }^{11} \mathrm{C}\right] \mathrm{PK} 11195$ and unlabelled $\left[{ }^{11} \mathrm{C}^{\mathrm{C}} \mathrm{CH}_{3} \mathrm{I}\right.$ is higher 
with $1 \mathrm{mg}$ of precursor, the radiochemical yields suggest that $0.5 \mathrm{mg}$ of precursor is enough to obtain the desired amount of labelled $\left[{ }^{11} \mathrm{C}\right] \mathrm{PK} 11195$ in the end of synthesis.

Finally, the reaction time of 5 minutes in the loop with precursor dissolved on $100 \mu$ of DMSO and saturated with $30 \mathrm{mg}$ of precursor, provided the best production of $\left[{ }^{11} \mathrm{C}\right] \mathrm{PK} 11195$ with RCY about $43.13 \%$ and activity on EOS about $234.3 \mathrm{mCi}$.

\subsubsection{Purification and reformulation of $(R)-\left[{ }^{11} \mathrm{C}\right] \mathrm{PK} 11195$}

Purification of (R)-[N-methyl- $\left.{ }^{11} \mathrm{C}\right] \mathrm{PK} 11195$ was performed successfully by reverse-phase HPLC C18 column (Phenomenex Luna C18(2), 5 $\mu$, 250x10 mm). It is an octadecyl carbon chain (C18) where compounds are separated based on their hydrophobic character.

The mobile phase chosen was a $0.1 \mathrm{~N}$ ammonium formate aqueous solution / acetonitrile (40:60) with a flow of $5 \mathrm{ml} / \mathrm{min}$. With this optimised parameters, $\left[{ }^{11} \mathrm{C}\right] \mathrm{PK} 11195$, the precursor and other reaction products were properly separated with retention times of 10.8-12.5 minutes for (R)- $\left[\mathrm{N}\right.$-methyl- $\left.{ }^{11} \mathrm{C}\right] \mathrm{PK} 11195$ and 15.8-17.5 minutes for (R)-[N-desmethyl]PK11195 (Figure $3.10)$.

The final step of the synthesis process is the reformulation of $\left[{ }^{11} \mathrm{C}\right] \mathrm{PK} 11195$ collected fraction on a ready-to-inject dose by SPE. A C18 column was used with an optimised reformulation disposable kit. SPE purification resulted in a recovery of $>95 \%$ using $1 \mathrm{ml}$ of ethanol followed by $9 \mathrm{ml}$ of physiological saline solution $(\mathrm{NaCl} 0.9 \%$ ) for the elution of $\left[{ }^{11} \mathrm{C}\right] \mathrm{PK} 11195$. Using the Millex-GV filter and a volume of $1 \mathrm{ml}$ of $\mathrm{EtOH}$, there were no problems of filtration and the labelled compound (R)-[N-methyl-11C]PK11195) was quantitatively recovered in the final vial.

\subsection{Routine synthesis, purification and reformulation of (R)-[N-methyl- $\left.{ }^{11} \mathrm{C}\right] \mathrm{PK} 11195$}

Production of $\left[{ }^{11} \mathrm{C}\right]$ methyl iodide results showed good reproducibility and that the amount of radioactivity produced after the $10 \mu \mathrm{Ah}$ irradiations $(1173.9 \pm 85.5 \mathrm{mCi})$, was sufficient for the radiosynthesis of the PK11195 in sufficient quantity and quality for human use. Good distillation yields were obtained $(84.12 \pm 12.03 \%)$ and sufficient for the N-methylation of the desmethylPK11195 precursor. For the labelling reaction, $0.5 \mathrm{mg}$ of precursor ( $N$-desmethyl-PK11195) was dissolved in $100 \mu \mathrm{l}$ of DMSO and then saturated it with $30 \mathrm{mg}$ of $\mathrm{KOH}$, and injected into the 
loop and made to react for 5 minutes with $\left[{ }^{11} \mathrm{C}\right] \mathrm{CH}_{3} \mathrm{I}$. $141.29 \pm 57.15 \mathrm{mCi}$ of $\left[{ }^{11} \mathrm{C}\right] \mathrm{PK} 11195$ at EOS were obtained and were easily separated from precursor, solvents and other products by the semi-preparative HPLC.

Radiochemical purity exceeded $99 \%$ as determined by radio-HPLC. No contamination with N-desmethyl-PK11195 precursor was observed (Figure 3.13). Residual solvents as determinate by GC were found to be $672.09 \mathrm{mg} / 10 \mathrm{ml}$ ethanol and $3.28 \mathrm{mg} / 10 \mathrm{ml}$ acetonitrile. $\mathrm{pH}$ was 6.19 . The specific activity of the final product $\left(\left[{ }^{11} \mathrm{C}\right] \mathrm{PK} 11195\right)$ was between $15-25 \mathrm{GBq} / \mu \mathrm{mol}$ and the radiochemical of about 10-16\% (non-decay corrected). All parameters are within specification for human use. 



\section{CHAPTER 5}

\section{Conclusion}

The present work aimed to optimise the synthesis, purification and reformulation of (R)- $\left[{ }^{11} \mathrm{C}\right] \mathrm{PK} 11195$ using the captive solvent method and make its available on a ready-to-inject sterile saline solution for PET imaging studies of neuroinflammation. PK11195 is a lipid soluble isoquinoline carboxamide that, when labelled with carbon-11 ((R)- $\left.\left[{ }^{11} \mathrm{C}\right] \mathrm{PK} 11195\right)$, can be used as an in vivo molecular imaging probe for the TSPO receptor. This $18 \mathrm{kDa}$ translocator protein is overexpressed when microglia is activated, a main feature of neuroinflammation.

Improved and efficient synthesis of (R)-[N-methyl- $\left.{ }^{11} \mathrm{C}\right] \mathrm{PK} 11195$ on an automated synthesis system was optimised for routine production with excellent radiochemical yields and good specific activities. Initially, the production of $\left[{ }^{11} \mathrm{C}\right]$ methyl iodide was improved by establishing the optimal production parameters. Possible sources of stable $\mathrm{CO}_{2}$ were investigated in order to obtain the best possible specific activity. Secondly, solvents, bases and times of reaction were optimised for the best radiochemical yield using the captive solvent loop. Finally, reaction products were purified by HPLC and formulated by SPE on a ready-to-inject non-pyrogenic saline solution. 
Quality control tests were performed to ensure the good quality of product. Activity obtained was $149.71 \pm 50.25 \mathrm{mCi}$ of $(\mathrm{R})-\left[{ }^{11} \mathrm{C}\right] \mathrm{PK} 11195$ at EOS with specific activities between 15$25 \mathrm{GBq} / \mu \mathrm{mol}$ on a short overall synthesis time.

The approach that we have developed allows the reliable and reproducible preparation $\left[{ }^{11} \mathrm{C}\right]$-radiopharmaceuticals such as $(\mathrm{R})-\left[{ }^{11} \mathrm{C}\right] \mathrm{PK} 11195$ several times a day, with activity and quality suitable for human studies. The optimizations made are applicable to most methylation syntheses by this method and are already being used at the lab for the development of the next generation of ${ }^{11} \mathrm{C}$-based radiotracers. 


\section{CHAPTER 6}

Future perspectives

Although the results of this work proved that we can produce (R)- $\left[{ }^{11} \mathrm{C}\right] \mathrm{PK} 11195$ with specific activity suitable for human studies, other tracers, mainly for targets that are poorly expressed in tbe region of interest or are destined for small animal research, require even higher levels of specific activity.

For that purpose, there is an interesting challenge in the short term, that is the production of $\left[{ }^{11} \mathrm{C}\right] \mathrm{CH}_{3} \mathrm{I}$ from the in-target production of $\left[{ }^{11} \mathrm{C}\right]$ methane $\left(\left[{ }^{11} \mathrm{C}\right] \mathrm{CH}_{4}\right)$. This method of $\left[{ }^{11} \mathrm{C}\right] \mathrm{CH}_{3} \mathrm{I}$ production, also referred to as the 'gas phase', exploits the conversion of $\left[{ }^{11} \mathrm{C}_{\mathrm{CH}_{4}}\right.$ into $\left[{ }^{11} \mathrm{C}\right] \mathrm{CH}_{3} \mathrm{I}$ by free radical iodination with iodine vapour at high temperatures $\left(700-750^{\circ} \mathrm{C}\right)$ in the gas phase [71]. The production of $\left[{ }^{11} \mathrm{C}_{\mathrm{CH}_{3} \mathrm{I}}\right.$ via the 'gas phase' method offers several advantages over the 'wet' method route. Firstly, it avoids the problem of stable $\mathrm{CO}_{2}$ present on $\mathrm{LiAlH}_{4}$, hence leading to a high specific activity. Likewise problems of low specific activities associated to stable $\mathrm{CO}_{2}$ present on gases, target chambers, and others source, are skipped. Secondly, 
avoidance of hydriodic acid prevents valves and tubing from deterioration. With implementation of 'gas phase' method on routine production of $\left[{ }^{11} \mathrm{C}\right]$-radiopharmaceuticals we expect a significant increasing of specific activities.

Other desired and promising demand is the introduction of microreactors in radiochemistry for enable reactions performed more rapidly, efficiently, and selectivity. This type of 'microchemistry' allows reducing the amount of reagents used in the reactions. And with some optimisation in time and temperature, allows us to perform reactions that are very difficult to control in a reactor, or loop. 
[1] A. Jacobs, and B. Tavitian, "Noninvasive molecular imaging of neuroinflammation", Journal of Cerebral Blood Flow and Metabolism, 2012.

[2] F. Chauveau, H. Boutin, N. Van Camp et al., "Nuclear imaging of neuroinflammation: a comprehensive review of [11C]PK11195 challengers", European Journal of Nuclear Medicine and Molecular Imaging, vol. 35, no. 12, pp. 2304-2319, 2008.

[3] M. Politis, P. Su, and P. Piccini, "Imaging of microglia in patients with neurodegenerative disorders", Frontiers in Pharmacology, vol. 3, 2012.

[4] S. Venneti, B. J. Lopresti, and C. A. Wiley, "The peripheral benzodiazepine receptor (Translocator protein $18 \mathrm{kDa}$ ) in microglia: From pathology to imaging", Progress in Neurobiology, vol. 80, no. 6, pp. 308-322, 2006.

[5] A. S. C. Ching, B. Kuhnast, A. Damont et al., "Current paradigm of the $18-\mathrm{kDa}$ translocator protein (TSPO) as a molecular target for PET imaging in neuroinflammation and neurodegenerative diseases", Insights into Imaging, vol. 3, no. 1, pp. 111-119, 2012. 
[6] W. J. Streit, "Microglial senescence: does the brain's immune system have an expiration date?", Trends in Neurosciences, vol. 29, no. 9, pp. 506-10, Sep, 2006.

[7] H. Kettenmann, U. Hanisch, M. Noda et al., "Physiology of Microglia", Physiological Reviews, vol. 91, no. 2, pp. 461-553, 2011.

[8] G. W. Kreutzberg, "Microglia, the first line of defence in brain pathologies", Aræzneimittelforscbung, vol. 45, no. 3A, pp. 357-60, Mar, 1995.

[9] P. del Rio-Hortega, "Microglia", Cytology \& cellular pathology of the nervous system, W. Penfield, ed., pp. 483-534, New York: P.B. Hoeber, Inc., 1932.

[10] P. Casellas, S. Galiegue, and A. S. Basile, "Peripheral benzodiazepine receptors and mitochondrial function", Neurochemistry International, vol. 40, no. 6, pp. 475-86, May, 2002.

[11] A. Winkeler, R. Boisgard, A. Martin et al., "Radioisotopic Imaging of Neuroinflammation", Journal of Nuclear Medicine, vol. 51, no. 1, pp. 1-4, 2010.

[12] L. Fetler, and S. Amigorena, "Neuroscience. Brain under surveillance: the microglia patrol", Science, vol. 309, no. 5733, pp. 392-3, 2005.

[13] D. Davalos, J. Grutzendler, G. Yang et al., "ATP mediates rapid microglial response to local brain injury in vivo", Nature Neuroscience, vol. 8, no. 6, pp. 752-8, Jun, 2005.

[14] R. M. Ransohoff, and V. H. Perry, "Microglial Physiology: Unique Stimuli, Specialized Responses“, Annual Review of Immunology, Annual Review of Immunology, pp. 119-145, Palo Alto: Annual Reviews, 2009.

[15] L. Walter, and H. Neumann, "Role of microglia in neuronal degeneration and regeneration", Seminars in Immunopathology, vol. 31, no. 4, pp. 513-525, 2009.

[16] C. Braestrup, R. Albrechtsen, and R. F. Squires, "High densities of benzodiazepine receptors in human cortical areas", Nature, vol. 269, no. 5630, pp. 702-4, 1977.

[17] J. G. Richards, and H. Möhler, "Benzodiazepine receptors", Neuropharmacology, vol. 23, no. 2, Part 2, pp. 233-242, 1984.

[18] M. Gavish, I. Bachman, R. Shoukrun et al., "Enigma of the peripheral benzodiazepine receptor", Pharmacol Rev, vol. 51, no. 4, pp. 629-50, Dec, 1999. 
[19] V. Papadopoulos, M. Baraldi, T. R. Guilarte et al., "Translocator protein (180kDa): new nomenclature for the peripheral-type benzodiazepine receptor based on its structure and molecular function", Trends in Pharmacological Sciences, vol. 27, no. 8, pp. 402-409, 2006.

[20] R. Rupprecht, V. Papadopoulos, G. Rammes et al., "Translocator protein (18 kDa) (TSPO) as a therapeutic target for neurological and psychiatric disorders", Nature Rev Drug Discovery, vol. 9, no. 12, pp. 971-988, 2010.

[21] A. M. Scarf, and M. Kassiou, "The translocator protein”, Journal of Nuclear Medicine, vol. 52, no. 5, pp. 677-80, 2011.

[22] S. H. Snyder, M. W. McEnery, and A. Verma, "Molecular mechanisms of peripheral benzodiazepine receptors", Neurochemical Research, vol. 15, no. 2, pp. 119-123, 1990.

[23] C. Thominiaux, F. Mattner, I. Greguric et al., "Radiosynthesis of 2-[6-chloro-2-(4iodophenyl)imidazo[1,2-a]pyridin-3-yl]-N-ethyl-N-[11C]methyl-acetamide, [11C]CLINME， a novel radioligand for imaging the peripheral benzodiazepine receptors with PET", Journal of Labelled Compounds and Radiopharmaceuticals, vol. 50, no. 4, pp. 229-236, 2007.

[24] M. K. Chen, and T. R. Guilarte, “Translocator protein $18 \mathrm{kDa}$ (TSPO): molecular sensor of brain injury and repair", Pharmacology \& Therapeutics, vol. 118, no. 1, pp. 1-17, 2008.

[25] A. M. Scarf, L. M. Ittner, and M. Kassiou, "The Translocator Protein (18 kDa): Central Nervous System Disease and Drug Design”, Journal of Medicinal Chemistry, vol. 52, no. 3, pp. 581-592, 2009.

[26] V. Papadopoulos, H. Amri, N. Boujrad et al., "Peripheral benzodiazepine receptor in cholesterol transport and steroidogenesis", Steroids, vol. 62, no. 1, pp. 21-8, Jan, 1997.

[27] L. Veenman, V. Papadopoulos, and M. Gavish, "Channel-like functions of the $18-\mathrm{kDa}$ translocator protein (TSPO): regulation of apoptosis and steroidogenesis as part of the hostdefense response", Curr Pharm Des, vol. 13, no. 23, pp. 2385-405, 2007.

[28] N. Rosenberg, O. Rosenberg, S. Leschiner et al., "Translocator Protein $18 \mathrm{KDa}$ (TSPO) endogeneous ligand regulates the metabolism of human osteoblast", Journal of Bone \& Joint Surgery, British Volume, vol. 90-B, no. SUPP III, pp. 516, Aug, 2008.

[29] S. Venneti, B. J. Lopresti, and C. A. Wiley, "Molecular imaging of microglia/macrophages in the brain", Glia, 2012. 
[30] V. Papadopoulos, L. Lecanu, R. C. Brown et al., "Peripheral-type benzodiazepine receptor in neurosteroid biosynthesis, neuropathology and neurological disorders", Neuroscience, vol. 138, no. 3, pp. 749-56, 2006.

[31] V. Papadopoulos, and L. Lecanu, "Translocator protein $(18 \mathrm{kDa})$ TSPO: an emerging therapeutic target in neurotrauma”, Experimental Neurology, vol. 219, no. 1, pp. 53-7, Sep, 2009.

[32] A. Batarseh, and V. Papadopoulos, "Regulation of translocator protein $18 \mathrm{kDa}$ (TSPO) expression in health and disease states", Molecular and Cellular Endocrinology, vol. 327, no. 1-2, pp. 1-12, 2010.

[33] F. Chauveau, N. Van Camp, F. Dolle et al., "Comparative evaluation of the translocator protein radioligands 11C-DPA-713, 18F-DPA-714, and 11C-PK11195 in a rat model of acute neuroinflammation", Journal of Nuclear Medicine, vol. 50, no. 3, pp. 468-76, 2009.

[34] C. Luus, R. Hanani, A. Reynolds et al., "The development of PET radioligands for imaging the translocator protein $(18 \mathrm{kDa})$ : What have we learned?", Journal of Labelled Compounds and Radiopharmaceuticals, vol. 53, no. 7, pp. 501-510, 2010.

[35] D. M. Zisterer, and D. C. Williams, "Peripheral-type benzodiazepine receptors", General Pharmacology: The Vascular System, vol. 29, no. 3, pp. 305-314, 1997.

[36] K. E. Krueger, "Molecular and functional properties of mitochondrial benzodiazepine receptors", Biochimica et Biophysica Acta, vol. 1241, no. 3, pp. 453-70, 1995.

[37] P. J. Schweitzer, B. A. Fallon, J. J. Mann et al., "PET tracers for the peripheral benzodiazepine receptor and uses thereof', Drug Discovery Today, vol. 15, no. 21-22, pp. 933-942, 2010.

[38] R. Camsonne, C. Crouzel, D. Comar et al., "Synthesis of N-(11C) methyl, N-(methyl-1 propyl), (chloro-2 phenyl)-1 isoquinoleine carboxamide-3 (PK 11195): A new ligand for peripheral benzodiazepine receptors", Journal of Labelled Compounds and Radiopharmaceuticals, vol. 21, no. 10, pp. 985-991, 1984.

[39] F. Shah, S. P. Hume, V. W. Pike et al., "Synthesis of the Enantiomers of [N-Methyl-C-11]PK11195 and Comparison of Their Behaviors as Radioligands for Pk Binding-Sites in Rats", Nuclear Medicine and Biology, vol. 21, no. 4, pp. 573-581, May, 1994.

[40] J. Hirvonen, A. Roivainen, J. Virta et al., "Human biodistribution and radiation dosimetry of 11C(R)-PK11195, the prototypic PET ligand to image inflammation", European Journal of Nuclear Medicine and Molecular Imaging, vol. 37, no. 3, pp. 606-12, 2010. 
[41] V. W. Pike, C. Halldin, C. Crouzel et al., "Radioligands for PET studies of central benzodiazepine receptors and PK (peripheral benzodiazepine) binding sites-current status", Nuclear Medicine and Biololy, vol. 20, no. 4, pp. 503-25, 1993.

[42] J. Doorduin, E. F. de Vries, R. A. Dierckx et al., "PET imaging of the peripheral benzodiazepine receptor: monitoring disease progression and therapy response in neurodegenerative disorders", Current Pharmaceutical Design, vol. 14, no. 31, pp. 3297-315, 2008.

[43] M. Wang, M. Gao, and Q. Zheng, "Fully automated synthesis of PET TSPO radioligands [11C]DAA1106 and [18F]FEDAA1106", Applied Radiation and Isotopes, vol. 70, no. 6, pp. 965-973, 2012.

[44] R. B. Banati, "Visualising microglial activation in vivo", Glia, vol. 40, no. 2, pp. 206-17, Nov, 2002.

[45] D. Eidelberg, Imaging in Parkinson's Disease: Oxford University Press, USA, 2011.

[46] D. J. Brooks, and N. Pavese, "Imaging biomarkers in Parkinson's disease", Progress in Neurobiology, vol. 95, no. 4, pp. 614-628, 2011.

[47] A. Gerhard, R. B. Banati, G. B. Goerres et al., "[11C](R)-PK11195 PET imaging of microglial activation in multiple system atrophy”, Neurology, vol. 61, no. 5, pp. 686-689, September 9, 2003, 2003.

[48] J. P. Vonsattel, and M. DiFiglia, "Huntington disease", J Neuropathol Exp Neurol, vol. 57, no. 5, pp. 369-84, May, 1998.

[49] N. Pavese, A. Gerhard, Y. F. Tai et al., "Microglial activation correlates with severity in Huntington disease: a clinical and PET study", Neurology, vol. 66, no. 11, pp. 1638-43, Jun 13, 2006.

[50] A. Compston, and A. Coles, "Multiple sclerosis", Lancet, vol. 359, no. 9313, pp. 1221-31, Apr 6, 2002.

[51] E. N. Benveniste, "Role of macrophages/microglia in multiple sclerosis and experimental allergic encephalomyelitis", Journal of Molecular Medicine, vol. 75, no. 3, pp. 165-173, 1997.

[52] L. A. Mattiace, P. Davies, S. H. Yen et al., "Microglia in cerebellar plaques in Alzheimer's disease", Acta Neuropathologica, vol. 80, no. 5, pp. 493-8, 1990.

[53] V. H. Perry, J. A. Nicoll, and C. Holmes, "Microglia in neurodegenerative disease", Nat Rev Neurol, vol. 6, no. 4, pp. 193-201, Apr, 2010. 
[54] G. N. Groom, L. Junck, N. L. Foster et al., "PET of peripheral benzodiazepine binding sites in the microgliosis of Alzheimer's disease", Journal of Nuclear Medicine, vol. 36, no. 12, pp. 2207-10, Dec, 1995.

[55] P. Edison, H. A. Archer, A. Gerhard et al., "Microglia, amyloid, and cognition in Alzheimer's disease: An [11C](R)PK11195-PET and [11C]PIB-PET study", Neurobiology of Disease, vol. 32, no. 3, pp. 412-419, 2008.

[56] M. L. James, R. R. Fulton, D. J. Henderson et al., "Synthesis and in vivo evaluation of a novel peripheral benzodiazepine receptor PET radioligand", Bioorg Med Chem, vol. 13, no. 22, pp. 618894, Nov 15, 2005.

[57] Y. Lee, "Radiopharmaceuticals for Molecular Imaging", The Open Nuclear Medicine Journal, vol. 2, pp. 178-185, 2010.

[58] R. Weissleder, and U. Mahmood, "Molecular Imaging", Radiology, vol. 219, no. 2, pp. 316-333, 2001.

[59] F. C. Wong, and E. E. Kim, "A review of molecular imaging studies reaching the clinical stage", European Journal of Radiology, vol. 70, no. 2, pp. 205-211, 2009.

[60] W. Wadsak, and M. Mitterhauser, "Basics and principles of radiopharmaceuticals for PET/CT", European Journal of Radiology, vol. 73, no. 3, pp. 461-469, 2010.

[61] D. J. Schlyer, "PET tracers and radiochemistry", Annals of the Academy of Medicine, Singapore, vol. 33, no. 2, pp. 146-54, 2004.

[62] I. A. E. Agency, Cyclotron Produced Radionuclides: Principles and Practice: International Atomic Energy Agency, 2008.

[63] M. Allard, E. Fouquet, D. James et al., "State of art in C-11 labelled radiotracers synthesis", Current Medicinal Chemistry, vol. 15, no. 3, pp. 235-277, 2008.

[64] V. Gómez-Vallejo, V. Gaja, J. Koziorowski et al., "Specific Activity of 11C-Labelled Radiotracers: A Big Challenge for PET Chemists", Positron Emission Tomograpby - Current Clinical and Research Aspects, C.-H. Hsieh, ed.: InTech, 2012.

[65] M. J. Welch, and C. S. Redvanly, Handbook of Radiopharmaceuticals: Radiochemistry and Applications: John Wiley \& Sons, 2003.

[66] A. D. McNaught, and A. Wilkinson. "Compendium of Chemical Terminology, 2nd ed. (the "Gold Book")", 2012-08-13, 2012. 
[67] A. A. Wilson, A. Garcia, L. Jin et al., "Radiotracer synthesis from [11C]-iodomethane: a remarkably simple captive solvent method", Nuclear Medicine and Biology, vol. 27, no. 6, pp. 529$532,2000$.

[68] G. B. Saha, Fundamentals of Nuclear Pharmacy, Sixth Edition ed., 2010.

[69] C. Crouzel, B. Langstrom, V. W. Pike et al., "Recommendations for a practical production of [11C]methyl iodide", International Journal of Radiation Applications and Instrumentation. Part A. Applied Radiation and Isotopes, vol. 38, no. 8, pp. 601-603, 1987.

[70] C. Lemaire, A. Plenevaux, J. Aerts et al., "Solid phase extraction-an alternative to the use of rotary evaporators for solvent removal in the rapid formulation of PET radiopharmaceuticals", Journal of Labelled Compounds and Radiopharmaceuticals, vol. 42, no. 1, pp. 63-75, 1999.

[71] P. Larsen, J. Ulin, K. Dahlstrom et al., "Synthesis of [11C]iodomethane by iodination of [11C]methane", Applied Radiation and Isotopes, vol. 48, no. 2, pp. 153-157, 1997. 